\title{
Potential relevance of altered cartilage oligomeric matrix protein in psoriasis
}

\author{
Renáta Bozó
}

PhD Thesis

Szeged

2020 


\section{Potential relevance of altered cartilage oligomeric matrix protein in psoriasis}

\section{Renáta Bozó}

$\mathrm{PhD}$ Thesis

Supervisor:

Dr. Gergely Groma

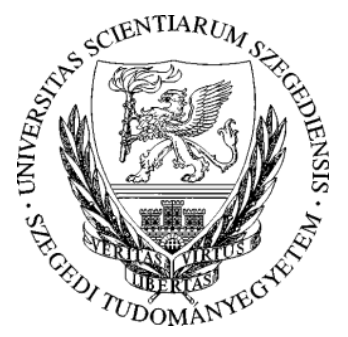

University of Szeged

Faculty of Medicine

Department of Dermatology and Allergology

Doctoral School of Clinical Medicine

Szeged

2020 


\section{LIST OF PUBLICATIONS}

\section{Scientific paper included in this thesis}

I. Bozó R, Szél E, Danis J, Gubán B, Bata-Csörgő Z, Szabó K, Kemény L, Groma G. Cartilage Oligomeric Matrix Protein Negatively Influences Keratinocyte Proliferation Via a5 31 -Integrin: Potential Relevance of Altered Cartilage Oligomeric Matrix Protein Expression in Psoriasis. J Invest Dermatol. 2020 Feb 11; doi: 10.1016/j.jid.2019.12.037. [Epub ahead of print]

IF: 6.290* (Journal specialization: Scopus - Dermatology, Location: D1)

\section{Publications not directly related to the thesis}

II. Erdei L, Bolla BS, Bozó R, Tax G, Urbán E, Kemény L, Szabó K. TNIP1 Regulates Cutibacterium acnes-Induced Innate Immune Functions in Epidermal Keratinocytes. Front Immunol. 2018;9:2155. doi: 10.3389/fimmu.2018.02155.

IF: 4.716 (Journal specialization: Scopus - Immunology, Location: Q1)

III. Tripolszki K, Danis J, Padhi AK, Gomes J, Bozó R, Nagy ZF, Nagy D, Klivényi P, Engelhardt JI, Széll M. Angiogenin mutations in Hungarian patients with amyotrophic lateral sclerosis: Clinical, genetic, computational, and functional analyses. Brain Behav. 2019;9(6):e01293. doi: 10.1002/brb3.1293.

IF: 2.072* (Journal specialization: Scopus - Behavioral Neuroscience, Location: Q2)

IV. Szél E, Bozó R, Hunyadi-Gulyás É, Manczinger M, Szabó K, Kemény L, Bata-Csörgő, Z, Groma, G. Comprehensive Proteomic Analysis Reveals Intermediate Stage of Non-Lesional Psoriatic Skin and Points out the Importance of Proteins Outside this Trend. Sci Rep. 2019 0;9(1):11382 doi: 10.1038/s41598-019-47774-5.

IF: 4.011* (Journal specialization: Scopus - Multidisciplinary, Location: D1) 


\section{LIST OF ABBREVIATIONS}

AB/AM: antibiotic/antimycotic solution

ANOVA: analysis of variance

BrdU: bromodeoxyuridine/5-bromo-2'-deoxyuridine

CI: cell index

COMP: cartilage oligomeric matrix protein/thrombospondin-5

DAPI: 4',6-diamidino-2-phenylindole

DMEM: Dulbecco's Modified Eagle Medium

DEJ: dermal-epidermal junction

ECM: extracellular matrix

BM: basement membrane

EDA+FN: fibronectin splice variant containing the extra domain A

FBS: fetal bovine serum

FN: fibronectin

HPV-KER: human immortalized keratinocytes

ITGA5: $\alpha 5$-integrin

ITGB1: $\beta 1$-integrin

KRT17: keratin-17

LAMA1: laminin alpha-1

NGS: normal goat serum

NHEK: normal human epidermal keratinocyte

PBS: phosphate-buffered saline

rhCOMP: recombinant human cartilage oligomeric matrix protein

SEM: standard error of the mean

TBS: TRIS-buffered saline. 


\section{TABLE OF CONTENT}

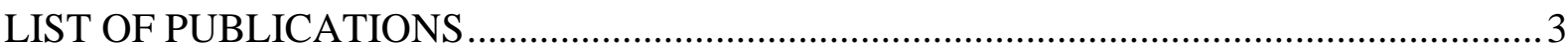

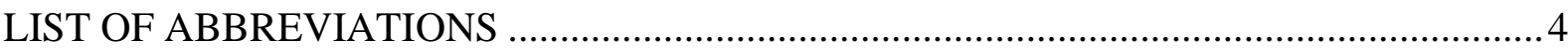

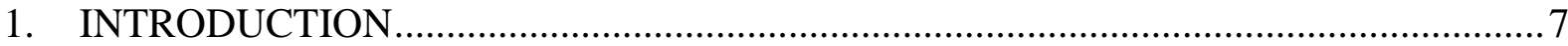

1.1. Characteristics of the inflammatory skin disease, psoriasis .................................... 7

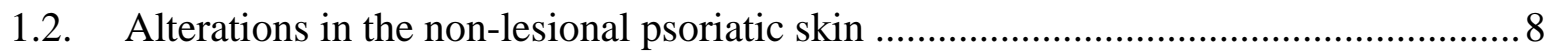

1.3. Structure, functions and interaction partners of COMP …..................................... 8

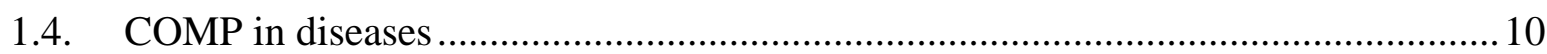

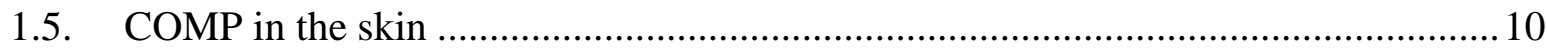

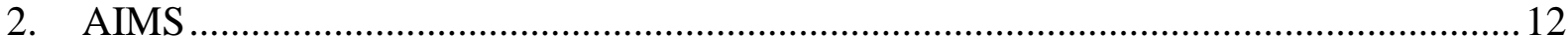

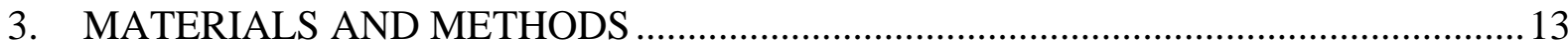

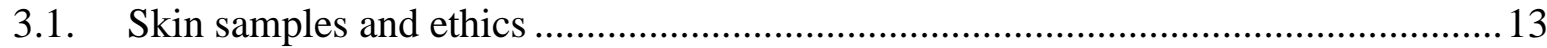

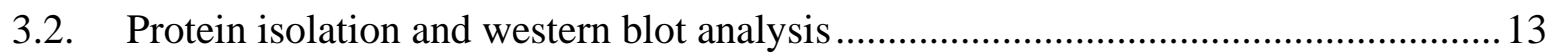

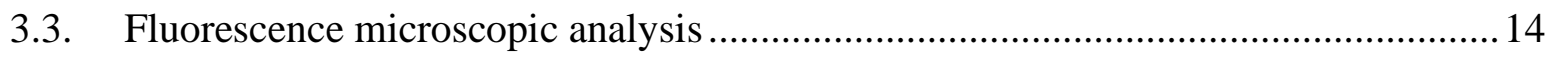

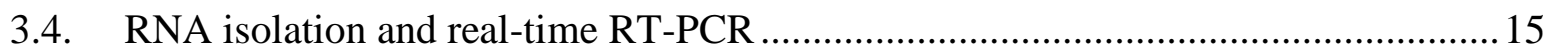

3.5. Cell cultures and examination of cellular properties ........................................... 15

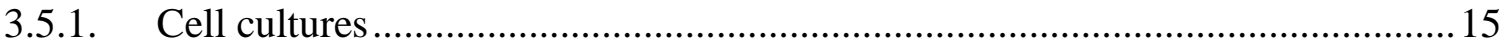

3.5.2. Real-time, label-free cellular analysis of HPV-KER cells using the

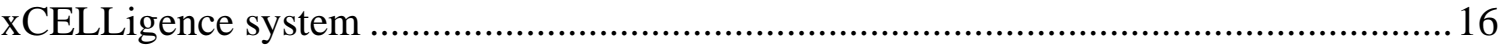

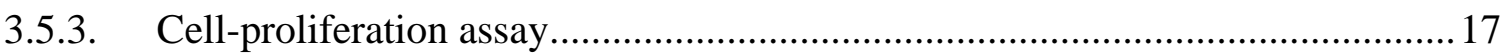

3.5.4. Further investigation of keratinocyte cell-proliferation.................................. 17

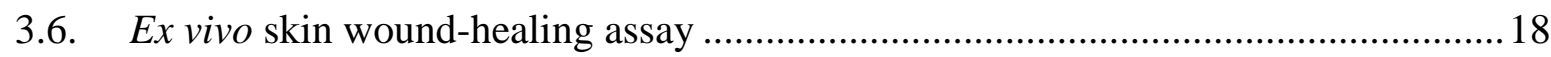

3.7. Hematoxylin eosin staining and light microscopic analysis .................................. 18

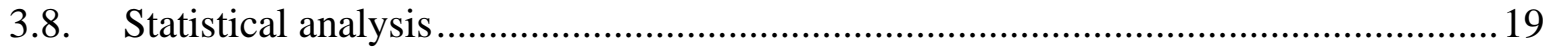

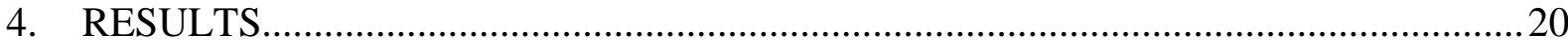

4.1. COMP level is elevated in psoriatic non-lesional skin .........................................20

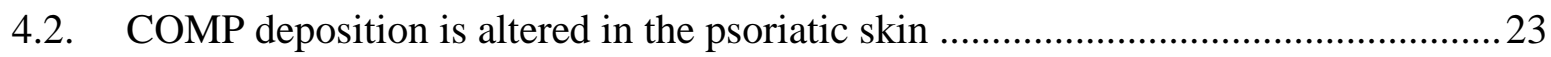

4.3. COMP mRNA expression is elevated in non-lesional fibroblasts ...........................26

4.4. COMP co-localization with $\beta 1$-integrin of basal keratinocytes and EDA+FN is increased and with LAMA1 is decreased in non-lesional psoriatic skin ..............................2 27

4.5. COMP negatively influences keratinocyte proliferation in vitro.............................. 32 
4.6. COMP negatively influences keratinocyte proliferation via $\alpha 5 \beta 1$-integrin in vitro.. 34 4.7. COMP has a negative effect on skin wound healing by attenuating keratinocyte proliferation and by compromising keratinocyte migration and activation in ex vivo wound models 38

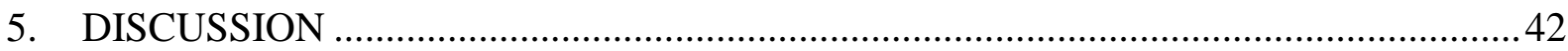

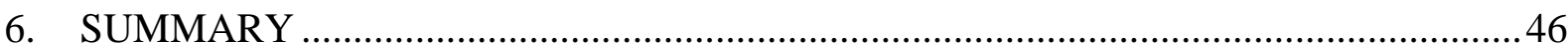

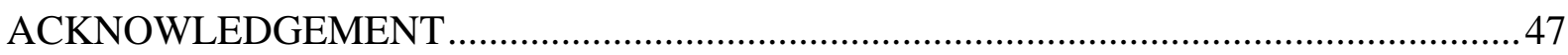

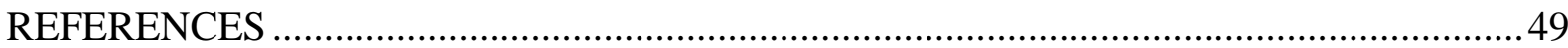




\section{INTRODUCTION}

\subsection{Characteristics of the inflammatory skin disease, psoriasis}

Plaque-type psoriasis (also known as Psoriasis vulgaris) is a chronic inflammatory, multifactorial, immune-mediated skin disease, characterized by dry, red, scaly patches and affects $1-3 \%$ of the global population. The pathogenesis of this complex disease is only partially understood, and currently only symptomatic treatments are available. Major characteristics of psoriatic plaques are hyperproliferation and altered differentiation of keratinocytes coupled with massive immune-cell infiltration. Secreted cytokines and chemokines are believed to key mediators of the initiation of the disease. The onset of symptoms is presumably triggered by an overreaction of the immune system. This is followed by the response of keratinocytes to cytokines by proliferation, activation and secretion of proinflammatory mediators (cytokines, chemokines, antimicrobial peptides) which help to amplify the inflammatory process (Harden et al., 2015; Kim and Krueger, 2015; Puig et al., 2014). Based on age, as well as genetic and immunopathogenic characteristics, chronic plaque type psoriasis has two distinct subtypes: early and late onset psoriasis. Early onset psoriasis presents at or before 40 years of age and affects $75 \%$ of patients, while late onset psoriasis first presents after the age of 40 years and affects $25 \%$ of patients (Henseler and Christophers, 1985; Theodorakopoulou et al., 2016).

Genetic factors play an important role in the pathogenesis of the disease (Puig et al., 2014). At least fifteen psoriasis susceptible loci (PSORS) have been already discovered in the human genome. PSORS1 locus -which located at the region of major histocompatibility complex on chromosome 6- is responsible for 30-50\% of genetic origin of the disease (Elder, 2006; Singh et al., 2019). On the PSORS1 locus, HLA-Cw6 is the most frequently mapped allele in population with early onset of the disease (Elder, 2006). Furthermore, single nucleotide polymorphisms are discovered in fifty different regions of the human genome by genome-wide association studies, which are in connection with psoriasis. Apart from the genetic factors, environmental effects could also play role in the pathogenesis of the disease including stress, physical trauma, smoking and alcohol (Harvima et al., 1996; Poikolainen et al., 1994; Weiss et al., 2002). 


\subsection{Alterations in the non-lesional psoriatic skin}

Alterations in healthy looking non-lesional skin of psoriasis patients have been described, which may contribute to the development of the symptoms. In addition to hyperproliferation, altered keratinocyte differentiation and massive immune-cell infiltration, the dermal extracellular matrix (ECM) and the basement membrane (BM) are also affected in non-lesional skin of patients (Bata-Csorgo et al., 1998; Gliński et al., 1993; Mondello et al., 1996; Vaccaro et al., 2002). Non-lesional epidermal keratinocytes have been shown to represent a "preactivated" state for hyperproliferation (Chen et al., 2001): these cells are more sensitive to stress (Szabó et al., 2014) and to proliferative signals (Bata-Csorgo et al., 1995). Alterations of the ECM that are already present in non-lesional skin also affect the cell attachment modulator fibronectin $(\mathrm{FN})$, which is differentially expressed in non-lesional skin. Previously, we found that fibroblasts, as well as basal keratinocytes, express high levels of the FN splice variant that contains the extra domain A (EDA+FN) in non-lesional skin (Gubán et al., 2016; Széll et al., 2004). Moreover, some integrins, including the FN-interacting $\alpha 5 \beta 1$-integrin, also exhibit an increased expression (Bata-Csorgo et al., 1998; Gubán et al., 2016) in keratinocytes at the dermal-epidermal junction (DEJ). The enhanced EDA+FN and $\alpha 5 \beta 1$-integrin production that we observed in psoriatic non-lesional skin may contribute to the induction of keratinocyte proliferation (Bata-Csorgo et al., 1998, 1995; Széll et al., 2004). Furthermore, at the DEJ in non-lesional skin, the laminin layer of the BM is discontinuous and the connection of keratinocytes to the BM is also altered (McFadden and Kimber, 2016; Mondello et al., 1996).

To gain further insight into the pathomechanism of psoriasis, we previously performed largescale proteomic study in which healthy, psoriatic non-lesional and lesional skin were compared (Szél et al., 2019). In this study, cartilage oligomeric matrix protein (COMP) exhibited elevated expression in non-lesional skin in comparison to healthy skin.

\subsection{Structure, functions and interaction partners of COMP}

COMP is a non-collagenous, 524-kDa, homopentameric, glycoprotein component of the ECM. It belongs to the family of thrombospondins and often referred to as thrombospondin-5. The main functions of thrombospondins are ECM organization and remodeling (Tan and Lawler, 2009). The homopentameric structure of COMP is formed via the N-terminal coiled- 
coil domain, resulting in a flexible molecule with a bouquet-like form that allows to interact with multiple cellular and extracellular components simultaneously (Malashkevich et al., 1996; Mörgelin et al., 1992) (Figure 1).

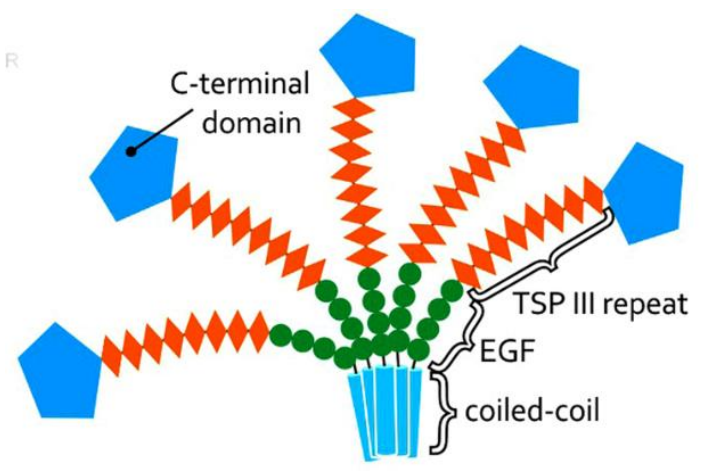

Figure 1.: Domain organization of COMP (Gebauer et al., 2018).

COMP is mainly expressed in cartilage, but it also appears in tendon, ligament, synovium, vascular smooth muscle cells, cardiomyocytes, activated platelets and skin as well (Müller et al., 1998; Posey et al., 2018; Tan and Lawler, 2009; Wang et al., 2010).

Interaction partners of COMP in the ECM are collagen type I and III and FN, among others (Di Cesare et al., 2002; Halász et al., 2007; Rosenberg et al., 1998) (Figure 2). Interestingly, the molecules mentioned above are also known to be affected in psoriasis (Kaladze and Gogebashvili, 2005; Koivukangas et al., 1995; McFadden et al., 2012).

COMP modulates cellular behavior via direct interactions with cell-surface proteins, including the $\alpha 5 \beta 1$ (Chen et al., 2005), $\alpha 7 \beta 1$ and $\alpha v \beta 3$ (Rock et al., 2010) members of the integrin family (Figure 2). $\alpha 5 \beta 1$-integrin modulates processes in psoriasis pathogenesis, including inflammatory responses and keratinocyte proliferation (Bata-Csorgo et al., 1998; Chen et al., 2001; Pellegrini et al., 1992). 


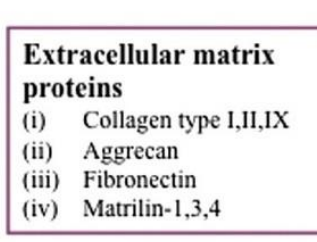

\begin{tabular}{|c|c|}
\hline $\begin{array}{l}\text { Integrin subunits \& } \\
\text { associated protein } \\
\text { (t) } \alpha 5 \beta 1\end{array}$ & $\begin{array}{l}\text { Growth factors } \\
\text { (i) TGF } \beta 1 \\
\text { (ii) BMP-2,4,7 }\end{array}$ \\
\hline
\end{tabular}

(u) $\alpha 5 \beta 3$

(iii) $\mathrm{CD} 47$

(iv) Matrilin- $1,3,4$

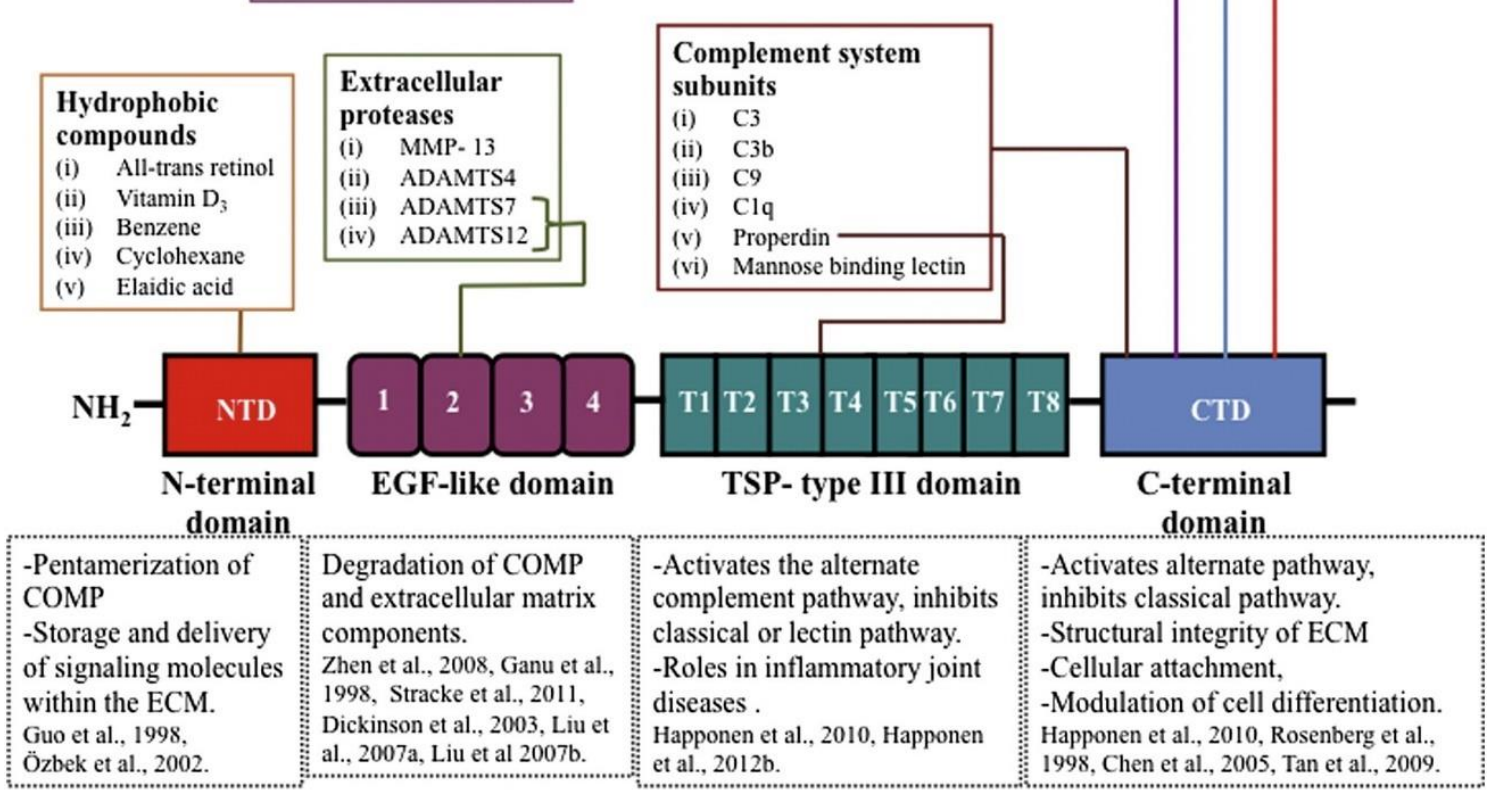

Figure 2.: The domains of COMP, its binding-partners and their functions

(Acharya et al., 2014).

\subsection{COMP in diseases}

COMP has been associated with several diseases. Autosomal dominant mutations in the COMP gene cause skeletal disorders, such as pseudoachondroplasia and multiple epiphyseal dysplasia (Briggs et al., 1995; Hecht et al., 1995). The presence of COMP in serum and synovial fluid (Jordan, 2005; Tseng et al., 2009) serves as a biomarker in inflammatory diseases affecting the cartilage of joints, such as rheumatic disorders including rheumatoid and psoriatic arthritis (Mortezavi et al., 2015).

\subsection{COMP in the skin}

In healthy skin, COMP is primarily produced by fibroblasts (Farina et al., 2006) and localizes to the papillary dermis where it is believed to take part in ECM stabilization and provide cohesion between the anchoring plaques of the upper dermis and the BM (Agarwal et al., 2012) (Figure 3). 


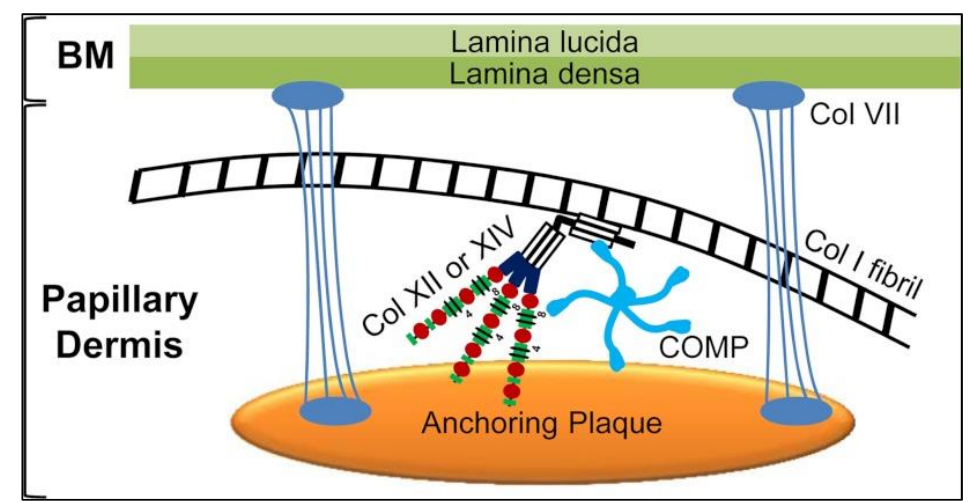

Figure 3.: The role of COMP in healthy skin (Agarwal et al., 2013).

COMP accumulation in the dermis is elevated in various skin disorders, including localized scleroderma, wounds and exudates of patients with venous leg ulcers, in the fibrotic stroma of basal cell carcinoma and skin keloids (Agarwal et al., 2013; Inui et al., 2011). Although COMP accumulation in the dermis is elevated in several skin disorders, it has not been previously investigated in the context of psoriasis. 


\section{AIMS}

Psoriasis is an inflammatory skin disease, where the non-lesional skin of patients contains alterations, which predispose to the development of the symptoms. These alterations affect the DEJ region, where the fibronectin splice variant, EDA+FN and $\alpha 5 \beta 1$-integrin showed increased expression, and the laminin layer within the $\mathrm{BM}$ is discontinuous.

In healthy skin, COMP is localized into the DEJ region, and believed to provide cohesion between the anchoring plaques of the upper dermis and the BM. Furthermore, it can directly interact with $\alpha 5 \beta 1$-integrin and fibronectin as well. Besides, in our previous proteomic study, we found elevated COMP protein level in non-lesional skin in comparison to healthy skin. Based on these previous results, we aimed to study the potential role of COMP in the pathomechanism of psoriasis.

We aimed to

- examine the tissue distribution of COMP in the healthy, psoriatic non-lesional and lesional skin.

- determine the protein level of COMP in the healthy, psoriatic non-lesional and lesional skin.

- determine COMP expression at the mRNA level in healthy and non-lesional cultured fibroblasts.

- study whether COMP accumulation allows interaction with basal keratinocytes through the discontinuous BM comparing the healthy and non-lesional skin.

- further study the DEJ region and examine, whether COMP accumulation allows interaction with a potential interaction partner, fibronectin splice variant EDA+FN which is known to influence the behavior of the keratinocytes-, comparing the healthy and non-lesional skin.

- examine whether COMP can affect the behavior of keratinocytes in vitro and ex vivo. 


\section{MATERIALS AND METHODS}

\subsection{Skin samples and ethics}

Skin punch biopsies $(\mathrm{d}=6 \mathrm{~mm})$ were collected from healthy volunteers $(\mathrm{n}=10$; age $18-70$ years, Table 1), and from psoriatic patients with moderate-to-severe chronic plaque-type psoriasis from lesional $(n=13)$ and non-lesional skin areas $(n=13$; minimum of $6 \mathrm{~cm}$ from lesional region; age 18-70 years (Table 1)). Psoriatic patients did not receive local therapy for at least 4 weeks and had not been subjected to systemic therapy for at least 8 weeks. Skin biopsies were taken from areas of skin that were not exposed to sun. Tissue collection was obtained after written informed consent, in accordance with the rules of the Helsinki Declaration. The study was confirmed by the Human Investigation Review Board of the University of Szeged (PSO-EDAFN-002, 34/2015, 3517, 23 February 2015, Szeged, Hungary; PSO-ECMPR-002 IF-562-5/2016 and; 157/2015-SZTE, 3638, 21 September 2015, Hungary).

\subsection{Protein isolation and western blot analysis}

For preparation of tissue protein extracts, skin biopsies (healthy, psoriatic non-lesional and psoriatic lesional) were cut into small pieces with a razor blade. $6 \mathrm{M}$ guanidine hydrochloride (Sigma Aldrich, Saint Louis, Missouri, USA) solution was used as an extraction buffer for 24 $\mathrm{h}$ at $4{ }^{\circ} \mathrm{C}$ under continuous agitation. For protein precipitation, an ethanol-based method was applied. Protein concentrations were measured using Bradford assay (Bio-Rad Laboratories, Hercules, California, USA). Protein extracts ( $25 \mu \mathrm{g})$ were separated on a 4-20\% gradient SDS polyacrylamide gel under reducing or non-reducing conditions. Proteins were transferred to a nitrocellulose membrane (Bio-Rad Laboratories, Hercules, California, USA) and blocked in 5\% non-fat milk powder containing Tris-buffered saline (TBS) for $60 \mathrm{~min}$ at room temperature (RT). Membranes were incubated for overnight at $4^{\circ} \mathrm{C}$ with goat anti-human COMP primary antibody (1:2000, R\&D Systems, Minneapolis, Minnesota, USA), and rabbit anti-human actin primary antibody (1:2000, Sigma Aldrich, Saint Louis, Missouri, USA). Subsequently, membranes were incubated with horseradish peroxidase-conjugated anti-goat (Thermo Fisher Scientific, Waltham, Massachusetts, USA), and anti-rabbit (Southern Biotech, Birmingham, USA) secondary antibodies, both diluted 1:2000, for 60 min at RT. Signal was visualized with 
Clarity Max Western ECL Substrate (Bio-Rad Laboratories, Hercules, California, USA) on a C-digit blot scanner (LI-COR Biosciences, Lincoln, Nebraska, USA).

\subsection{Fluorescence microscopic analysis}

Biopsies from healthy, psoriatic non-lesional and psoriatic lesional tissues were frozen in a cryogenic matrix (Thermo Fisher Scientific, Waltham, Massachusetts, USA) and were subsequently cut into $5 \mu \mathrm{m}$ sections. The sections were fixed in a $4 \%$ paraformaldehyde solution and were permeabilized in $0.25 \%$ TritonX-100 (Thermo Fisher Scientific, Waltham, Massachusetts, USA) containing TBS. Permeabilized samples were digested with chondroitinase ABC (5U, diluted 1:100; Sigma Aldrich, Saint Louis, Missouri, USA) for 90 min, at $37^{\circ} \mathrm{C}$ and blocked for $60 \mathrm{~min}$ at RT with $10 \%$ fetal bovine serum (FBS, Euroclone, Pero, Italy) and 5\% normal goat serum (NGS, Sigma Aldrich, Saint Louis, Missouri, USA) containing TBS. Samples were incubated with the following primary antibodies: polyclonal rabbit antihuman COMP (1:250), a kind gift from Prof. Dr. Mats Paulsson and Dr. Frank Zaucke from the University of Cologne (Agarwal et al., 2012); mouse anti-human $\beta 1$-integrin (ITGB1, clone: JB1B, 1:100, Abcam, Cambridge, United Kingdom), mouse anti human laminin alpha-1 (LAMA1, clone: LAM-89, 1:100, R\&D Systems, Minneapolis, Canada USA), mouse antihuman fibronectin (EDA+FN, clone: IST-9, 1:500, Abcam, Cambridge, United Kingdom). Isotype controls were the following: rabbit polyclonal IgG (Santa Cruz Biotechnology, California, USA) and mouse IgG1 (Beckton Dickinson, Franklin Lakes, New Jersey, USA) antibodies. As secondary antibodies, Alexa Fluor 546 conjugated anti-rabbit IgG and Alexa Fluor 647 conjugated anti-mouse IgG (Life Technologies, Carlsbad, California, USA) were used. Nuclei were visualized with 4',6-diamidino-2-phenylindole (DAPI, Sigma Aldrich, Saint Louis, Missouri, USA) staining. Zeiss LSM 880 or Zeiss Axio Imager Z1 microscopes (Carl Zeiss AG, Oberkochen, Germany) were used for visualization.

Pearson's correlation coefficient, R, was calculated using ImageJ/Fiji software (ImageJ, Wisconsin, USA).

Paraffin embedded sections $(5 \mu \mathrm{m})$ from ex vivo skin wound-healing models were deparaffinized, heat-denatured in citrate buffer $(\mathrm{pH}=6)$, fixed and permeabilized with the Foxp3 staining buffer set (eBioScience, Santa Clara, California, USA), and blocked for 60 min at RT with TBS containing $1 \%$ bovine serum albumin (BSA) and 1\% NGS. Samples were incubated 
with the following primary antibodies: rabbit anti-human actin (1:100, Sigma Aldrich, Saint Louis, Missouri, USA), mouse anti-human Ki67 (1:100, Beckton Dickinson, Franklin Lakes, New Jersey, USA), mouse anti human keratin-17 (KRT17, ready to use, Dako, Santa Clara, California, USA). Isotype controls were the following: rabbit polyclonal IgG (Santa Cruz Biotechnology, California, USA) and mouse IgG1 (Beckton Dickinson, Franklin Lakes, New Jersey, USA) antibodies. As secondary antibodies, Alexa Fluor 546 conjugated anti-rabbit IgG and Alexa Fluor 647 conjugated anti-mouse IgG (Life Technologies, Carlsbad, California, USA) were used. Nuclei were visualized with DAPI (Sigma Aldrich, Saint Louis, Missouri, USA) staining. Zeiss LSM 880 (Carl Zeiss AG, Oberkochen, Germany) were used for visualization.

\subsection{RNA isolation and real-time RT-PCR}

Total RNA was isolated from primary fibroblasts from healthy and psoriatic non-lesional skin cultured in $75 \mathrm{~cm}^{2}$ cell culture flasks (Corning, New York, USA) and collected at the fifth passage using TRI-Reagent (Molecular Research Center; Cincinnati, United States) as described by the manufacturer. The iScript ${ }^{\mathrm{TM}}$ cDNA Synthesis kit (Bio-Rad Laboratories, Hercules, California, USA) was used for cDNA synthesis, and $0.5 \mu \mathrm{g}$ total RNA was reverse transcribed. Real-time RT-PCR was performed on a C1000 Touch Thermal Cycler (Bio-Rad Laboratories, Hercules, California, USA) with the Universal Probe Library system (Roche Diagnostics, Risch, Switzerland) using qPCRBIO Probe Mix Lo-ROX (PCR Biosystem Ltd., London, UK) and the following primers: COMP FWD: CACCGACGTCAACGAGTG, COMP REV: TGGTGTTGATACAGCGGACT; 18S rRNA FWD: CGCTCCACCAACTAAGAACG, 18S rRNA REV: CTCAACACGGGAAACCTCAC. The expression of COMP was normalized to $18 \mathrm{~S}$ rRNA expression using the $\Delta \Delta \mathrm{Ct}$ method.

\subsection{Cell cultures and examination of cellular properties}

\subsubsection{Cell cultures}

Primary dermal fibroblasts were isolated from healthy and psoriatic non-lesional skin biopsies, and normal human epidermal keratinocytes (NHEKs) were isolated from healthy skin samples. The epidermis was separated from the dermis with overnight incubation at $4{ }^{\circ} \mathrm{C}$ in 
Dispase II (neutral protease, grade II, 2U/ml, Roche Diagnostics, Risch, Switzerland) (Szabad et al., 2007) solution.

Keratinocytes were obtained from the epidermal part after trypsin digestion for $10 \mathrm{~min}$ at $37^{\circ} \mathrm{C}$ (Sigma Aldrich, Saint Louis, Missouri, USA). NHEK cells were then grown in keratinocyte serum-free medium (KSFM, Life Technologies, Carlsbad, California, USA) supplemented with $1 \%$ antibiotic/antimycotic solution (AB/AM, Sigma Aldrich, Saint Louis, Missouri, USA), brain pituitary extract (50 $\mu \mathrm{g} / \mathrm{ml}$, Life Technologies, Carlsbad, California, USA) and epidermal growth factor ( $5 \mathrm{ng} / \mathrm{ml}$, Life Technologies, Carlsbad, California, USA).

Fibroblasts were obtained from the dermal part after digestion for $120 \mathrm{~min}$ at $37^{\circ} \mathrm{C}$. The media (Dulbecco's Modified Eagle Medium, DMEM, supplemented with 1 g/l glucose, Lonza Group, Basel, Switzerland) also contained collagenase (from Clostridium histolyticum, 2.7 mg/ml, Sigma Aldrich, Saint Louis, Missouri, USA), deoxyribonuclease I (from bovine pancreas, $0.1 \mathrm{mg} / \mathrm{ml}$, Sigma Aldrich, Saint Louis, Missouri, USA), hyaluronidase (from bovine testes, $1.25 \mathrm{mg} / \mathrm{ml}$, Sigma Aldrich, Saint Louis, Missouri, USA) and FBS (2.5\%, EuroClone, Pero, Italy) (Gubán et al., 2016). Fibroblasts were cultured in DMEM 1 g/l glucose (Lonza Group, Basel, Switzerland), supplemented with 5\% FBS (EuroClone, Pero, Italy), $1 \%$ AB/AM, Sigma Aldrich, Saint Louis, Missouri, USA) and 1\% L-glutamine (PAA Laboratories GmbH, Pasching, Austria).

The human immortalized keratinocyte cell line HPV-KER was also used for our experiments. HPV-KER is a stable cell line, generated from normal human epidermal keratinocytes transfected with the HPV16/E6 oncogene in a pCMV vector. It was established by continuous culturing (Tax et al., 2016). It shows similar responses to NHEK cells in various immune activation protocols (Danis et al., 2018; Erdei et al., 2018). Culture conditions of HPVKER cells are the same as NHEK cells.

Each cell type was cultured at $37^{\circ} \mathrm{C}$ in a humidified atmosphere with $5 \% \mathrm{v} / \mathrm{v} \mathrm{CO} 2$.

\subsubsection{Real-time, label-free cellular analysis of HPV-KER cells using the xCELLigence system}

xCELLigence (ACEA Biosciences, San Diego, USA) is a real-time, impedance measurement-based cellular analysis system, where dimensionless Cell Index (CI) value is 
calculated $(\mathrm{CI}=$ (impedance at time point $\mathrm{n}$ - impedance in the absence of cells $) /$ nominal impedance value). Differences in CI values could be due to altered cell proliferation rate, viability, morphology and adhesion (Dickhuth et al., 2015). This system was used to investigate the effect of the COMP protein on keratinocytes. HPV-KER cells were plated at a density of 10,000 cells/well in uncoated 96-well E-plates (ACEA Biosciences, San Diego, USA) or wells that were coated with low-concentration $(1 \mu \mathrm{g} / \mathrm{ml})$ or high-concentration $(10 \mu \mathrm{g} / \mathrm{ml})$ recombinant human COMP protein (rhCOMP, R\&D Systems, Minneapolis, Minnesota, USA). Impedance measurement was performed in every $15 \mathrm{~min}$ for $140 \mathrm{~h}$, and a dimension-free CI value was calculated for every time point. Four technical replicates were performed.

\subsubsection{Cell-proliferation assay}

To investigate the effect of COMP on keratinocyte proliferation, a bromodeoxyuridine/5bromo-2'-deoxyuridine (BrdU) cell-proliferation colorimetric ELISA assay (Abcam, Cambridge, United Kingdom) was performed. HPV-KER cells, a stable human keratinocyte cell line that has been characterized in our laboratory (Danis et al., 2018; Erdei et al., 2018; Tax et al., 2016), and NHEK cells were plated at a density of 10,000 cells/well in 96-well plates (Corning, New York, USA) that were uncoated or coated with low- $(1 \mu \mathrm{g} / \mathrm{ml})$ or highconcentration $(10 \mu \mathrm{g} / \mathrm{ml})$ rhCOMP protein (R\&D Systems, Minneapolis, Minnesota, USA), in three technical replicates. For the blocking of $\alpha 5$-integrin (ITGA5) and $\beta 1$-integrin, the following antibodies ( $1 \mu \mathrm{g}$ antibody for $10^{6}$ cells) were used: mouse anti-human $\alpha 5$-integrin antibody (clone: IIA1, Beckton Dickinson, Franklin Lakes, New Jersey, USA), mouse antihuman $\beta 1$-integrin (clone: JB1B, Abcam, Cambridge, United Kingdom). Goat anti-human COMP antibody ( $1 \mu \mathrm{g}$ antibody for $10 \mu \mathrm{g} / \mathrm{ml}$ rhCOMP protein, R\&D Systems, Minneapolis, Minnesota, USA) was applied to block the COMP protein. Integrin- and COMP-blocking was applied to cells grown on uncoated plates or plates coated with $10 \mu \mathrm{g} / \mathrm{ml} \mathrm{rhCOMP}$ protein. BrdU assay was performed at 24 and 72 hours after blocking, according to the manufacturer's instructions.

\subsubsection{Further investigation of keratinocyte cell-proliferation}

To further investigate the effect of COMP on NHEK cell's proliferation, Ki67 immunofluorescent staining (mouse anti-human Ki67 antibody, 1:100, Beckton Dickinson, 
Franklin Lakes, New Jersey, USA) was applied, using integrin and COMP-blocking as described above. Cells were plated at a density of 20,000 cells/well in 8-well chamber slides (SPL Life Sciences, Naechon-Myeon, Pocheon-si, Korea) that were uncoated or coated with high-concentration $(10 \mu \mathrm{g} / \mathrm{ml})$ rhCOMP (R\&D Systems, Minneapolis, Minnesota, USA), in three biological replicates. Ki67 positive cells were counted on three randomly selected areas per group, and statistical analysis was performed.

\subsection{Ex vivo skin wound-healing assay}

Healthy skin samples were collected for the ex vivo organotypic wound healing assay. Approximately $1 \mathrm{~cm}$ diameter skin pieces were cut and mildly wounded in the middle using a $4 \mathrm{~mm}$ punch biopsy blade (Steele Supply Company, St. Joseph, MI, USA). Wounded skin samples and unwounded control samples were incubated for 72 hours at an air-liquid interface on the upper part of transwell cell culture inserts. The dermal part was in contact with DMEM F12 culture media (Lonza Group, Basel, Switzerland) supplemented with 10\% FBS (EuroClone, Pero, Italy) and 1\% AB/AM solution (Sigma Aldrich, Saint Louis, Missouri, USA). The middle of the wounds was treated for 72 hours with high-concentration $(10 \mu \mathrm{g} / \mathrm{ml})$ rhCOMP (R\&D Systems, Minneapolis, Minnesota, USA) diluted in phosphate buffered saline (PBS) or PBS only as a control. Samples were fixed in formalin and embedded in paraffin for immunofluorescent staining. To determine the rate of proliferation, 50 cells on each wound edge were counted and the proportion of ki67 positive cells was determined. Re-epithelization of untreated, control (where only PBS was administered), and COMP-treated wounds were assessed by measuring the area using the ImageJ (ImageJ, Wisconsin, USA) software.

\subsection{Hematoxylin eosin staining and light microscopic analysis}

To visualize the tissue structure of ex vivo wound model samples, hematoxylin-eosin (Leica Biosystems, Wetzlar, Germany) staining was performed according to the manufacturer's instructions in a Leica ST5020 Multistainer device (Leica Biosystems, Wetzlar, Germany). The stained samples were visualized with a Nikon eclipse TS100 microscope (Nikon, Minato, Tokyo, Japan). 


\subsection{Statistical analysis}

For comparing only two groups, two-tailed Student $\mathrm{t}$ test was performed. One-way analysis of variance (ANOVA) with Tukey post hoc test was used to compare more than two groups. Differences were considered statistically significant at $* * \mathrm{P}<0.01, * \mathrm{P}<0.05$. Data were analyzed using R-Studio software, version 3.2.2 (R-Studio, Boston, USA).

\begin{tabular}{|c|c|c|c|c|c|c|c|}
\hline \multicolumn{5}{|c|}{ Donor Information } & \multicolumn{3}{|c|}{$\begin{array}{c}\text { Experimental application list of } \\
\text { donor samples }\end{array}$} \\
\hline $\begin{array}{l}\text { Donor } \\
\text { Groups }\end{array}$ & $\begin{array}{l}\text { Donor } \\
\text { ID }\end{array}$ & Gender & Age & $\begin{array}{l}\text { PASI } \\
\text { score }\end{array}$ & $\begin{array}{c}\text { Western } \\
\text { blot } \\
\text { analysis }\end{array}$ & $\begin{array}{c}\text { Immuno- } \\
\text { fluorescence } \\
\text { staining }\end{array}$ & $\begin{array}{l}\text { real- } \\
\text { time } \\
\text { RT- } \\
\text { PCR }\end{array}$ \\
\hline \multirow{13}{*}{$\begin{array}{c}\text { Plaque } \\
\text { type } \\
\text { psoriasis }\end{array}$} & PS1 & male & 66 & 17.1 & + & + & - \\
\hline & PS2 & male & 52 & 5.5 & + & + & - \\
\hline & PS3 & male & 61 & 12 & - & + & - \\
\hline & PS4 & male & 55 & 12.1 & + & + & - \\
\hline & PS5 & male & 70 & 5.9 & - & + & - \\
\hline & PS6 & male & 53 & 21.2 & + & + & + \\
\hline & PS7 & male & 67 & 17.8 & - & + & + \\
\hline & PS8 & male & 40 & 19.6 & + & + & + \\
\hline & PS9 & male & 69 & 12.4 & + & + & + \\
\hline & PS10 & male & 70 & 9.8 & - & + & + \\
\hline & PS11 & male & 69 & 11.5 & - & - & + \\
\hline & PS12 & male & 60 & 4.1 & - & - & + \\
\hline & PS13 & male & 63 & 26.4 & - & - & + \\
\hline \multirow{10}{*}{ Healthy } & $\mathrm{H} 1$ & male & 39 & $\mathrm{n} / \mathrm{a}$ & + & + & + \\
\hline & $\mathrm{H} 2$ & male & 29 & $\mathrm{n} / \mathrm{a}$ & + & + & - \\
\hline & $\mathrm{H} 3$ & male & 37 & $\mathrm{n} / \mathrm{a}$ & - & + & + \\
\hline & $\mathrm{H} 4$ & male & 48 & $\mathrm{n} / \mathrm{a}$ & + & + & + \\
\hline & $\mathrm{H} 5$ & male & 53 & $\mathrm{n} / \mathrm{a}$ & + & + & + \\
\hline & H6 & male & 51 & $\mathrm{n} / \mathrm{a}$ & + & + & + \\
\hline & $\mathrm{H} 7$ & male & 46 & $\mathrm{n} / \mathrm{a}$ & - & + & + \\
\hline & $\mathrm{H} 8$ & male & 61 & $\mathrm{n} / \mathrm{a}$ & + & + & + \\
\hline & H9 & male & 37 & $\mathrm{n} / \mathrm{a}$ & - & + & + \\
\hline & $\mathrm{H} 10$ & male & 39 & $\mathrm{n} / \mathrm{a}$ & - & + & - \\
\hline
\end{tabular}

Table 1. Donor data and experiments applied to donor samples. 


\section{RESULTS}

\subsection{COMP level is elevated in psoriatic non-lesional skin}

Non-lesional skin carries several known alterations of the ECM in the papillary dermis (Bos et al., 1983; Ting et al., 2000). Since COMP has previously been reported to also be present in the papillary dermis, COMP-protein accumulation was characterized in non-lesional and lesional skin from psoriasis patients and skin from healthy individuals. COMP protein was detected with western blot analysis under reducing (Figure $4 a, 4 b$ and Figure 5) and nonreducing (Figure 6) conditions. Under reducing conditions, we detected elevated COMP monomer and fragment levels in psoriatic non-lesional protein extracts, compared to healthy skin (Figure 4a, $4 b$ and Figure 5).
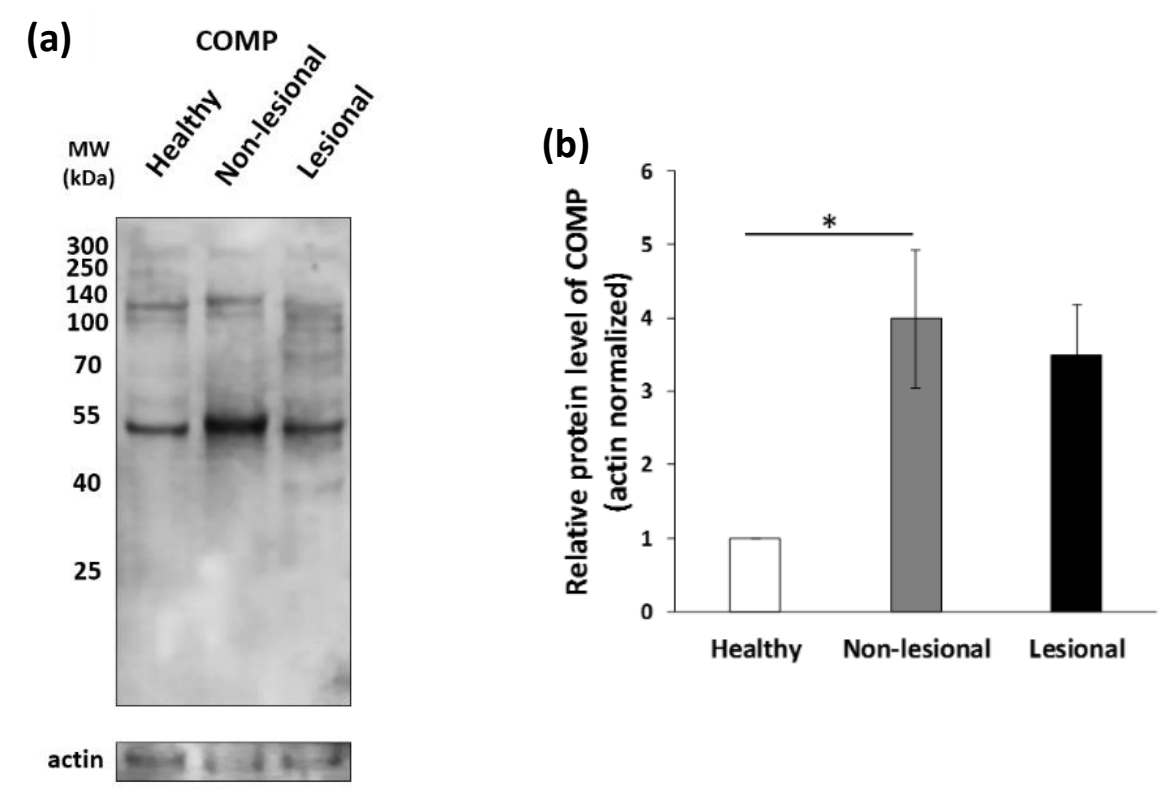

Figure 4.: COMP protein detection under reducing conditions.

(a) COMP protein was detected with western blot analysis from healthy, psoriatic non-lesional and lesional skin. Actin was used as a loading control. A representative blot is shown under reducing condition. (b) Band intensities of COMP monomer were quantitated with Image Studio software (LI-COR Biosciences, Lincoln, Nebraska, USA) and presented as fold changes normalized to actin. The graph shows mean+/-SEM (standard error of the mean, n=6) vs. healthy control. *:P<0.05 calculated by one-way ANOVA, followed by Tukey's post hoc test. 

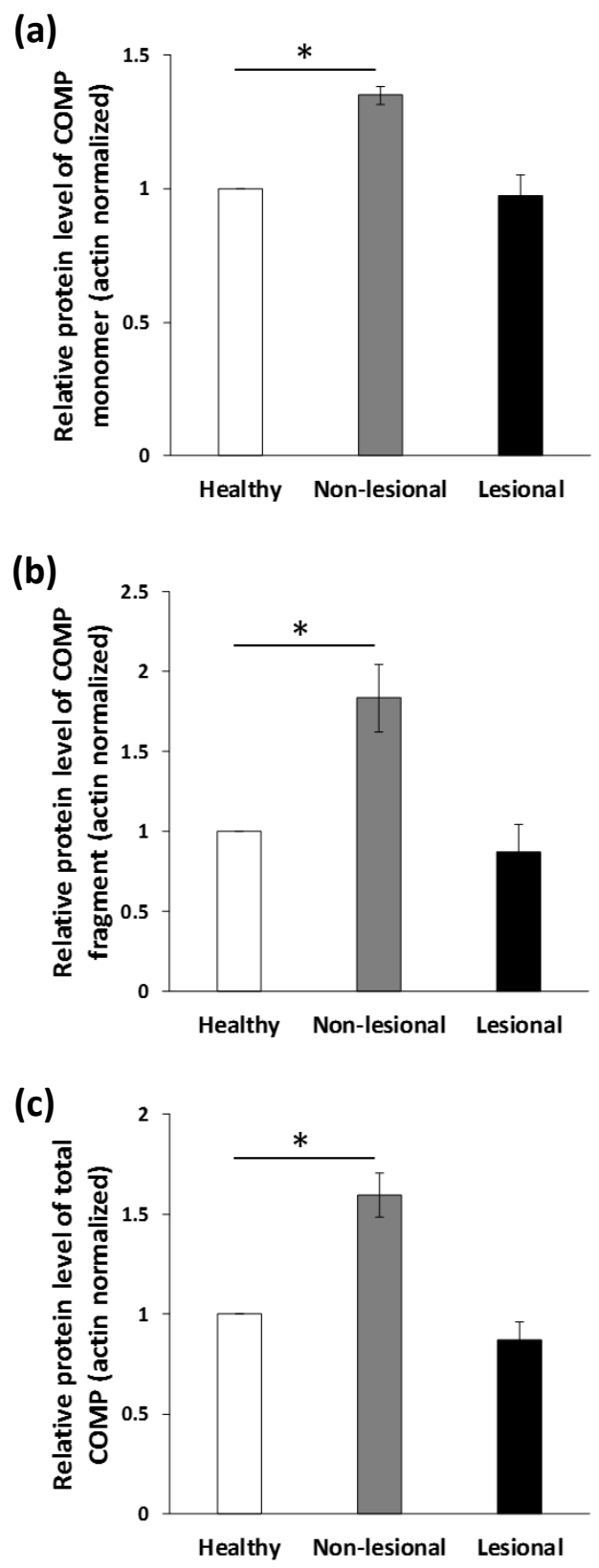

Figure 5.: COMP monomer and fragment level is elevated in psoriatic non-lesional skin under reducing conditions.

COMP monomers and fragments were detected with western blot analysis from healthy, psoriatic non-lesional and lesional skin under reducing conditions $(n=3)$. The band intensities of (a) COMP monomer, (b) COMP fragment separately, as well as (c) the level of monomer and fragment together were analyzed with Image Studio software (LI-COR Biosciences, Lincoln, Nebraska, USA) and presented as fold changes normalized to actin. The graph shows 
mean+/-SEM ( $\mathrm{n}=3), *: \mathrm{P}<0.05$ vs. healthy control, calculated by one-way ANOVA, followed by Tukey's post hoc test.

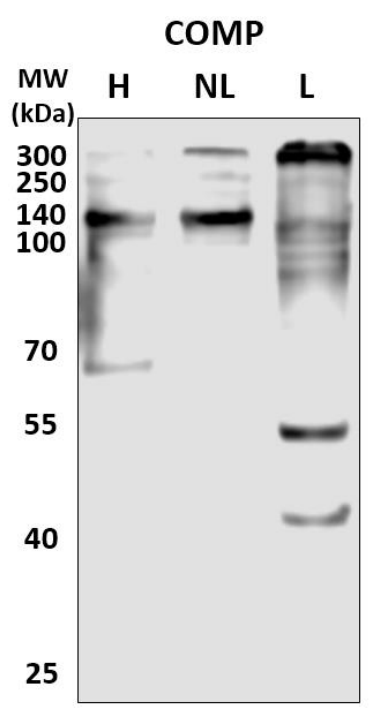

Figure 6.: COMP protein detection under non-reducing conditions.

COMP protein was detected with western blot analysis from healthy, psoriatic non-lesional and lesional skin under non-reducing conditions $(n=3)$. A representative blot is shown. (H: healthy, NL: non-lesional, L: lesional). 


\subsection{COMP deposition is altered in the psoriatic skin}

Subsequently, the distribution of COMP in tissues was analyzed using immunofluorescence staining. In line with previous reports, COMP was detected in the papillary dermis of healthy skin (Farina et al., 2006). However, we found, that in psoriatic non-lesional samples, COMP deposition extended deeper into the dermis and formed a more even and continuous layer than observed in healthy samples (Figure 7 and Figure 8). In contrast, COMP deposition in lesional skin extended to the upper part of the reticular dermis and exhibited a discontinuously scattered distribution (Figure 7 and Figure 8).

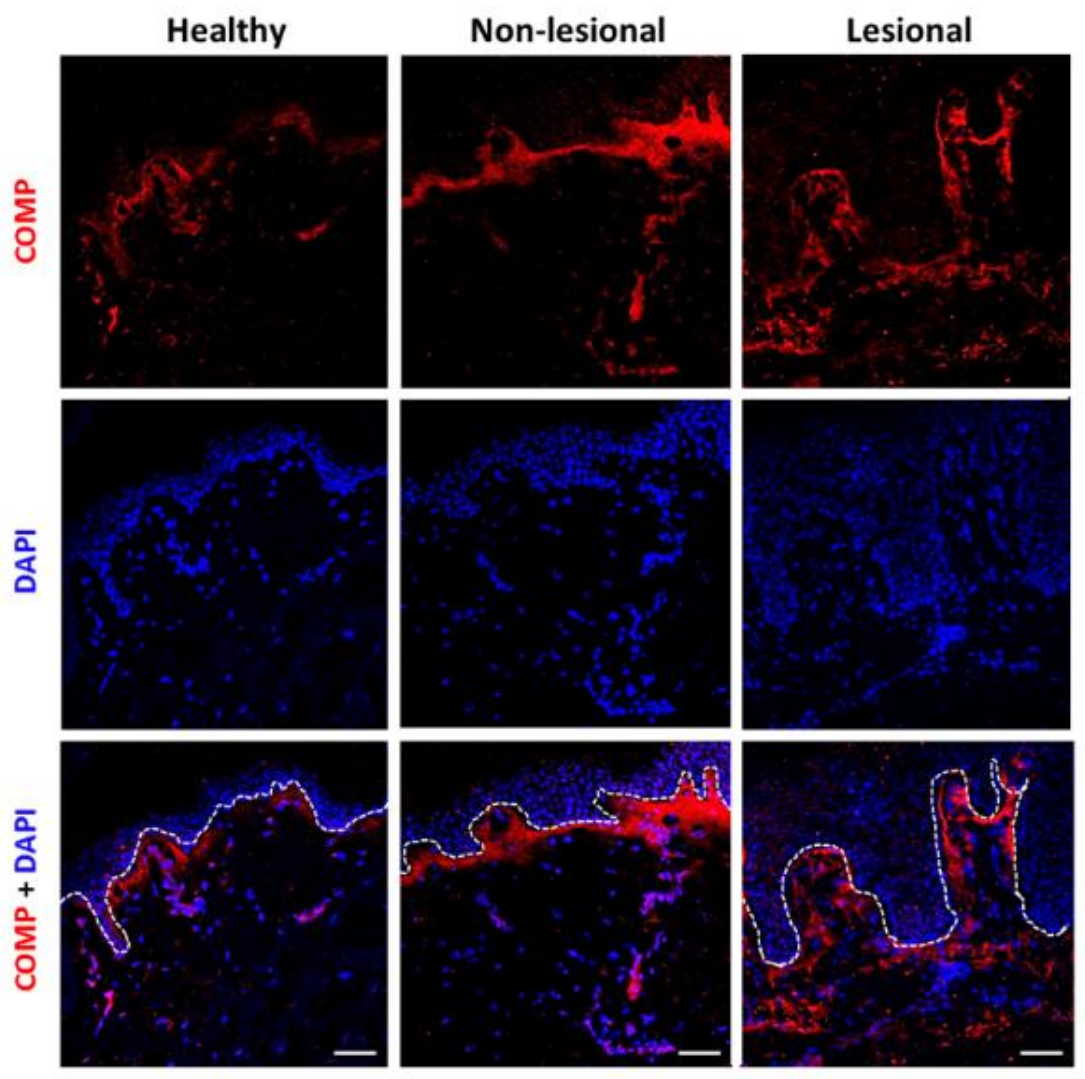

Figure 7.: COMP deposition in healthy, non-lesional and lesional skin.

Immunofluorescence staining for COMP in healthy (left column), psoriatic non-lesional (middle column) and psoriatic lesional (right column) skin. Representative images are shown. Dotted lines indicate the border of the dermal-epidermal junction ( $n=10$, magnification: 20x; scale bar: $50 \mu \mathrm{m})$. 

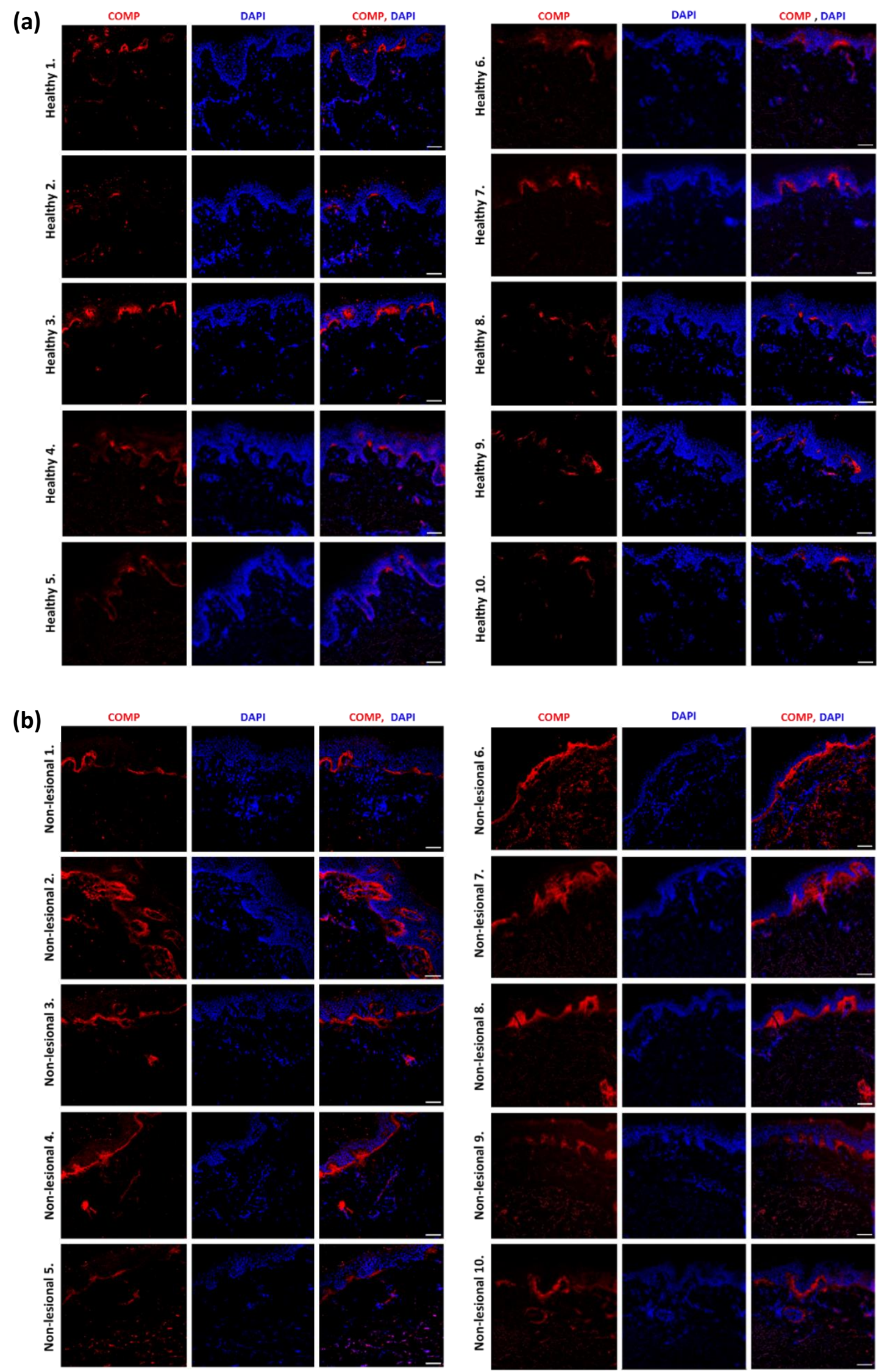
(c)





Figure 8.: Characterization of COMP deposition in healthy, non-lesional and lesional skin. Immunofluorescence staining for COMP in (a) healthy, (b) psoriatic non-lesional and (c) psoriatic lesional skin. ( $\mathrm{n}=10$, magnification: 20x, scale bar: $50 \mu \mathrm{m})$. 


\subsection{COMP mRNA expression is elevated in non-lesional fibroblasts}

Because skin fibroblasts are the major producers of COMP protein (Dodge et al., 1998), we examined the mRNA expression of COMP in primary dermal fibroblasts derived from healthy and psoriatic non-lesional skin and detected elevated COMP mRNA expression in non-lesional fibroblasts (Figure 9).



Figure 9.: COMP mRNA expression in healthy and non-lesional cultured fibroblasts.

Real-time RT-PCR analysis of COMP cDNA from cultured human dermal fibroblasts of healthy and psoriatic non-lesional skin. Data were normalized to $18 \mathrm{~S}$ rRNA using the $\Delta \Delta \mathrm{Ct}$ method. The graph shows mean+/-SEM (n=8) vs. healthy cultured fibroblasts $* *: \mathrm{P}<0.01$, determined by two-tailed Student $t$ test. 


\subsection{COMP co-localization with $\beta 1$-integrin of basal keratinocytes and EDA+FN is increased and with LAMA1 is decreased in non-lesional psoriatic skin}

COMP is known to interact with several members of the integrin cell-surface receptor family, including $\alpha 5 \beta 1$-integrin (Chen et al., 2005), whose expression increases together with $\mathrm{EDA}+\mathrm{FN}$ in non-lesional skin, possibly due to damaged BM (Bata-Csorgo et al., 1998; Mondello et al., 1996; Ting et al., 2000). To investigate the possible interactions of COMP with proteins in the DEJ that have been altered, confocal microscopic analysis with dual immunofluorescence staining was applied and consecutive sections of the appropriate area were analyzed.

To determine whether COMP accumulation at the DEJ allows interaction with basal epidermal keratinocytes, COMP and $\beta 1$-integrin co-immunofluorescence staining was applied. In the papillary dermis, COMP staining partially co-localized with the $\beta 1$-integrin from basal keratinocytes in healthy and non-lesional skin (Figure 10a and Figure 11). However, the colocalization of the two proteins was most prominent in psoriatic non-lesional skin (Figure 10d).

LAMA1 is a component of the BM laminin layer, which is fragmented and occasionally completely missing in non-lesional psoriatic skin (Mondello et al., 1996; Vaccaro et al., 2002). Therefore, to examine whether the damaged BM of non-lesional skin allows the interaction of COMP and $\beta 1$-integrin, LAMA1-COMP dual immunostaining was performed. In non-lesional skin, COMP- $\beta 1$-integrin double-positive regions exhibited a discontinuous LAMA1 staining pattern (Figure 10b) and the co-occurrence of COMP and LAMA1 was significantly lower in non-lesional skin compared to healthy skin (Figure 10e).

In addition, fibronectin has also been reported to interact with COMP (Di Cesare et al., 2002); therefore, confocal microscopic analysis was also applied to COMP and EDA+FN. In psoriatic non-lesional skin, in which co-localization of COMP and $\beta 1$-integrin was apparent, partial colocalization of COMP and EDA+FN was observed (Figure 10c), and the intensity of colocalization was significantly higher in non-lesional skin relative to healthy skin (Figure 10f). 


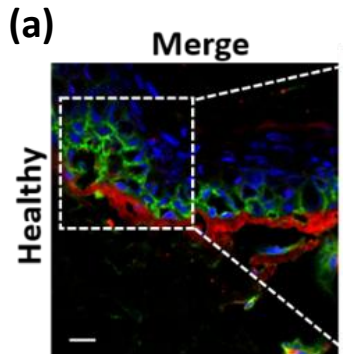

Merge

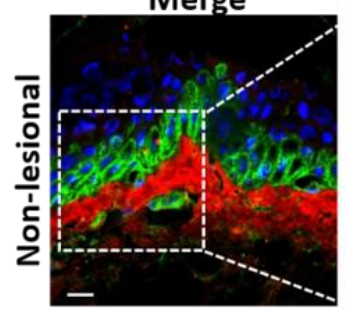

(b)

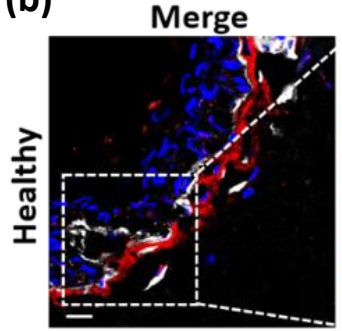

Merge



(c)

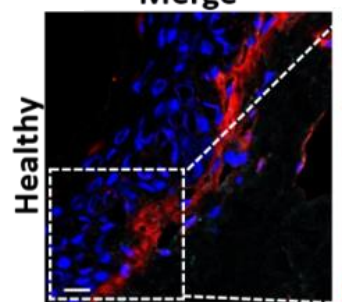

Merge

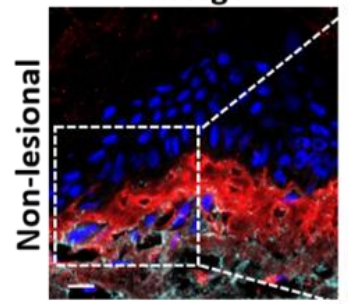

COMP

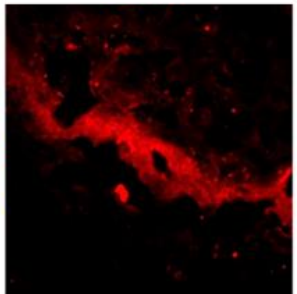

COMP
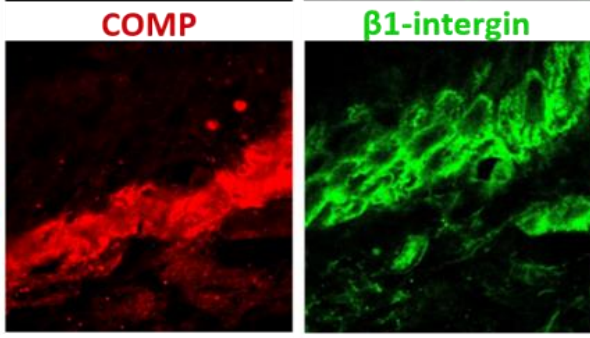

$\beta 1$-intergin

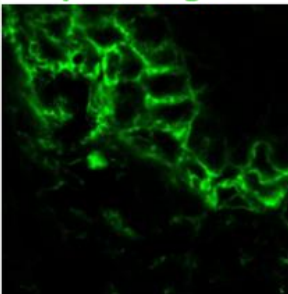

COMP, $\beta 1$-intergin Colocalized pixels



COMP, $\beta 1$-intergin Colocalized pixels
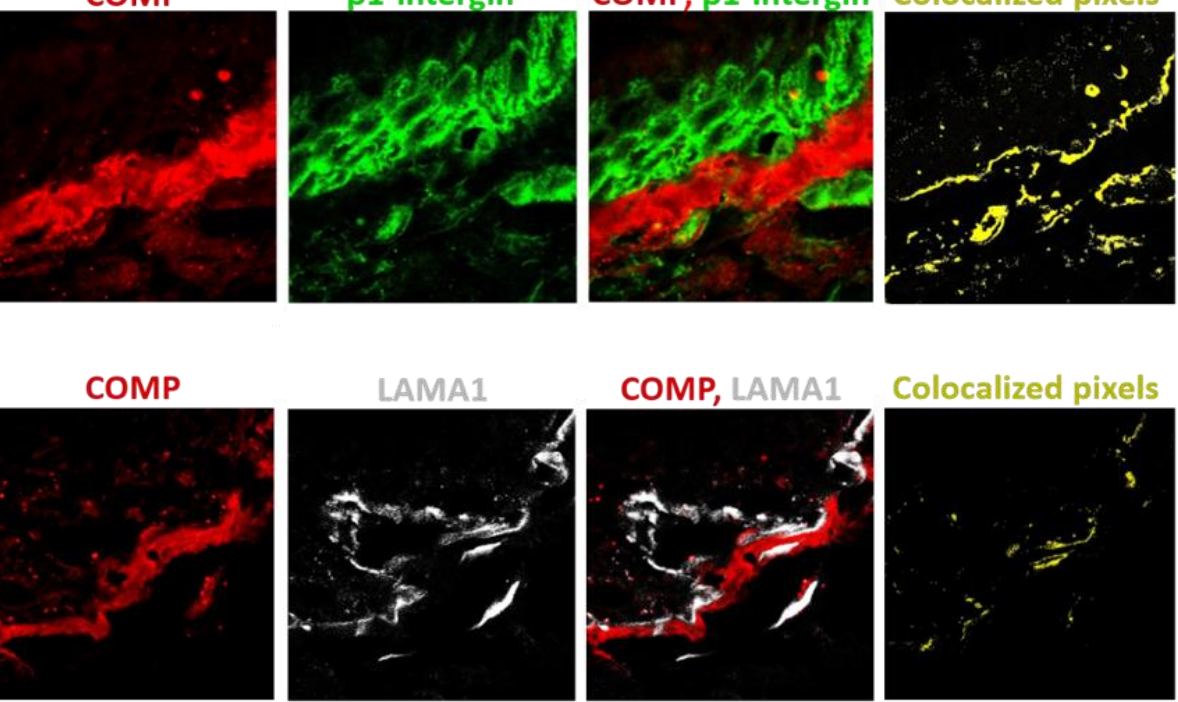

COMP

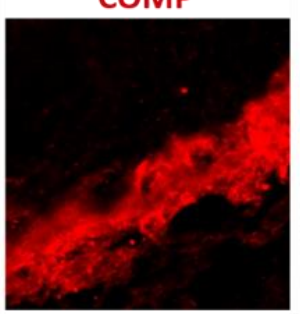

LAMA1

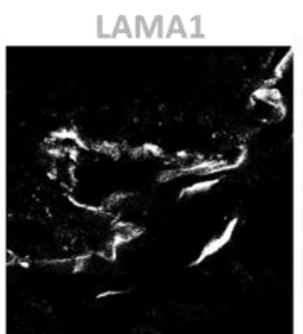

COMP, LAMA1

Colocalized pixels

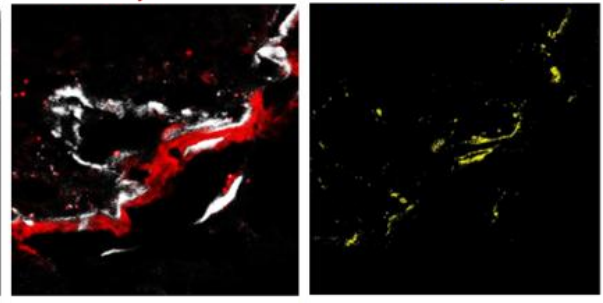

COMP, LAMA1

Colocalized pixels
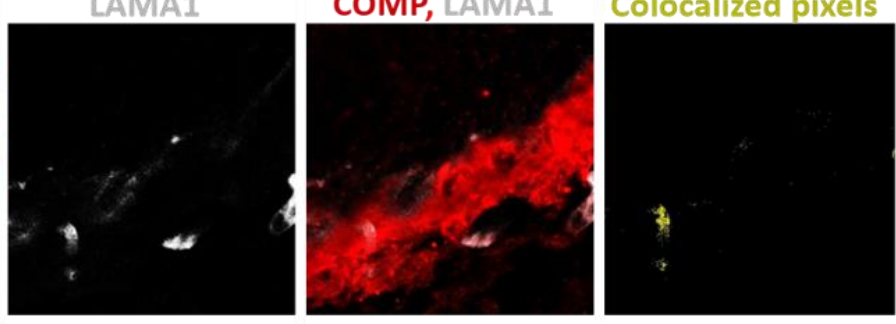

COMP



COMP, EDA+FN

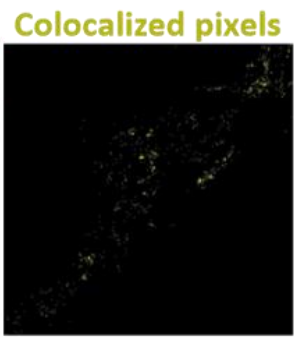

EDA+FN

COMP, EDA+FN

Colocalized pixels

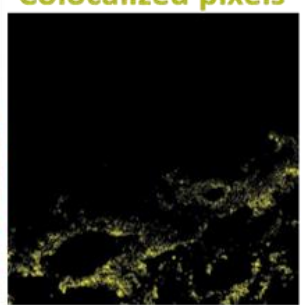


(d)

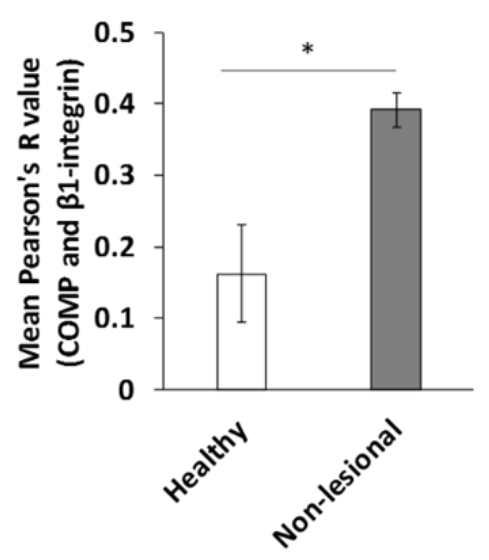

(e)

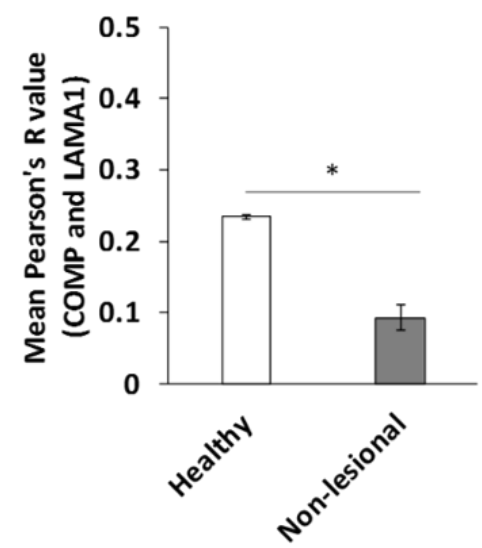

(f)

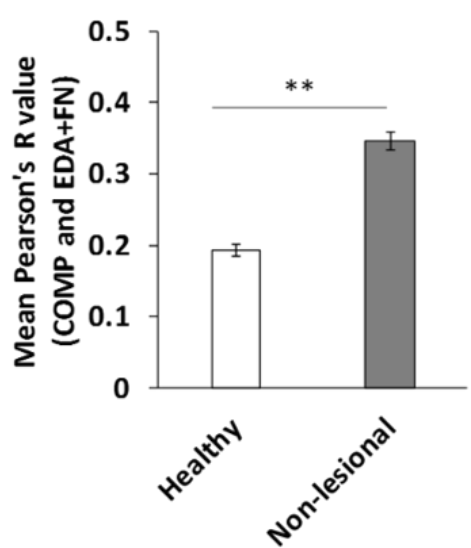

Figure 10.: COMP co-localization with basal keratinocyte $\beta 1$-integrin and EDA+FN increases and with LAMA1 decreases in non-lesional psoriatic skin.

Confocal microscopic immunofluorescence analysis of (a) COMP and $\beta 1$-integrin, (b) COMP and LAMA1, (c) COMP and EDA+FN co-localization in healthy (first row) and psoriatic nonlesional (second row) skin. Representative images are shown. Dotted lines indicate the enlarged regions. Co-localized pixels of the indicated proteins were calculated with ImageJ software (ImageJ, Wisconsin, USA; $\mathrm{n}=5$, magnification: 63x; scale bar:10 $\mu \mathrm{m}$ ). The extent of colocalization of (d) COMP- $\beta 1$-integrin, (e) COMP-LAMA1, (f) COMP-EDA+FN were calculated using ImageJ/Fiji software (ImageJ, Wisconsin, USA). The graphs show mean Pearson's correlation coefficient, $\mathrm{R}+/-\mathrm{SEM}(\mathrm{n}=5)$ vs. healthy control, $*: \mathrm{P}<0.05, * *: \mathrm{P}<0.01$ determined by two-tailed Student $t$ test. 
(a)
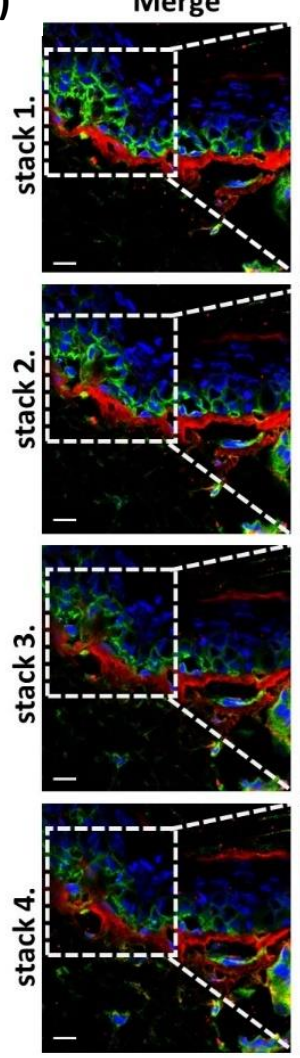

(b)


COMP
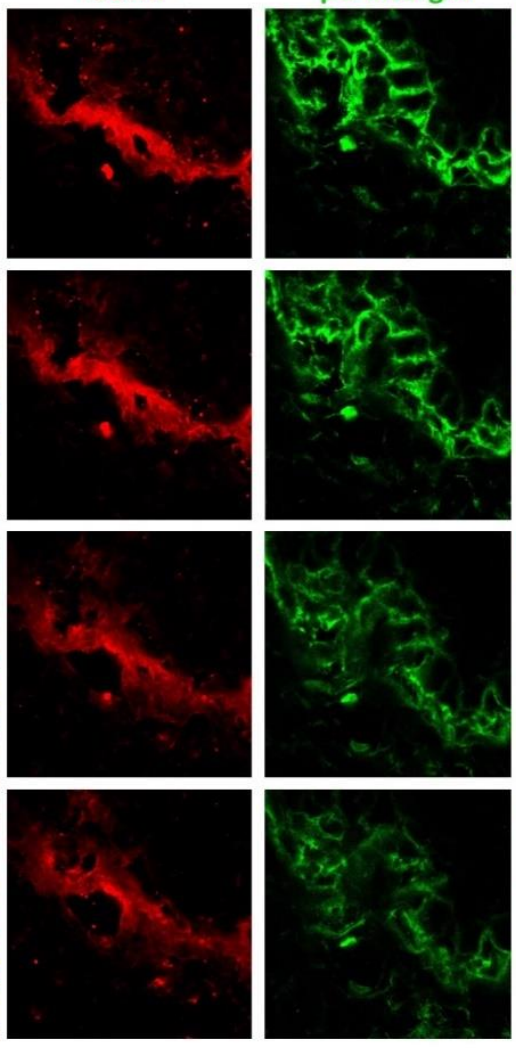

$\beta 1$-intergin


$\beta 1$-intergin
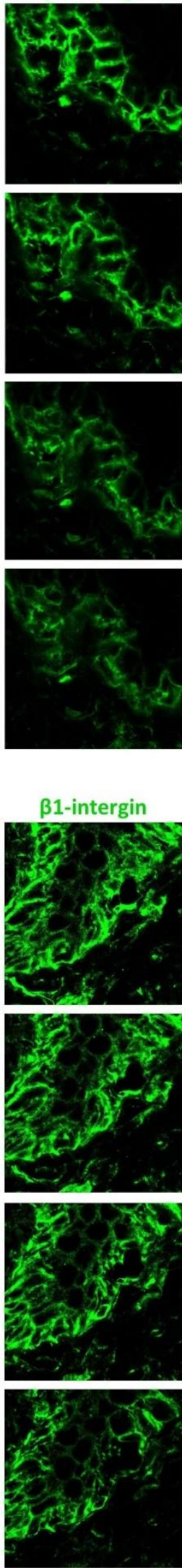
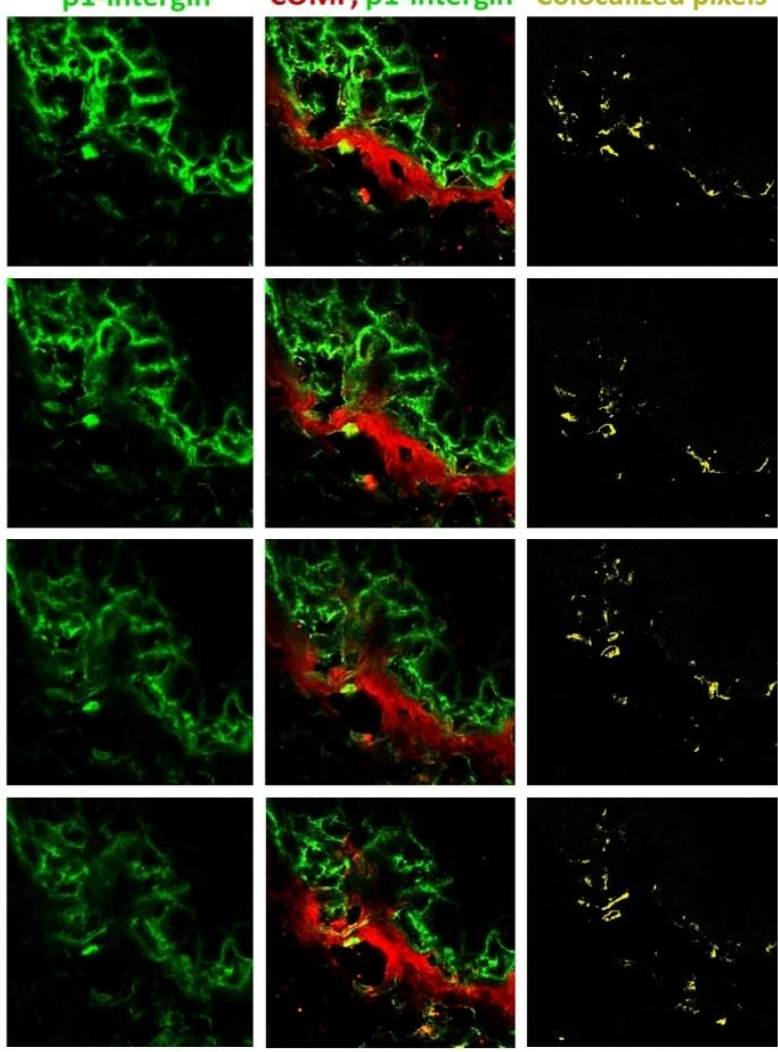

COMP, $\beta 1$-intergin Colocalized pixels

Figure 11.: Enhanced co-localization of COMP with $\beta 1$-integrin the in non-lesional psoriatic skin.

Confocal microscopic immunofluorescence analysis of COMP and $\beta 1$-integrin in (a) healthy and (b) psoriatic non-lesional skin using z-stack pictures. Dotted lines indicate the borders of enlarged regions. Co-localized pixels of COMP and $\beta 1$-integrin were calculated by ImageJ software (ImageJ, Wisconsin, USA; $n=5$, magnification: 63x; scale bar:10 $\mu \mathrm{m}$ ). 


\subsection{COMP negatively influences keratinocyte proliferation in vitro}

To investigate whether the possible interaction between COMP and $\beta 1$-integrin influences keratinocyte cellular behavior, we first performed an impedance measurement-based, real-time cellular analysis of the HPV-KER immortalized keratinocyte cell line. When the culturing plate was pre-coated with recombinant human COMP, cells exhibited reduced CI values in a manner that was dependent on COMP concentration compared to cells grown on uncoated surfaces (Figure 12a). CI is influenced by changes in cell proliferation, viability, morphology and adhesion (Dickhuth et al., 2015). To investigate whether the proliferation rate of HPV-KER cells was affected, a BrdU cell proliferation assay was performed. Pre-coating the surface with a high concentration $(10 \mu \mathrm{g} / \mathrm{ml})$ of rhCOMP resulted in significantly reduced proliferation rates at 24 and 72 hours, compared to cells grown on an uncoated surface (Figure 12b). Cell proliferation of primary NHEK was also reduced when the surface was coated with $10 \mu \mathrm{g} / \mathrm{ml}$ rhCOMP (Figure 12c).

(a)

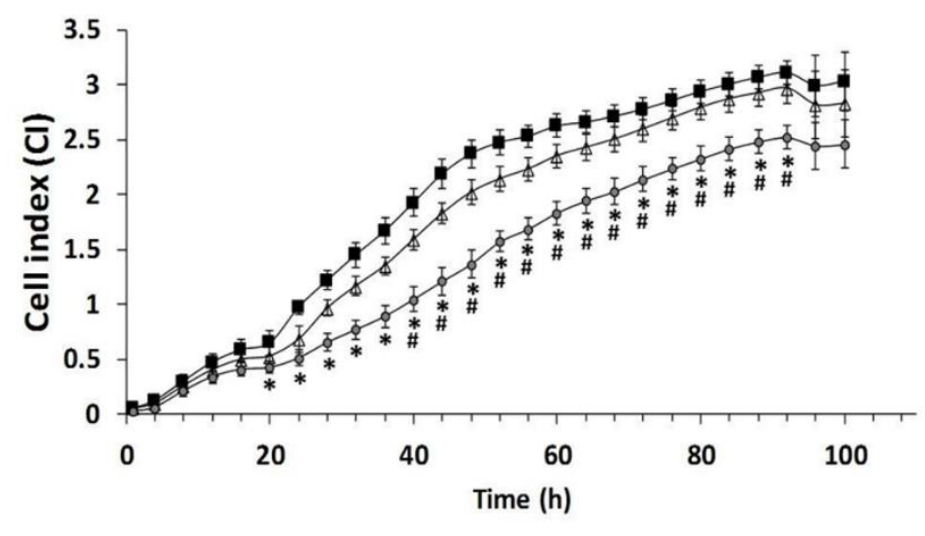

- uncoated $\quad \triangle 1 \mu \mathrm{g} / \mathrm{ml}$ COMP coated $\quad \rightarrow 10 \mu \mathrm{g} / \mathrm{ml}$ COMP coated

(b)

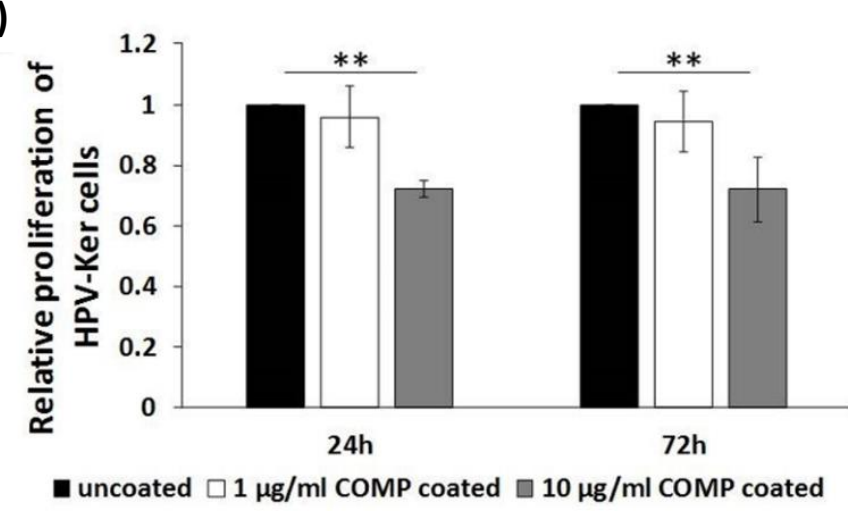






Figure 12.: COMP negatively influences keratinocyte cell proliferation.

(a) Cell index measurement of HPV- KER cells cultured on surfaces that were uncoated or coated with rhCOMP ( 1 and $10 \mu \mathrm{g} / \mathrm{ml}$ ). CI was determined using real-time impedance measurement-based cellular analysis. The graph is representative of four independent experiments, all showing similar results. The graph shows mean CI+/-SEM of four technical replicas for each group, $*: \mathrm{P}<0.05$ vs. uncoated control, $\#: \mathrm{P}<0.05$ vs. $1 \mu \mathrm{g} / \mathrm{ml}$ rhCOMP coated group calculated by one-way ANOVA, followed by Tukey's post hoc test. BrdU cell proliferation assay of (b) HPV-KER and (c) NHEK cells cultured on uncoated and rhCOMP protein $(1$ and $10 \mu \mathrm{g} / \mathrm{ml})$ coated surfaces at 24 and 72 hours following seeding. The graphs show mean proliferation +/-SEM $(\mathrm{n}=3)$. $* *: \mathrm{P}<0.01$, calculated by one-way ANOVA, followed by Tukey's post hoc test. 


\subsection{COMP negatively influences keratinocyte proliferation via $\alpha 5 \beta 1$-integrin in vitro}

To test whether integrins mediate the observed negative effect of COMP on cell proliferation, blocking experiments using anti- $\alpha 5$ and anti- $\beta 1$-integrin polyclonal antibodies were performed. Blocking of either $\alpha 5$ - or $\beta 1$-integrin subunit in cells grown on a surface precoated with $10 \mu \mathrm{g} / \mathrm{ml}$ rhCOMP abolished the negative effect of COMP on HPV-KER proliferation, whereas blocking either $\alpha 5$ - or $\beta 1$-integrin alone had no negative effect on these cells (Figure 13a, 13b and Figure 14). Similarly, the negative effect of COMP on the proliferation rate of primary NHEK cells could also be abolished by blocking COMP, $\alpha 5-$ or $\beta 1$-integrin, as determined with the BrdU assay (Figure 13c, 13d) and Ki67 immunofluorescent staining (Figure 13e, 13f).

(a)
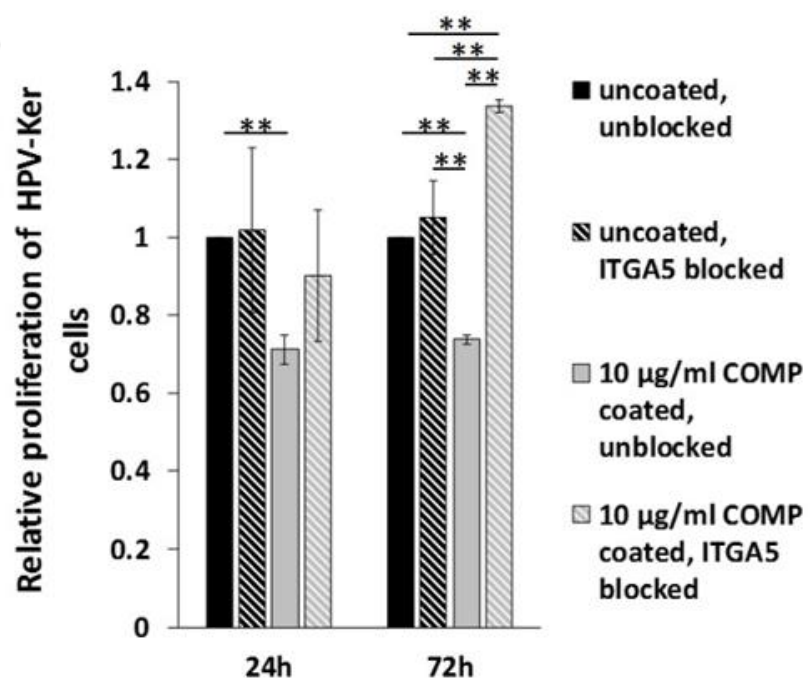

(b)

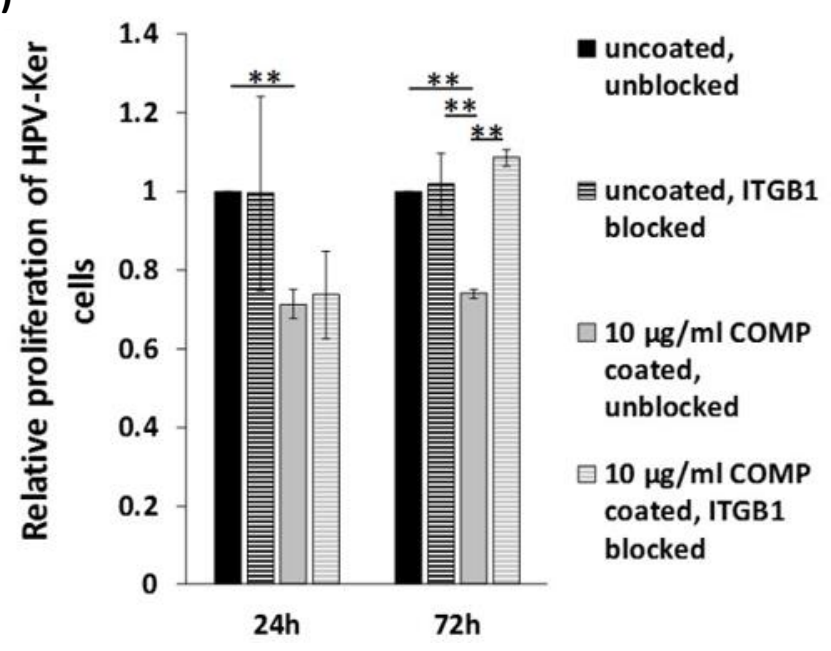


(c)



(d)

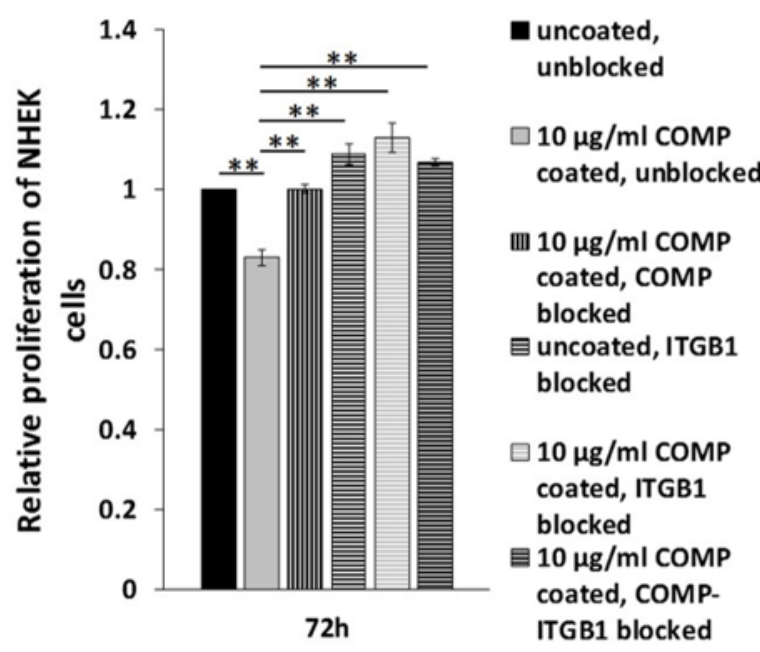

(e)

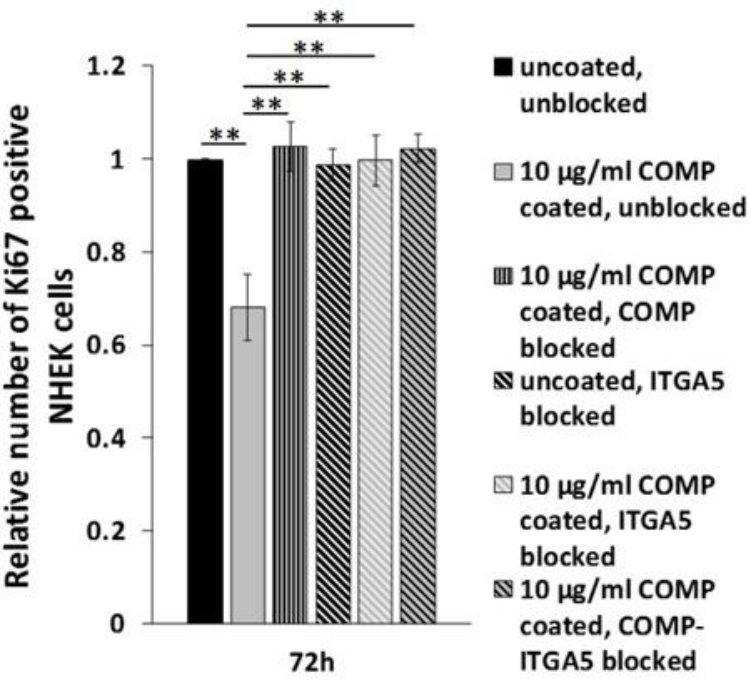






Figure 13.: COMP influences keratinocyte proliferation via a5ß1 integrin.

BrdU cell proliferation assay of $(a, b)$ HPV-KER cells cultured on surfaces that were uncoated or coated with rhCOMP protein $(10 \mu \mathrm{g} / \mathrm{ml})$ for 24 and 72 hours following seeding and treated with (a) anti- $\alpha 5$ or (b) anti- $\beta 1$-integrin subunit antibodies. (c, d) BrdU assay, and (e, f) Ki67positive proliferating cell number determination of NHEKs grown on surfaces that were uncoated or coated with rhCOMP protein $(10 \mu \mathrm{g} / \mathrm{ml})$ for 72 hours following seeding and treated with (c, e) anti- $\alpha 5$ and $(\mathrm{d}, \mathrm{f})$ anti- $\beta 1$-integrin subunit antibody in a combination with COMP protein neutralization. The graphs show mean proliferation/mean number of Ki67-positive cells+/-SEM ( $\mathrm{n}=3$ ) vs. uncoated control, $*: \mathrm{P}<0.05, * *: \mathrm{P}<0.01$ calculated by one-way ANOVA, followed by Tukey's post hoc test.
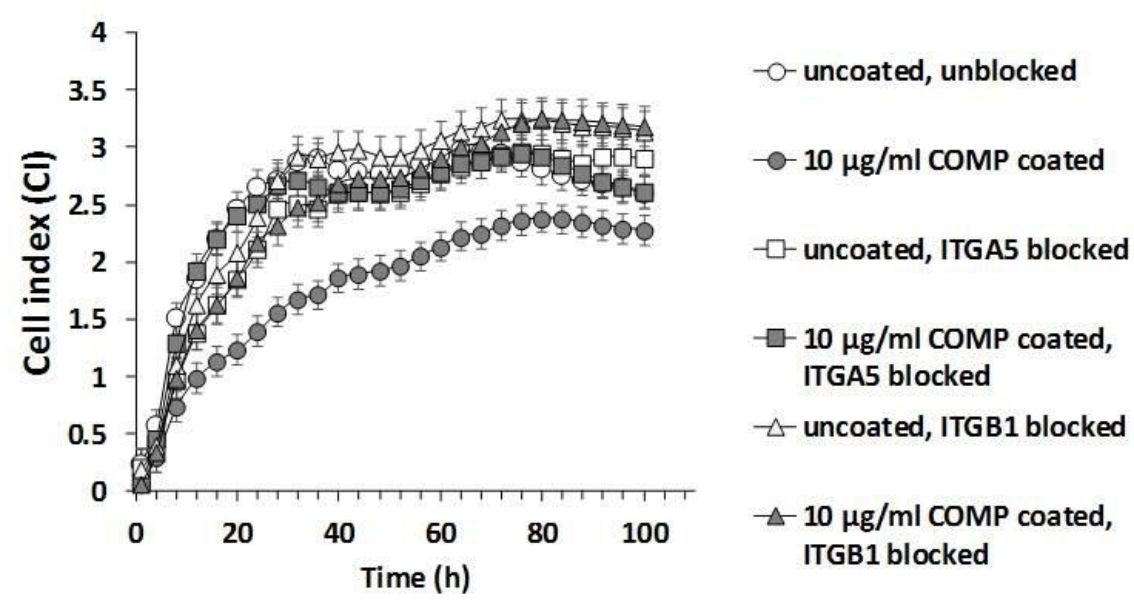

Figure 14.: COMP negatively influences keratinocyte cell index via a5ß1 integrin. 
Cell index measurement of HPV-KER cells cultured on uncoated and rhCOMP-coated (10 $\mu \mathrm{g} / \mathrm{ml}$ ) surfaces. CI was determined using real-time impedance measurement-based cellular analysis. The graph is representative of three independent experiments, all showing similar results. Mean CI+/-SEM of four technical replicas for each group. 


\subsection{COMP has a negative effect on skin wound healing by attenuating keratinocyte proliferation and by compromising keratinocyte migration and activation in $e x$ vivo wound models}

To further study the effect of COMP on keratinocytes, an ex vivo three-dimensional skin wound-healing model was applied. Standardized wounded skin samples, with or without rhCOMP treatment $(10 \mu \mathrm{g} / \mathrm{ml}$ ) (Figure 15a), and unwounded controls were examined at 72 hours after wounding. Immunofluorescent staining revealed COMP-localization on the dermal surface of the injured region in COMP-treated wounds, whereas COMP was not detected at the injured region of untreated wounds 72 hours after treatment (Figure 15a). By applying Ki67 immunofluorescent staining to detect proliferating cells, we found a markedly reduced number of Ki67 positive cells in COMP-treated wounds, indicating a decreased rate of proliferation (Figure 15b, 15c and Figure 16a).

Cell migration processes at the wound edge during the closure of injuries require dynamic reorganization of the actin cytoskeleton in the keratinocytes located close to wound margins. To visualize these cells, immunofluorescence staining for actin was applied. In wounds not exposed to COMP, we found that keratinocytes exhibited high levels of actin expression at wound edges, while actin expression at wound edges was markedly decreased in COMP-treated wounds, indicating that actin expression was compromised, possibly resulting in a reduction of active cell migration (Figure 15d).

KRT17 expression is known to be induced in keratinocytes at wound edges during healing (Mazzalupo et al., 2003). Therefore, we performed KRT17 immunofluorescence staining to further investigate the effect of COMP in the ex vivo wound healing model. In rhCOMP-treated wounds, KRT17 expression and re-epithelization were reduced and restricted to a smaller proportion of keratinocytes, compared to untreated control wounds (Figure 15e and Figure 16b, 16c). This suggests that the presence of COMP compromised keratinocyte activation. 
(a)

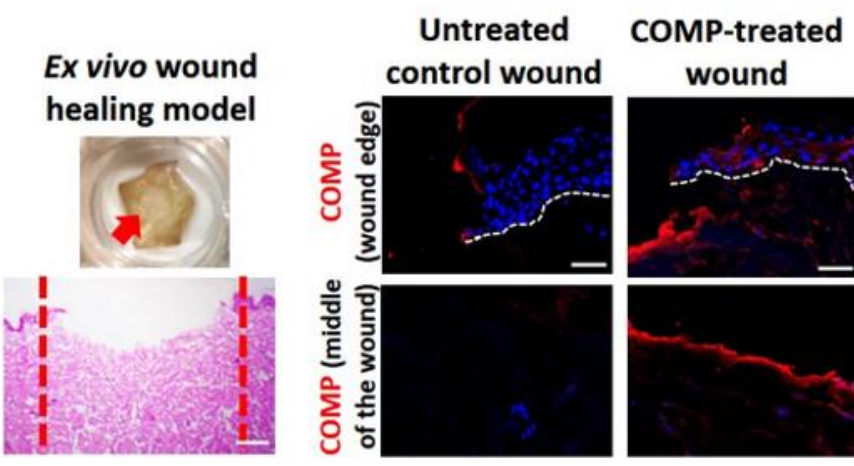

(b) Unwounded, Untreated COMP-treated untreated control control wound wound
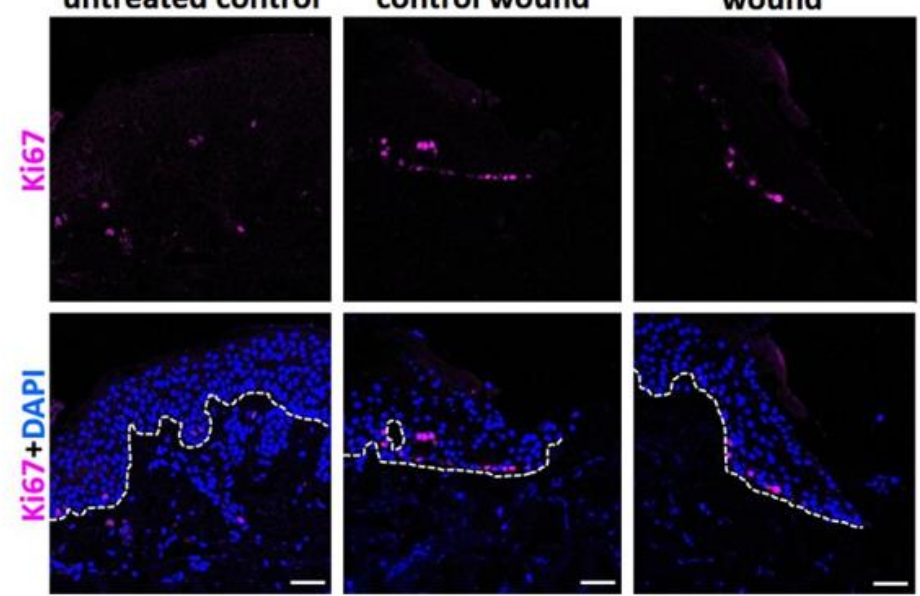

(c)



(d) Unwounded, wound



Untreated control wound COMP-treated

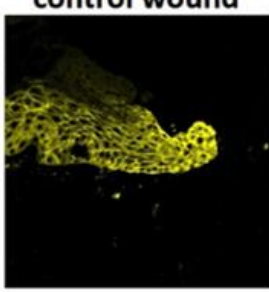

wound
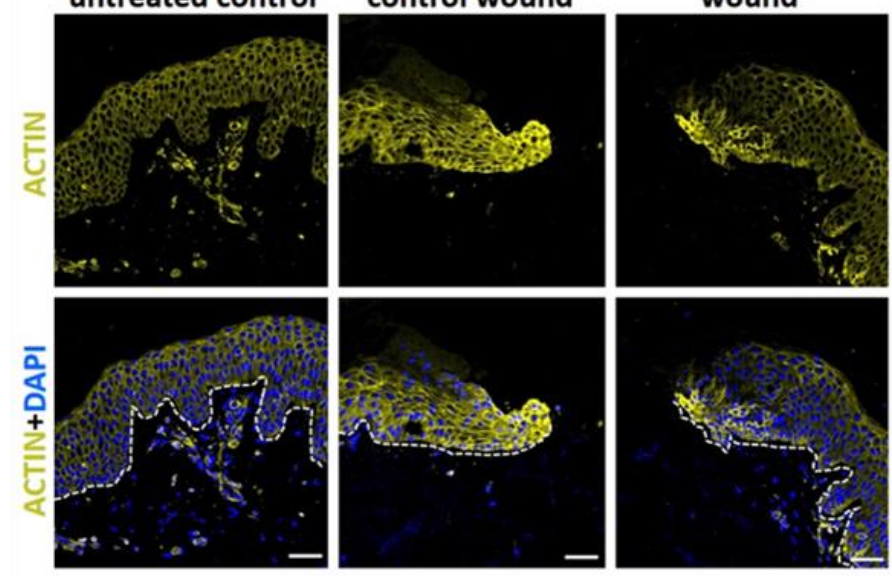




Figure 15.: COMP has a negative effect on keratinocyte proliferation and is involved in keratinocyte migration and activation in ex vivo wound models.

(a) Representative images of the ex vivo skin wound healing models ( $\mathrm{n}=3$; magnification: 4x; scale bar: $250 \mu \mathrm{m})$. Immunofluorescent staining for COMP at wound edges and at the middle of the wounds of untreated controls and wounds treated with rhCOMP $(n=3$; magnification: 20x; scale bar: $50 \mu \mathrm{m})$. Immunostaining for (b) Ki67, (d) actin or (e) keratin-17 in the ex vivo unwounded skin (left column), and wound-healing skin models with (right column) and without (middle column) rhCOMP treatment. Representative images are shown. Dotted lines indicate the border of the dermal-epidermal junction ( $n=3$; magnification: $20 x$; scale bar: $50 \mu \mathrm{m})$. (c) Ki67 positive cells in wounds that were not treated and were treated with rhCOMP protein. The graph shows mean number of Ki67-positive cells +/-SEM ( $n=3$ ) vs. uncoated, untreated control $* *: \mathrm{P}<0.01$ determined by two-tailed Student $t$ test.

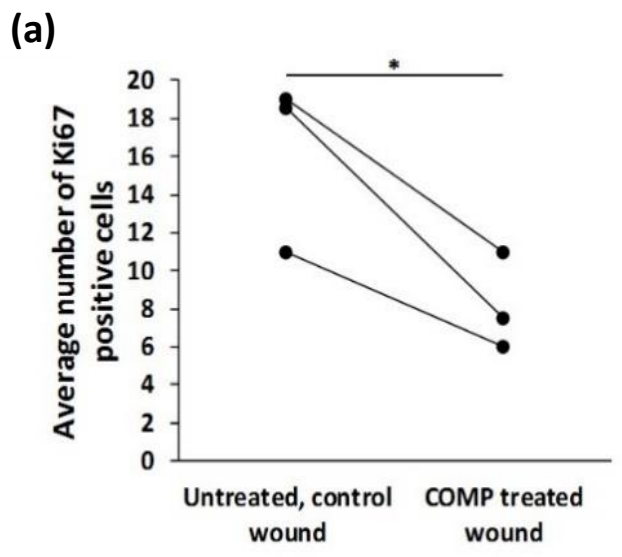



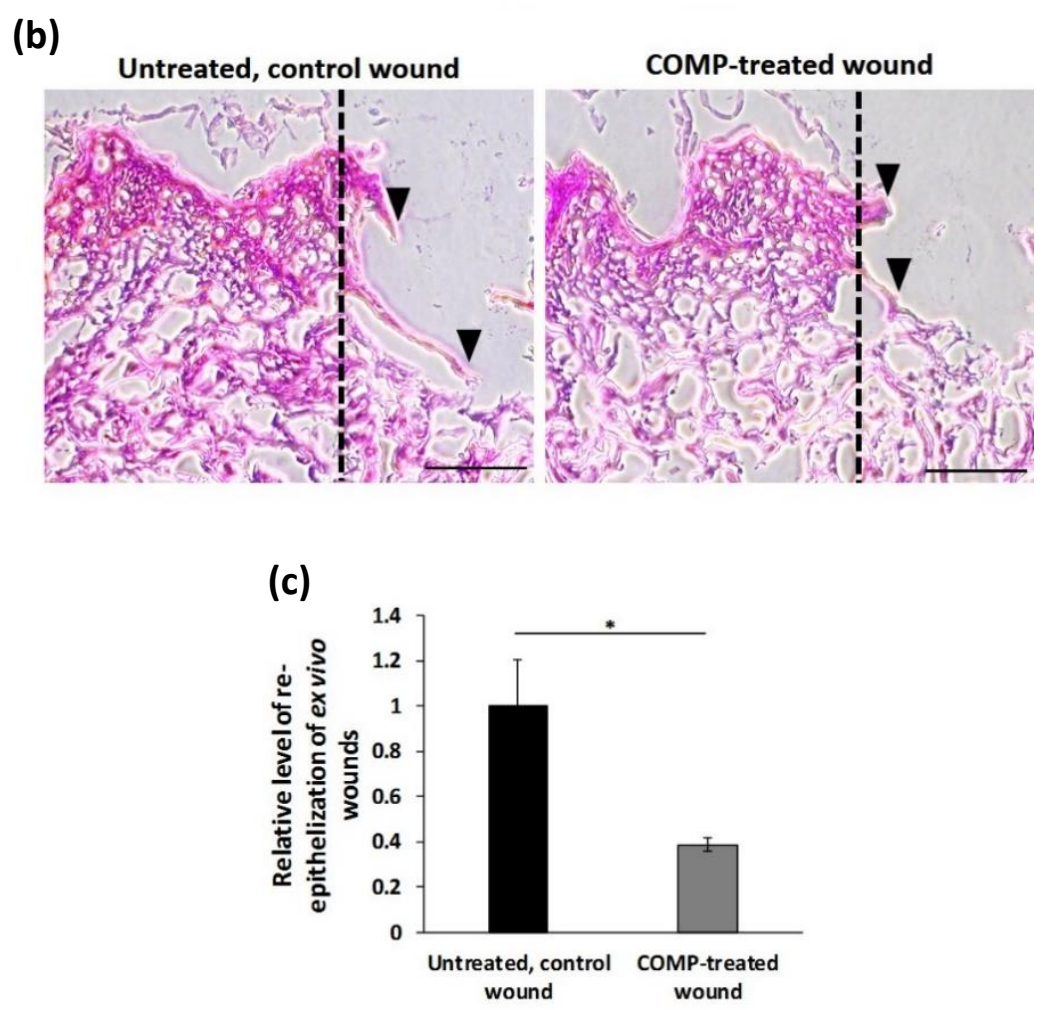

Figure 16.: Reduced proliferation and re-epithelization in the presence of COMP during ex vivo skin wound healing.

(a) Reduced number of Ki67 positive cells was detected in wound samples treated with rhCOMP $(10 \mu \mathrm{g} / \mathrm{ml})$, compared to untreated control wounds. The graph shows mean+/-SEM $(\mathrm{n}=3), *: \mathrm{P}<0.05$ vs. untreated control, calculated by two-tailed Student $\mathrm{t}$ test. (b) Reepithelization of artificial untreated and rhCOMP-treated $(10 \mu \mathrm{g} / \mathrm{ml})$ wounds on hematoxylineosin stained sections ( $\mathrm{n}=3$; magnification: 20x; scale bar: $50 \mu \mathrm{m}$ ). Representative pictures are shown. Arrowheads indicate the newly synthetized areas. (c) Re-epithelization of untreated, control- and rhCOMP-treated wounds were measured using area measurement of ImageJ software (ImageJ, Wisconsin, USA). The graph shows mean+/-SEM ( $n=3), *: P<0.05$ vs. untreated control, calculated by two-tailed Student t test. 


\section{DISCUSSION}

In psoriasis, the non-lesional skin contains ECM alterations compared to healthy skin. COMP is localized to the papillary dermis of healthy skin (Farina et al., 2006) and, through its interactions with type XII and XIV collagens, contributes to the stabilization of the DEJ (Agarwal et al., 2012). We found that, in psoriatic non-lesional skin, COMP is localized to the papillary dermis and, in contrast to healthy skin, it forms a continuous, more compact, linear layer beneath the basal keratinocytes. Apart from this altered localization, COMP expression was also elevated in dermal fibroblasts from psoriatic samples.

Psoriatic non-lesional skin is more sensitive to stress (Sonkoly et al., 2005; Széll et al., 2016), and abnormalities at the DEJ and the BM are believed to be important in the development of the disease (Bos et al., 1983; Ting et al., 2000). Interruption of the BM (Mondello et al., 1996; Vaccaro et al., 2002) may allow ECM components, normally located directly below the BM, to come in direct contact with basal keratinocytes. COMP reportedly binds directly to the extracellular domain of $\beta 1$-integrin of both cardiomyocytes (Huang et al., 2013) and cardiac fibroblasts, resulting in the stabilization of $\beta 1$-integrin by preventing its degradation and, subsequently, improving cellular survival (Huang et al., 2013; Posey et al., 2018). In cartilage, COMP mediates chondrocyte attachment and stabilization partially via $\alpha 5 \beta 1$-integrin (Tan et al., 2009). Our confocal microscopic analysis revealed a partial co-localization of papillary dermal COMP and $\beta 1$-integrin in basal keratinocytes, which indicates the possibility of a direct interaction between these two proteins in vivo. In non-lesional skin, the $\alpha 5$-integrin subunit is overexpressed in the basal layer of the epidermis, in contrast to healthy skin, where it is present at low levels or completely missing (Bata-Csorgo et al., 1998). Our findings are in line with this observation, as COMP and $\beta 1$-integrin strongly co-localize in psoriatic non-lesional epidermis and expression of both are upregulated in non-lesional skin. Moreover, the BM is partially discontinuous in psoriatic non-lesional skin (Mondello et al., 1996; Vaccaro et al., 2002), allowing direct interaction. The possibility of this interaction is supported by our finding that, in areas where COMP and $\beta 1$-integrin were found to have strong co-localization in psoriatic non-lesional skin, the expression of LAMA1, a member of the BM, is reduced or completely absent.

COMP also interacts with $\alpha 7 \beta 1$ - and $\alpha v \beta 3$-integrins (Chen et al., 2005; Rock et al., 2010). Of these proteins, only $\alpha 7 \beta 1$ contains a $\beta 1$-integrin subunit. There is currently no information 
available about $\alpha 7 \beta 1$-integrin expression in basal keratinocytes. Thus, we assumed that, if COMP exhibits a strong interaction with $\beta 1$-integrin, its $\alpha$-subunit is likely to be $\alpha 5$-integrin. In addition to binding to $\alpha 5 \beta 1$-integrin, a fibronectin receptor, COMP might also bind to the fibronectin protein itself (Di Cesare et al., 2002). Furthermore, $\alpha 5 \beta 1$-integrin-associated fibronectin and EDA+FN are known to play roles in psoriasis pathogenesis (Bata-Csorgo et al., 1998; Ting et al., 2000). Enriched expression of $\alpha 5 \beta 1$-integrin and EDA+FN in non-lesional skin are thought to be due to the incompleteness of the laminin layer (Mondello et al., 1996; Vaccaro et al., 2002). Our confocal microscopic analysis revealed partial co-localization of $\mathrm{COMP}$ and EDA+FN in non-lesional skin. These results suggest that, in addition to interacting with EDA+FN, COMP may also affect basal keratinocytes via interactions with both the $\mathrm{EDA}+\mathrm{FN}$ and its receptor, $\alpha 5 \beta 1$-integrin.

Keratinocyte behavior is influenced by ECM proteins through interactions with different cell surface integrins (Hamill et al., 2012; Tjin et al., 2014), and connection of basal keratinocytes to the altered BM could enhance proliferation (Yang et al., 2016). We analyzed the biological relevance of the interaction of COMP and $\beta 1$-integrin in basal keratinocytes using HPV-KER and NHEK cells in vitro. We found that the presence of COMP resulted in reduced keratinocyte proliferation in both cell types and that this affect was reversible by blocking COMP with a specific antibody.

We also analyzed whether the observed negative effect of COMP on keratinocyte proliferation involves interaction with $\alpha 5 \beta 1$-integrin. By partially blocking the function of the $\beta 1$ - or $\alpha 5$-integrin subunits with specific antibodies, the negative effect of COMP on cell proliferation was abolished, suggesting that the negative influence of COMP on keratinocyte proliferation involves $\alpha 5 \beta 1$-integrin.

Our in vitro findings were also validated in an ex vivo wound model: exogenous COMP treatment delayed healing of artificial wounds, and this affect was coupled with reduced keratinocyte proliferation and compromised actin expression, both important aspects of wound healing (Gurtner et al., 2008). In addition, keratinocyte KRT17 expression, considered a hallmark of normal wound healing (Mazzalupo et al., 2003), was also decreased in the presence of COMP. These results suggest that COMP has a negative influence on ex vivo wound healing. Interestingly, in normally healing wounds of healthy donors, COMP was hardly detectable when re-epithelialization was complete (Agarwal et al., 2013). Similarly, in psoriatic lesions, 
in which keratinocyte proliferation is abnormally increased, COMP was found to be discontinuous or completely absent from the papillary dermis. Although there are no data regarding keratinocyte proliferation or migration in wounds of COMP-deficient mice (Schulz et al., 2016), in human non-healing wounds, such as venous leg ulcers, the level of COMP is reported to be highly elevated (Agarwal et al., 2013). Our findings are in agreement with this observation.

In conclusion, our study shows that COMP is present at an elevated level in the papillary dermis of non-lesional psoriatic skin and that it possibly reduces keratinocyte proliferation via the $\alpha 5 \beta 1$-integrin. These aspects of COMP contribute to the maintenance of the non-lesional, non-hyperproliferative state of psoriatic non-lesional epidermis, despite the overexpression of EDA $+F N$ and $\alpha 5$-integrin. Similar interactions may also take place in other skin diseases in which non-healing wounds are coupled with massive COMP accumulation (Figure 17). 


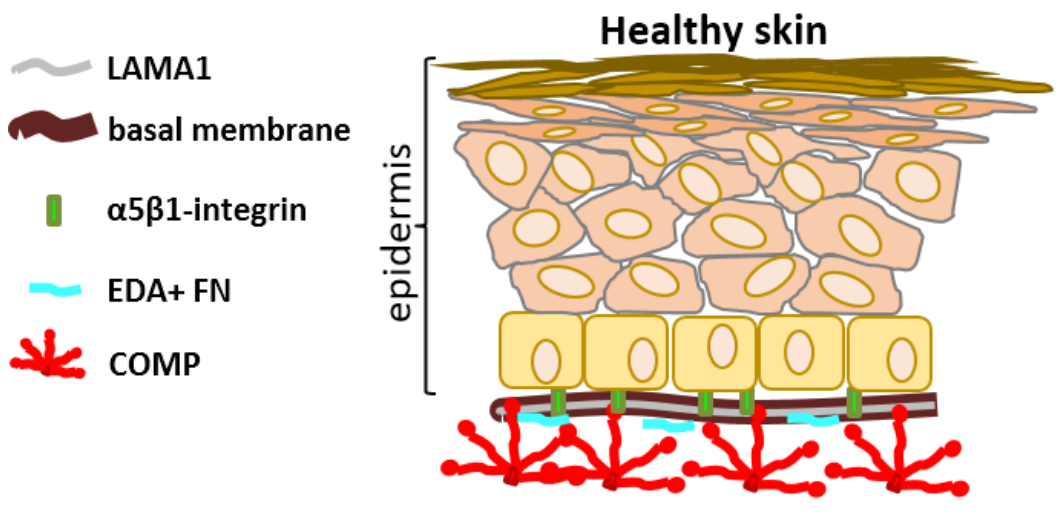

Keratinocyte proliferation
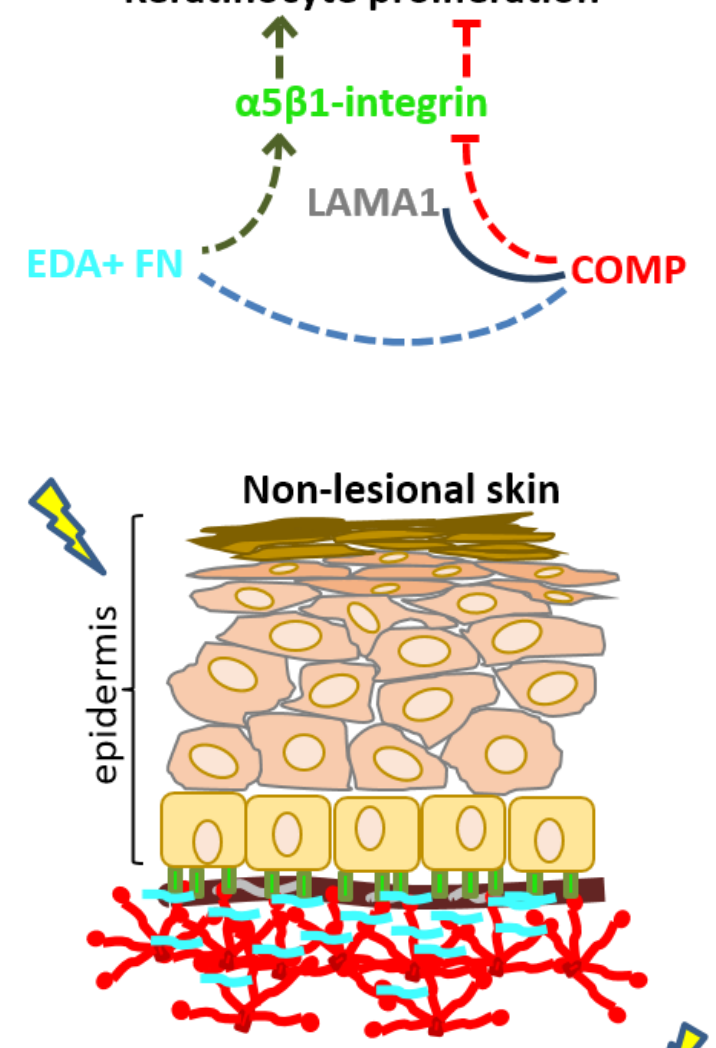

Keratinocyte proliferation

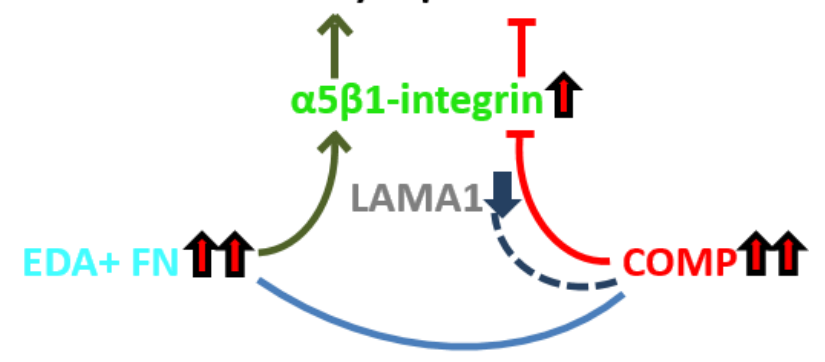

Figure 17.: The potential role of COMP in non-lesional and healthy skin. 


\section{SUMMARY}

In psoriasis, the non-lesional skin contains alterations, which affect the DEJ region, where the laminin-layer within the BM is discontinuous, as well as the fibronectin splice variant $\mathrm{EDA}+\mathrm{FN}$ and the $\alpha 5 \beta 1$-integrin showed increased expression and could be responsible for keratinocyte hyperproliferation. COMP can modulate cellular behavior via cell-surface receptors. Furthermore, it is part of the papillary dermis of healthy skin, but its expression has not yet been studied in psoriatic skin.

In this study, we found that COMP extended deeper into the dermis and formed a more continuous layer in psoriatic non-lesional skin compared to healthy skin, while in psoriatic lesions, COMP showed a partially discontinuous deposition at the DEJ. Co-localization of COMP was increased together with basal keratinocyte $\beta 1$-integrin and EDA+FN and decreased with LAMA1 in non-lesional psoriatic skin. In in vitro models, the presence of exogenous COMP decreased the proliferation-rate of keratinocytes and this proliferation suppressing effect was diminished by the blocking of the $\alpha 5 \beta 1$-integrin.

Finally, our results suggest that interacting with $\alpha 5 \beta 1$-integrin of non-lesional basal keratinocytes through the discontinuous LAMA1 in psoriatic non-lesional skin, COMP may contribute to restrain the proliferation rate of non-lesional basal keratinocytes, thus maintaining the non-lesional, non-hyperproliferative state of psoriatic non-lesional epidermis despite the overexpression of EDA+FN and $\alpha 5 \beta 1$-integrin. The antiproliferative effect of COMP is likely to be relevant to other skin diseases in which chronic non-healing wounds are coupled with massive COMP accumulation. 


\section{ACKNOWLEDGEMENT}

It gives me a pleasure to thank to my supervisor, Dr. Gergely Groma, for his supervision of my scientific research. He always gave me valuable suggestions and helped me in technical questions. Furthermore, with his help I was able to learn the independent thinking and working, which will be useful for me in the future.

I would like to express my special thanks to Professor Lajos Kemény and to Professor Zsuzsanna Bata-Csörgö for the opportunity to be able to perform my studies in the University of Szeged, Department of Dermatology and Allergology. I am grateful for their excellent help support and comments related to my work.

I would like to thank to Dr. Kornélia Szabó for her excellent support during the preparation of the manuscript.

I am especially grateful to my colleagues Dr. Edit Szél, Dr. Judit Danis, Dr. Barbara Konczné Gubán, Dr. Tünde Buknicz, Dr. Anikó Göblös, Lilla Erdei and Beáta Szilvia Bolla for their intellectual and technical help and support and for their friendship during the years. Besides I would like to thank for all the members of the Molecular Biology- and Cell Biology Laboratories for their help.

I wish to also thank Mónika Kohajda for her excellent technical assistance and Dr. Máté Manczinger and Balázs Koncz for their help in the statistical analysis. I am really grateful for all the members of Histology Laboratory, in particular for Dr. István Balázs Németh, Róbertné Függ, and Krisztina Kószóné Lauf for their help.

I am grateful for Dr. Nóra Belső, Dr. Brigitta Gál, Dr. Krisztina Vas and for Dr. Róbert Kui for collecting tissue samples from patients.

I also thank all of my colleagues, who have helped me during the years at the Department of Dermatology and Allergology.

I would like to thank Prof. Dr. Mats Paulsson and PD. Dr. Frank Zaucke for the COMP antibody.

I am especially grateful to my friends and family, for their help and support. My special thanks go to my Partner, who always stood by me and constantly and patiently encouraged me with special love.

This study was supported by grants from the National Research, Development and Innovation Office research grants (OTKA PD116992, K111885 and GINOP-2.2.1-15-2016- 
00007) and co-financed by the European Social Fund in the framework of TAMOP-4.2.4.A/211-1/2012-0001 “National Excellence Program” A2-SZGYA-FOK-13-0001.

I am grateful for the Ph.D scholarship of the Gedeon Richter Talentum Foundation (H-1103 Budapest, Gyömröi str. 19-21.) and for the scholarships of the New National Excellence Program of the Ministry of Human Capacities (UNKP-17-3, UNKP-18-3) and for the New National Excellence Program of the Ministry for Innovation and Technology (ÚNKP-19-3). 


\section{REFERENCES}

Acharya, C., Yik, J.H.N., Kishore, A., Van Dinh, V., Di Cesare, P.E., Haudenschild, D.R., 2014. Cartilage oligomeric matrix protein and its binding partners in the cartilage extracellular matrix: interaction, regulation and role in chondrogenesis. Matrix Biol. 37, 102-111.

Agarwal, P., Schulz, J.-N., Blumbach, K., Andreasson, K., Heinegård, D., Paulsson, M., Mauch, C., Eming, S.A., Eckes, B., Krieg, T., 2013. Enhanced deposition of cartilage oligomeric matrix protein is a common feature in fibrotic skin pathologies. Matrix Biol. $32,325-331$.

Agarwal, P., Zwolanek, D., Keene, D.R., Schulz, J.-N., Blumbach, K., Heinegård, D., Zaucke, F., Paulsson, M., Krieg, T., Koch, M., Eckes, B., 2012. Collagen XII and XIV, new partners of cartilage oligomeric matrix protein in the skin extracellular matrix suprastructure. J. Biol. Chem. 287, 22549-22559.

Bata-Csorgo, Z., Cooper, K.D., Ting, K.M., Voorhees, J.J., Hammerberg, C., 1998. Fibronectin and alpha5 integrin regulate keratinocyte cell cycling. A mechanism for increased fibronectin potentiation of $\mathrm{T}$ cell lymphokine-driven keratinocyte hyperproliferation in psoriasis. J. Clin. Invest. 101, 1509-1518.

Bata-Csorgo, Z., Hammerberg, C., Voorhees, J.J., Cooper, K.D., 1995. Kinetics and regulation of human keratinocyte stem cell growth in short-term primary ex vivo culture. Cooperative growth factors from psoriatic lesional $\mathrm{T}$ lymphocytes stimulate proliferation among psoriatic uninvolved, but not normal, stem keratinocytes. J. Clin. Invest. 95, 317-327.

Bos, J.D., Hulsebosch, H.J., Krieg, S.R., Bakker, P.M., Cormane, R.H., 1983. Immunocompetent cells in psoriasis. In situ immunophenotyping by monoclonal antibodies. Arch. Dermatol. Res. 275, 181-189.

Briggs, M.D., Hoffman, S.M., King, L.M., Olsen, A.S., Mohrenweiser, H., Leroy, J.G., Mortier, G.R., Rimoin, D.L., Lachman, R.S., Gaines, E.S., 1995. Pseudoachondroplasia and multiple epiphyseal dysplasia due to mutations in the cartilage oligomeric matrix protein gene. Nat. Genet. 10, 330-336.

Chen, F.H., Thomas, A.O., Hecht, J.T., Goldring, M.B., Lawler, J., 2005. Cartilage oligomeric matrix protein/thrombospondin 5 supports chondrocyte attachment through interaction with integrins. J. Biol. Chem. 280, 32655-32661.

Chen, G., McCormick, T.S., Hammerberg, C., Ryder-Diggs, S., Stevens, S.R., Cooper, K.D., 2001. Basal keratinocytes from uninvolved psoriatic skin exhibit accelerated spreading and focal adhesion kinase responsiveness to fibronectin. J. Invest. Dermatol. 117, 15381545.

Danis, J., Janovák, L., Gubán, B., Göblös, A., Szabó, K., Kemény, L., Bata-Csörgő, Z., Széll, M., 2018. Differential Inflammatory-Response Kinetics of Human Keratinocytes upon Cytosolic RNA- and DNA-Fragment Induction. Int J Mol Sci 19.

Di Cesare, P.E., Chen, F.S., Moergelin, M., Carlson, C.S., Leslie, M.P., Perris, R., Fang, C., 2002. Matrix-matrix interaction of cartilage oligomeric matrix protein and fibronectin. Matrix Biol. 21, 461-470.

Dickhuth, J., Koerdt, S., Kriegebaum, U., Linz, C., Müller-Richter, U.D., Ristow, O., Kübler, A.C., Reuther, T., 2015. In vitro study on proliferation kinetics of oral mucosal keratinocytes. Oral Surg Oral Med Oral Pathol Oral Radiol 120, 429-435. 
Dodge, G.R., Hawkins, D., Boesler, E., Sakai, L., Jimenez, S.A., 1998. Production of cartilage oligomeric matrix protein (COMP) by cultured human dermal and synovial fibroblasts. Osteoarthr. Cartil. 6, 435-440.

Elder, J.T., 2006. PSORS1: linking genetics and immunology. J. Invest. Dermatol. 126, 12051206.

Erdei, L., Bolla, B.S., Bozó, R., Tax, G., Urbán, E., Kemény, L., Szabó, K., 2018. TNIP1 Regulates Cutibacterium acnes-Induced Innate Immune Functions in Epidermal Keratinocytes. Front Immunol 9, 2155.

Farina, G., Lemaire, R., Korn, J.H., Widom, R.L., 2006. Cartilage oligomeric matrix protein is overexpressed by scleroderma dermal fibroblasts. Matrix Biol. 25, 213-222.

Gliński, W., Stepień-Sopniewska, B., Majewski, S., Glińska-Ferenz, M., Górski, A., 1993. Alterations of T-cell: extracellular matrix proteins interactions in psoriasis. Immunol. Lett. 35, 153-157.

Gubán, B., Vas, K., Balog, Z., Manczinger, M., Bebes, A., Groma, G., Széll, M., Kemény, L., Bata-Csörgö, Z., 2016. Abnormal regulation of fibronectin production by fibroblasts in psoriasis. Br. J. Dermatol. 174, 533-541.

Gurtner, G.C., Werner, S., Barrandon, Y., Longaker, M.T., 2008. Wound repair and regeneration. Nature 453, 314-321.

Halász, K., Kassner, A., Mörgelin, M., Heinegård, D., 2007. COMP acts as a catalyst in collagen fibrillogenesis. J. Biol. Chem. 282, 31166-31173.

Hamill, K.J., Hopkinson, S.B., Hoover, P., Todorović, V., Green, K.J., Jones, J.C.R., 2012. Fibronectin expression determines skin cell motile behavior. J. Invest. Dermatol. 132, 448-457.

Harden, J.L., Krueger, J.G., Bowcock, A.M., 2015. The immunogenetics of Psoriasis: A comprehensive review. J. Autoimmun. 64, 66-73.

Harvima, R.J., Viinamäki, H., Harvima, I.T., Naukkarinen, A., Savolainen, L., Aalto, M.L., Horsmanheimo, M., 1996. Association of psychic stress with clinical severity and symptoms of psoriatic patients. Acta Derm. Venereol. 76, 467-471.

Hecht, J.T., Nelson, L.D., Crowder, E., Wang, Y., Elder, F.F., Harrison, W.R., Francomano, C.A., Prange, C.K., Lennon, G.G., Deere, M., 1995. Mutations in exon 17B of cartilage oligomeric matrix protein (COMP) cause pseudoachondroplasia. Nat. Genet. 10, 325329.

Henseler, T., Christophers, E., 1985. Psoriasis of early and late onset: characterization of two types of psoriasis vulgaris. J. Am. Acad. Dermatol. 13, 450-456.

Huang, Y., Xia, J., Zheng, J., Geng, B., Liu, P., Yu, F., Liu, B., Zhang, H., Xu, M., Ye, P., Zhu, Y., Xu, Q., Wang, X., Kong, W., 2013. Deficiency of cartilage oligomeric matrix protein causes dilated cardiomyopathy. Basic Res. Cardiol. 108, 374.

Inui, S., Shono, F., Nakajima, T., Hosokawa, K., Itami, S., 2011. Identification and characterization of cartilage oligomeric matrix protein as a novel pathogenic factor in keloids. Am. J. Pathol. 179, 1951-1960.

Jordan, J.M., 2005. Update on cartilage oligomeric matrix protein as a marker of osteoarthritis. J. Rheumatol. 32, 1145-1147.

Kaladze, R.A., Gogebashvili, N.V., 2005. [Humoral mechanisms of autoimmune process against type I collagen in psoriasis]. Georgian Med News 132-134.

Kim, J., Krueger, J.G., 2015. The immunopathogenesis of psoriasis. Dermatol Clin 33, 13-23. 
Koivukangas, V., Kallionen, M., Karvonen, J., Autio-Harmainen, H., Risteli, J., Risteli, L., Oikarinen, A., 1995. Increased collagen synthesis in psoriasis in vivo. Arch. Dermatol. Res. 287, 171-175.

Malashkevich, V.N., Kammerer, R.A., Efimov, V.P., Schulthess, T., Engel, J., 1996. The crystal structure of a five-stranded coiled coil in COMP: a prototype ion channel? Science 274, 761-765.

Mazzalupo, S., Wong, P., Martin, P., Coulombe, P.A., 2003. Role for keratins 6 and 17 during wound closure in embryonic mouse skin. Dev. Dyn. 226, 356-365.

McFadden, J., Fry, L., Powles, A.V., Kimber, I., 2012. Concepts in psoriasis: psoriasis and the extracellular matrix. Br. J. Dermatol. 167, 980-986.

McFadden, J.P., Kimber, I., 2016. A Review on the Potential Role of Basement Membrane Laminin in the Pathogenesis of Psoriasis. Scand. J. Immunol. 83, 3-9.

Mondello, M.R., Magaudda, L., Pergolizzi, S., Santoro, A., Vaccaro, M., Califano, L., Cannavò, S.P., Guarneri, B., 1996. Behaviour of laminin 1 and type IV collagen in uninvolved psoriatic skin. Immunohistochemical study using confocal laser scanning microscopy. Arch. Dermatol. Res. 288, 527-531.

Mörgelin, M., Heinegård, D., Engel, J., Paulsson, M., 1992. Electron microscopy of native cartilage oligomeric matrix protein purified from the $S$ warm rat chondrosarcoma reveals a five-armed structure. J. Biol. Chem. 267, 6137-6141.

Mortezavi, M., Thiele, R., Ritchlin, C., 2015. The joint in psoriatic arthritis. Clin. Exp. Rheumatol. 33, S20-25.

Müller, G., Michel, A., Altenburg, E., 1998. COMP (cartilage oligomeric matrix protein) is synthesized in ligament, tendon, meniscus, and articular cartilage. Connect. Tissue Res. 39, 233-244.

Pellegrini, G., De Luca, M., Orecchia, G., Balzac, F., Cremona, O., Savoia, P., Cancedda, R., Marchisio, P.C., 1992. Expression, topography, and function of integrin receptors are severely altered in keratinocytes from involved and uninvolved psoriatic skin. J. Clin. Invest. 89, 1783-1795.

Poikolainen, K., Reunala, T., Karvonen, J., 1994. Smoking, alcohol and life events related to psoriasis among women. Br. J. Dermatol. 130, 473-477.

Posey, K.L., Coustry, F., Hecht, J.T., 2018. Cartilage oligomeric matrix protein: COMPopathies and beyond. Matrix Biol. 71-72, 161-173.

Puig, L., Julià, A., Marsal, S., 2014. The pathogenesis and genetics of psoriasis. Actas Dermosifiliogr 105, 535-545.

Rock, M.J., Holden, P., Horton, W.A., Cohn, D.H., 2010. Cartilage oligomeric matrix protein promotes cell attachment via two independent mechanisms involving CD47 and alphaVbeta3 integrin. Mol. Cell. Biochem. 338, 215-224.

Rosenberg, K., Olsson, H., Mörgelin, M., Heinegård, D., 1998. Cartilage oligomeric matrix protein shows high affinity zinc-dependent interaction with triple helical collagen. J. Biol. Chem. 273, 20397-20403.

Schulz, J.-N., Nüchel, J., Niehoff, A., Bloch, W., Schönborn, K., Hayashi, S., Kamper, M., Brinckmann, J., Plomann, M., Paulsson, M., Krieg, T., Zaucke, F., Eckes, B., 2016. COMP-assisted collagen secretion--a novel intracellular function required for fibrosis. J. Cell. Sci. 129, 706-716.

Singh, S., Pradhan, D., Puri, P., Ramesh, V., Aggarwal, S., Nayek, A., Jain, A.K., 2019. Genomic alterations driving psoriasis pathogenesis. Gene 683, 61-71. 
Sonkoly, E., Bata-Csorgo, Z., Pivarcsi, A., Polyanka, H., Kenderessy-Szabo, A., Molnar, G., Szentpali, K., Bari, L., Megyeri, K., Mandi, Y., Dobozy, A., Kemeny, L., Szell, M., 2005. Identification and characterization of a novel, psoriasis susceptibility-related noncoding RNA gene, PRINS. J. Biol. Chem. 280, 24159-24167.

Szabad, G., Kormos, B., Pivarcsi, A., Széll, M., Kis, K., Kenderessy Szabó, A., Dobozy, A., Kemény, L., Bata-Csörgo, Z., 2007. Human adult epidermal melanocytes cultured without chemical mitogens express the EGF receptor and respond to EGF. Arch. Dermatol. Res. 299, 191-200.

Szabó, K., Bata-Csörgő, Z., Dallos, A., Bebes, A., Francziszti, L., Dobozy, A., Kemény, L., Széll, M., 2014. Regulatory networks contributing to psoriasis susceptibility. Acta Derm. Venereol. 94, 380-385.

Szél, E., Bozó, R., Hunyadi-Gulyás, É., Manczinger, M., Szabó, K., Kemény, L., Bata-Csörgő, Z., Groma, G., 2019. Comprehensive Proteomic Analysis Reveals Intermediate Stage of Non-Lesional Psoriatic Skin and Points out the Importance of Proteins Outside this Trend. Sci Rep 9, 11382.

Széll, M., Bata-Csörgo, Z., Koreck, A., Pivarcsi, A., Polyánka, H., Szeg, C., Gaál, M., Dobozy, A., Kemény, L., 2004. Proliferating keratinocytes are putative sources of the psoriasis susceptibility-related EDA+ (extra domain A of fibronectin) oncofetal fibronectin. J. Invest. Dermatol. 123, 537-546.

Széll, M., Danis, J., Bata-Csörgő, Z., Kemény, L., 2016. PRINS, a primate-specific long noncoding RNA, plays a role in the keratinocyte stress response and psoriasis pathogenesis. Pflugers Arch. 468, 935-943.

Tan, K., Duquette, M., Joachimiak, A., Lawler, J., 2009. The crystal structure of the signature domain of cartilage oligomeric matrix protein: implications for collagen, glycosaminoglycan and integrin binding. FASEB J. 23, 2490-2501.

Tan, K., Lawler, J., 2009. The interaction of Thrombospondins with extracellular matrix proteins. J Cell Commun Signal 3, 177-187.

Tax, G., Urbán, E., Palotás, Z., Puskás, R., Kónya, Z., Bíró, T., Kemény, L., Szabó, K., 2016. Propionic Acid Produced by Propionibacterium acnes Strains Contri-butes to Their Pathogenicity. Acta Derm. Venereol. 96, 43-49.

Theodorakopoulou, E., Yiu, Z.Z.N., Bundy, C., Chularojanamontri, L., Gittins, M., Jamieson, L.A., Motta, L., Warren, R.B., Griffiths, C.E.M., 2016. Early- and late-onset psoriasis: a cross-sectional clinical and immunocytochemical investigation. Br. J. Dermatol. 175, $1038-1044$.

Ting, K.M., Rothaupt, D., McCormick, T.S., Hammerberg, C., Chen, G., Gilliam, A.C., Stevens, S., Culp, L., Cooper, K.D., 2000. Overexpression of the oncofetal Fn variant containing the EDA splice-in segment in the dermal-epidermal junction of psoriatic uninvolved skin. J. Invest. Dermatol. 114, 706-711.

Tjin, M.S., Chua, A.W.C., Ma, D.R., Lee, S.T., Fong, E., 2014. Human epidermal keratinocyte cell response on integrin-specific artificial extracellular matrix proteins. Macromol Biosci 14, 1125-1134.

Tseng, S., Reddi, A.H., Di Cesare, P.E., 2009. Cartilage Oligomeric Matrix Protein (COMP): A Biomarker of Arthritis. Biomark Insights 4, 33-44.

Vaccaro, M., Magaudda, L., Cutroneo, G., Trimarchi, F., Barbuzza, O., Guarneri, F., Guarneri, B., 2002. Changes in the distribution of laminin alphal chain in psoriatic skin: immunohistochemical study using confocal laser scanning microscopy. Br. J. Dermatol. 146, 392-398. 
Wang, L., Zheng, J., Du, Y., Huang, Y., Li, J., Liu, B., Liu, C., Zhu, Y., Gao, Y., Xu, Q., Kong, W., Wang, X., 2010. Cartilage oligomeric matrix protein maintains the contractile phenotype of vascular smooth muscle cells by interacting with alpha(7)beta(1) integrin. Circ. Res. 106, 514-525.

Weiss, G., Shemer, A., Trau, H., 2002. The Koebner phenomenon: review of the literature. J Eur Acad Dermatol Venereol 16, 241-248.

Yang, S., Sun, Y., Geng, Z., Ma, K., Sun, X., Fu, X., 2016. Abnormalities in the basement membrane structure promote basal keratinocytes in the epidermis of hypertrophic scars to adopt a proliferative phenotype. Int. J. Mol. Med. 37, 1263-1273. 


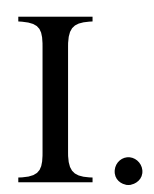




\title{
Cartilage Oligomeric Matrix Protein Negatively Influences Keratinocyte Proliferation Via $\alpha 5 \beta 1$ - Integrin: Potential Relevance of Altered Cartilage Oligomeric Matrix Protein Expression in Psoriasis
}

\author{
Renáta Bozó ${ }^{1}$, Edit Szél ${ }^{1}$, Judit Danis ${ }^{1,2}$, Barbara Gubán ${ }^{1}$, Zsuzsanna Bata-Csörgő ${ }^{1,2}$, Kornélia Szabó ${ }^{1,2}$, \\ Lajos Kemény ${ }^{1,2,3}$ and Gergely Groma ${ }^{1,2}$
}

In psoriasis, nonlesional skin shows alterations at the dermal-epidermal junction compared with healthy skin. Cartilage oligomeric matrix protein (COMP) is part of the papillary dermis of healthy skin, and its expression has not yet been studied in psoriatic skin. In this study, we found that COMP localization extended deeper into the dermis and formed a more continuous layer in psoriatic nonlesional skin compared with healthy skin, whereas in psoriatic lesions, COMP showed a partially discontinuous deposition at the dermal-epidermal junction. COMP and $\beta 1$-integrin showed strong colocalization in nonlesional skin, where the laminin layer within the basement membrane is discontinuous. In in vitro models, the presence of exogenous COMP decreased the proliferation rate of keratinocytes, and this proliferation-suppressing effect was diminished by blocking $\alpha 5 \beta 1$-integrin. Our results suggest that COMP can interact with $\alpha 5 \beta 1$-integrin of basal keratinocytes through the disrupted basement membrane, and this interaction might stabilize the epidermis in the nonlesional state by contributing to the suppression of keratinocyte proliferation. The antiproliferative effect of COMP is likely to be relevant to other skin diseases in which chronic nonhealing wounds are coupled with massive COMP accumulation.

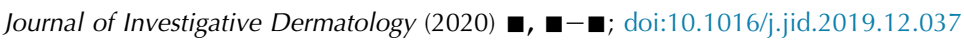

\section{INTRODUCTION}

The pathogenesis of plaque-type psoriasis (Psoriasis vulgaris) is only partially understood, and only symptomatic treatment is currently available. In addition to hyperproliferation, altered keratinocyte differentiation, and massive immune cell infiltration, the dermal extracellular matrix (ECM) and the basement membrane (BM) are also affected in healthylooking nonlesional skin of patients (Bata-Csorgo et al., 1998; Gliński et al., 1993; Mondello et al., 1996; Vaccaro et al., 2002). Nonlesional epidermal keratinocytes have been shown to represent a preactivated state for hyperproliferation (Chen et al., 2001); these cells are more sensitive to stress (Szabó et al., 2014) and to proliferative signals (Bata-Csorgo et al., 1995). Alterations of the ECM that are

\footnotetext{
${ }^{1}$ Department of Dermatology and Allergology University of Szeged, Szeged, Hungary; ${ }^{2}$ MTA-SZTE Dermatological Research Group, Szeged, Hungary; and ${ }^{3}$ HCEMM-SZTE Skin Research Group, Szeged, Hungary

Correspondence: Gergely Groma, Department of Dermatology and Allergology, Korányi Fasor 6, Szeged, Hungary H-6720. E-mail: groma. gergely@med.u-szeged.hu or groma.gergo@gmail.com

Abbreviations: $B M$, basement membrane; COMP, cartilage oligomeric matrix protein; DEJ, dermal-epidermal junction; ECM, extracellular matrix; $E D A+F N$, fibronectin splice variant containing extra domain $A ; F N$, fibronectin; KRT17, keratin 17; rhCOMP, recombinant human COMP

Received 11 March 2019; revised 27 November 2019; accepted 6 December 2019; accepted manuscript published online XXX; corrected proof published online XXX
}

already present in nonlesional skin also affect the cell attachment modulator fibronectin (FN), which is differentially expressed in nonlesional skin. Previously, we found that fibroblasts as well as basal keratinocytes express high levels of the FN splice variant that contains the extra domain A (EDA + FN) in nonlesional skin (Gubán et al., 2016; Széll et al., 2004). Moreover, some integrins, including the FNinteracting $\alpha 5 \beta 1$-integrin, also exhibit an increased expression (Bata-Csorgo et al., 1998; Gubán et al., 2016) in keratinocytes at the dermal-epidermal junction (DEJ). The enhanced EDA + FN and $\alpha 5 \beta 1$-integrin production that we observed in psoriatic nonlesional skin may contribute to the induction of keratinocyte proliferation (Bata-Csorgo et al., 1998, 1995; Széll et al., 2004). Furthermore, at the DEJ in nonlesional skin, the laminin layer of the BM is discontinuous and the connection of keratinocytes to the BM is also altered (McFadden and Kimber, 2016; Mondello et al., 1996).

Cartilage oligomeric matrix protein (COMP) is a noncollagenous glycoprotein component of the ECM. The flexible structure of the COMP homopentamer allows simultaneous interactions with multiple cellular and extracellular components (Malashkevich et al., 1996; Mörgelin et al., 1992). COMP is mainly deposited in cartilage, but it is also located in tendons, ligaments, synovium, and skin. In addition, it is expressed in vascular smooth muscle cells, cardiomyocytes, and activated platelets (Müller et al., 1998; Posey et al., 2018; Tan and Lawler, 2009; Wang et al., 
$\boldsymbol{R}$ Bozó et al.

Cartilage Oligomeric Matrix Protein in Psoriasis

Figure 1. COMP level is elevated in psoriatic nonlesional skin. (a) COMP protein was detected with western blot analysis from healthy, psoriatic nonlesional, and lesional skin. Actin was used as a loading control. A representative blot is shown under reducing condition. (b) Band intensities of COMP monomer were quantitated with Image Studio software (LI-COR Biosciences, Lincoln, NE) and presented as fold changes normalized to actin. The graph shows mean \pm SEM $(n=6)$ versus healthy control. ${ }^{*} P<0.05$ calculated by one-way ANOVA, followed by Tukey's post-hoc test. (c) Immunofluorescence staining of COMP in healthy (left column), psoriatic nonlesional (middle column), and psoriatic lesional (right column) skin. Representative images are shown. Dotted lines indicate the border of the dermal-epidermal junction $(\mathrm{n}=10)$ (Supplementary Figure S3). Original magnification: $\times 20$. Bar $=50 \mu \mathrm{m}$. (d) RT-PCR analysis of COMP CDNA from cultured human dermal fibroblasts of healthy and psoriatic nonlesional skin. Data were normalized to $18 \mathrm{~S}$ rRNA using the $\Delta \Delta \mathrm{Ct}$ method. The graph shows mean $\pm \operatorname{SEM}(\mathrm{n}=8)$ versus healthy cultured fibroblasts. ${ }^{* *} P<0.01$, determined by two-tailed Student $t$-test. COMP, cartilage oligomeric matrix protein. a
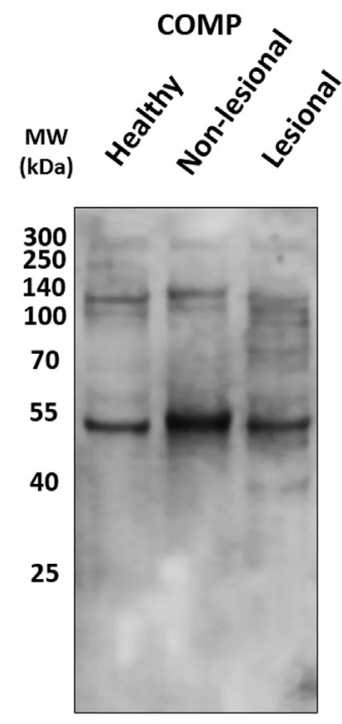

actin
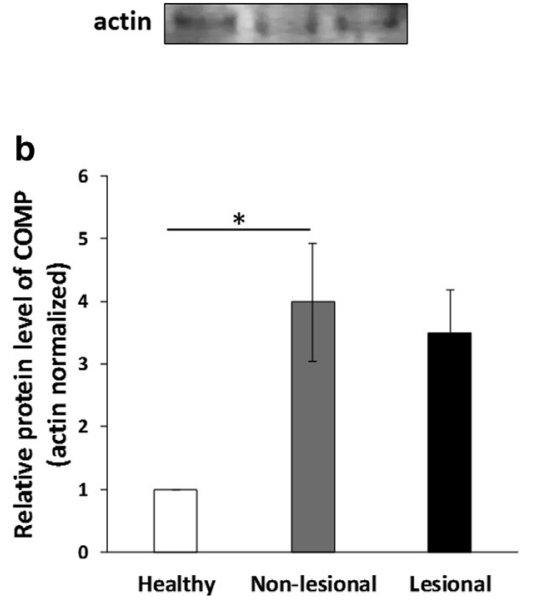

C
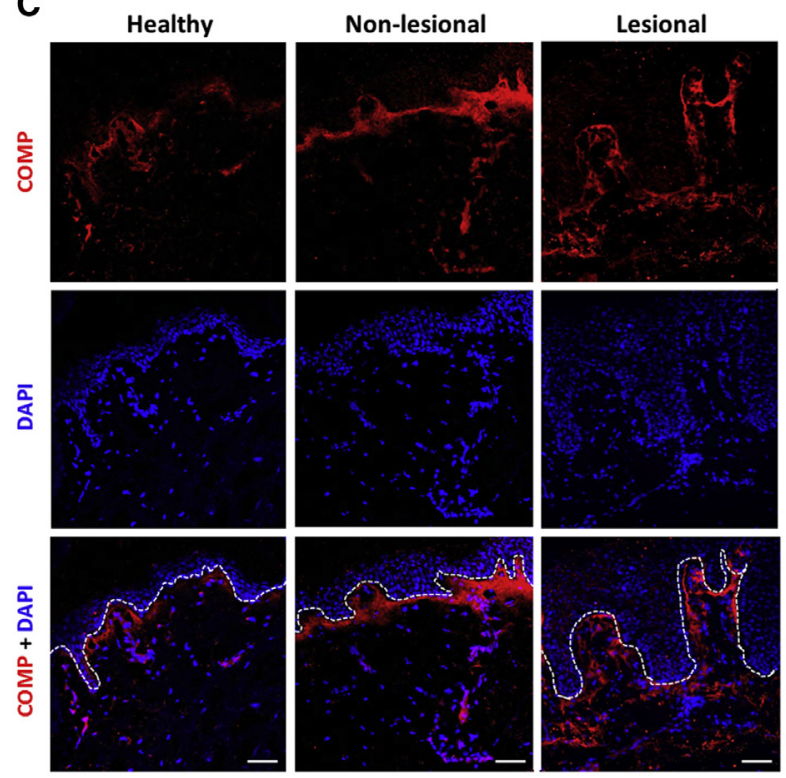

d

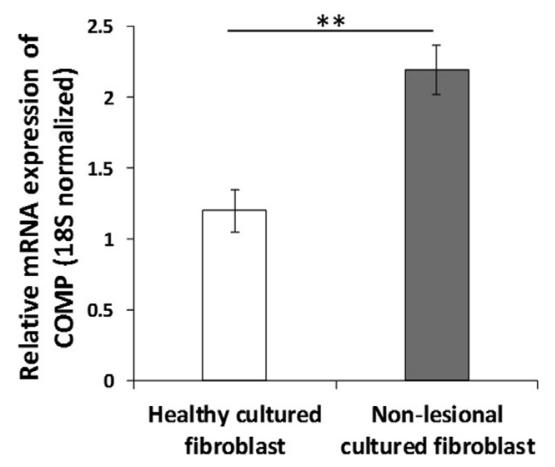

2010). In healthy skin, COMP is primarily produced by fibroblasts (Dodge et al., 1998) and localizes to the papillary dermis, where it is believed to take part in ECM stabilization and provide cohesion between the anchoring plaques of the upper dermis and the BM (Agarwal et al., 2012; Farina et al., 2006). Although COMP accumulation in the dermis is elevated in various fibrotic skin disorders (Agarwal et al., 2013; Inui et al., 2011), COMP has not been investigated previously in the context of psoriasis.

COMP modulates cellular behavior via direct interactions with cell surface proteins, including the $\alpha 5 \beta 1$ (Chen et al., 2005), $\alpha 7 \beta 1$, and $\alpha v \beta 3$ (Rock et al., 2010) members of the integrin family. $\alpha 5 \beta 1$-integrin modulates processes in psoriasis pathogenesis, including inflammatory responses and keratinocyte proliferation (Bata-Csorgo et al., 1998; Chen et al., 2001; Pellegrini et al., 1992).

Here we show that the COMP level is elevated in nonlesional psoriatic skin, where it colocalizes with $\alpha 5 \beta 1$-integrin and $\mathrm{EDA}+\mathrm{FN}$ and has a suppressive effect on keratinocyte proliferation, which is likely mediated through $\alpha 5 \beta 1$-integrin. In this way, COMP can override the proliferation-promoting effect of increased EDA $+F N$ and $\alpha 5 \beta 1$-integrin, which is associated with the disrupted laminin layer. (Bata-Csorgo et al., 1998; Mondello et al., 1996). These results indicate a crucial role for COMP in the pathomechanism of psoriasis.

\section{RESULTS}

\section{COMP level is elevated in psoriatic nonlesional skin}

Nonlesional skin carries several known alterations of the ECM in the papillary dermis (Bos et al., 1983; Ting et al., 2000). Because COMP previously has been reported to also be present in the papillary dermis, COMP protein accumulation was characterized in nonlesional and lesional skin from patients with psoriasis and skin from healthy individuals. COMP protein was detected with western blot analysis under reducing (Figure $1 \mathrm{a}$ and $\mathrm{b}$ and Supplementary Figure S1) and nonreducing (Supplementary Figure S2) conditions. Under reducing conditions, we detected elevated COMP monomer and fragment levels in psoriatic nonlesional protein extracts compared with healthy skin (Figure 1a and b and Supplementary Figure S1).

Subsequently, the distribution of COMP in tissues was analyzed using immunofluorescence staining. In line with previous reports, COMP was detected in the papillary dermis of healthy skin (Farina et al., 2006). In psoriatic nonlesional samples, COMP deposition extended deeper into the dermis 
and formed a more even and continuous layer than observed in healthy samples (Figure 1c and Supplementary Figure S3). In contrast, COMP deposition in lesional skin extended to the upper part of the reticular dermis and exhibited a discontinuously scattered distribution (Figure 1c and Supplementary Figure S3).

Because skin fibroblasts are the major producers of COMP protein (Dodge et al., 1998), we examined the mRNA expression of COMP in primary dermal fibroblasts derived from healthy and psoriatic nonlesional skin and detected elevated COMP mRNA expression in nonlesional fibroblasts (Figure 1d).

\section{COMP colocalization with ITGB1 of basal keratinocytes and EDA + FN is increased and with LAMA1 is decreased in nonlesional psoriatic skin}

COMP is known to interact with several members of the integrin cell-surface receptor family, including $\alpha 5 \beta 1$-integrin (Chen et al., 2005), whose expression increases together with $\mathrm{EDA}+\mathrm{FN}$ in nonlesional skin, possibly owing to damaged BM (Bata-Csorgo et al., 1998; Mondello et al., 1996; Ting et al., 2000). To investigate the possible interactions of COMP with proteins in the DEJ that have been altered, confocal microscopic analysis with dual immunofluorescence staining was applied and consecutive sections of the appropriate area were analyzed.

To determine whether COMP accumulation at the DEJ allows interaction with basal epidermal keratinocytes, COMP and $\beta 1$-integrin (ITGB1) co-immunofluorescence staining was applied. In the papillary dermis, COMP staining partially colocalized with the ITGB1 from basal keratinocytes in healthy and nonlesional skin (Figure 2a and Supplementary Figure S4). However, the colocalization of the two proteins was most prominent in psoriatic nonlesional skin (Figure 2d).

LAMA1 is a component of the BM laminin layer, which is fragmented and occasionally completely missing in nonlesional psoriatic skin (Mondello et al., 1996; Vaccaro et al., 2002). Therefore, to examine whether the damaged BM of nonlesional skin allows the interaction of COMP and ITGB1, LAMA1-COMP dual immunostaining was performed. In nonlesional skin, COMP-ITGB1 double-positive regions exhibited a discontinuous LAMA1 staining pattern (Figure 2b), and the co-occurrence of COMP and LAMA1 was significantly lower in nonlesional skin compared with healthy skin (Figure 2e).

In addition, $\mathrm{FN}$ has also been reported to interact with COMP (Di Cesare et al., 2002); therefore, confocal microscopic analysis was also applied to COMP and EDA + FN. In psoriatic nonlesional skin, in which colocalization of COMP and ITGB1 was apparent, partial colocalization of COMP and $\mathrm{EDA}+\mathrm{FN}$ was observed (Figure 2c), and the intensity of colocalization was significantly higher in nonlesional skin relative to healthy skin (Figure $2 \mathrm{f}$ ).

\section{COMP negatively influences keratinocyte proliferation via} $\alpha 5 \beta 1$-integrin in vitro

To investigate whether the possible interaction between COMP and ITGB1 influences keratinocyte cellular behavior, we first performed an impedance measurement-based, realtime cellular analysis of the HPV-KER immortalized keratinocyte cell line. When the culturing plate was precoated with recombinant human COMP (rhCOMP), cells exhibited reduced cell index values in a manner that was dependent on COMP concentration compared with cells grown on uncoated surfaces (Figure 3a). Cell index is influenced by changes in cell proliferation, viability, morphology, and adhesion (Dickhuth et al., 2015). To investigate whether the proliferation rate of HPV-KER cells was affected, a BrdU cell proliferation assay was performed. Precoating the surface with a high concentration $(10 \mu \mathrm{g} / \mathrm{ml})$ of rhCOMP resulted in significantly reduced proliferation rates at 24 and 72 hours compared with cells grown on an uncoated surface. Cell proliferation of primary normal human epidermal keratinocytes was also reduced when the surface was coated with 10 $\mu \mathrm{g} / \mathrm{ml}$ rhCOMP (Figure 3c).

To test whether integrins mediate the observed negative effect of COMP on cell proliferation, blocking experiments using anti-ITGA5 and anti-ITGB1 polyclonal antibodies were performed. Blocking of either the ITGA5 or ITGB1 subunit in cells grown on a surface precoated with $10 \mu \mathrm{g} / \mathrm{ml}$ rhCOMP abolished the negative effect of COMP on HPV-KER proliferation, whereas blocking either ITGA5 or ITGB1 alone had no negative effect on these cells (Figure $4 a$ and $b$ and Supplementary Figure S5). Similarly, the negative effect of COMP on the proliferation rate of primary normal human epidermal keratinocyte cells could also be abolished by blocking COMP, ITGA5, or ITGB1, as determined with the BrdU assay (Figure 4c and d) and Ki67 immunofluorescent staining (Figure $4 \mathrm{e}$ and $\mathrm{f}$ ).

\section{COMP has a negative effect on skin wound healing by attenuating keratinocyte proliferation and by compromising keratinocyte migration and activation in ex vivo wound models}

To further study the effect of COMP on keratinocytes, an ex vivo three-dimensional skin wound-healing model was applied. Standardized wounded skin samples, with or without rhCOMP treatment $(10 \mu \mathrm{g} / \mathrm{ml})$ (Figure $5 \mathrm{a})$, and unwounded controls were examined at 72 hours after wounding. Immunofluorescent staining revealed COMP localization on the dermal surface of the injured region in COMP-treated wounds, whereas COMP was not detected at the injured region of untreated wounds 72 hours after treatment (Figure 5a). By applying Ki67 immunofluorescent staining to detect proliferating cells, we found a markedly reduced number of Ki67-positive cells in COMP-treated wounds, indicating a decreased rate of proliferation (Figure $5 \mathrm{~b}$ and $\mathrm{c}$, Supplementary Figure S6a).

Cell migration processes at the wound edge during the closure of injuries require dynamic reorganization of the actin cytoskeleton in the keratinocytes located close to wound margins. To visualize these cells, immunofluorescence staining for actin was applied. In wounds not exposed to COMP, we found that keratinocytes exhibited high levels of actin expression at wound edges, whereas actin expression at wound edges was markedly decreased in COMP-treated wounds, indicating that actin expression was compromised, possibly resulting in a reduction of active cell migration (Figure 5d).

Keratin 17 (KRT17) expression is known to be induced in keratinocytes at wound edges during healing (Mazzalupo 
$\boldsymbol{R}$ Bozó et al.

Cartilage Oligomeric Matrix Protein in Psoriasis

Figure 2. COMP colocalization with basal keratinocyte $\beta 1$-integrin and $\mathrm{EDA}+\mathrm{FN}$ increases and with LAMA1 decreases in nonlesional psoriatic skin. Confocal microscopic immunofluorescence analysis of (a) COMP and $\beta 1$-integrin, (b) COMP and LAMA1, and (c) COMP and EDA + FN colocalization in healthy (first row) and psoriatic nonlesional (second row) skin. Representative images are shown. Dotted lines indicate the enlarged regions. Colocalized pixels of the indicated proteins were calculated with Imagel software $(n=5)$. Original magnification: $\times 63$. Bar $=10 \mu \mathrm{m}$. The extent of colocalization of (d) COMP and $\beta 1$-integrin, (e) COMP and LAMA1, and (f) COMP and EDA + FN was calculated using Image//Fiji software. The graphs show mean Pearson's correlation coefficient $\mathrm{R} \pm \operatorname{SEM}(\mathrm{n}=5)$ versus healthy control. ${ }^{*} P<0.05$, ** $P<0.01$ determined by two-tailed Student $t$-test. EDA $+\mathrm{FN}$, fibronectin splice variant containing extra domain $\mathrm{A}$. COMP, cartilage oligomeric matrix protein.

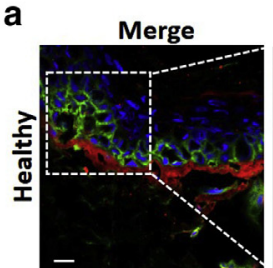

Merge



b

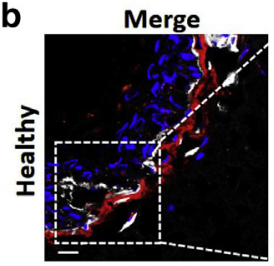

Merge

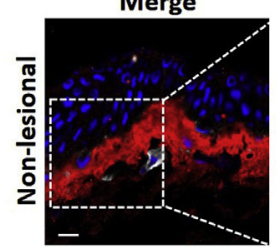

C Merge

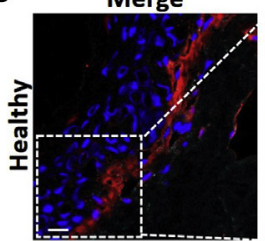

Merge



d

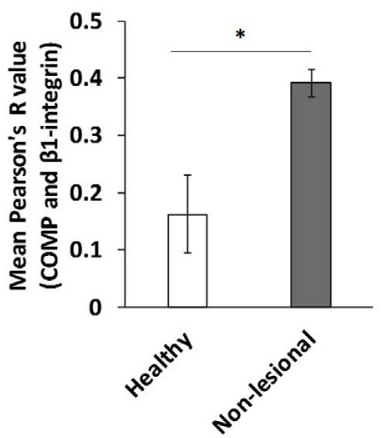

COMP

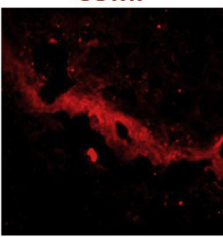

COMP

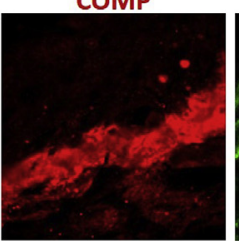

COMP

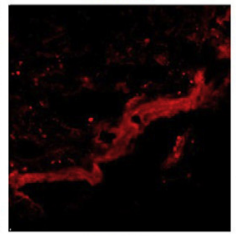

COMP

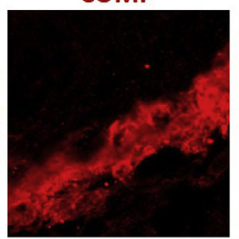

COMP



COMP



e

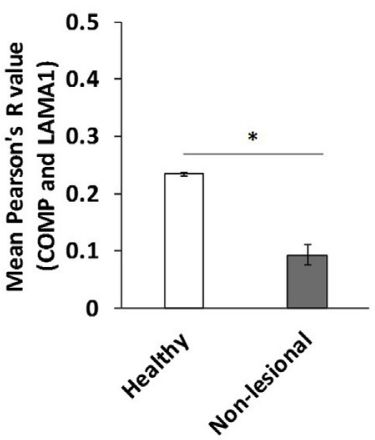

B1-intergin

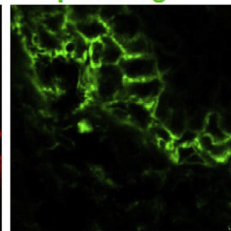

B1-intergin


LAMA1

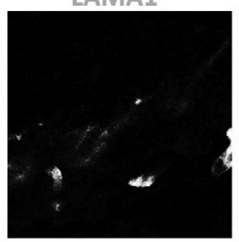

$E D A+F N$

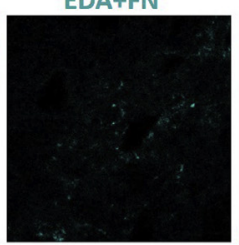

$E D A+F N$



COMP, B1-intergin Colocalized pixels
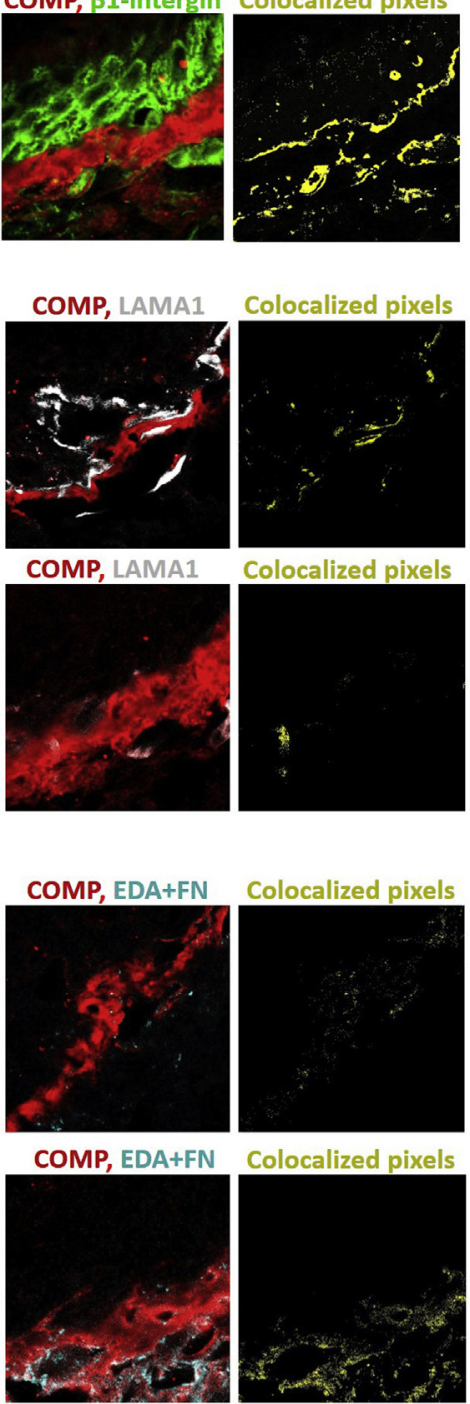

$\mathbf{f}$

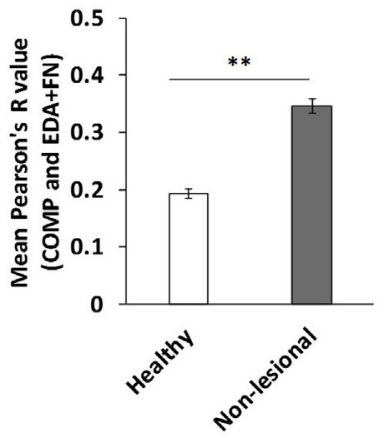


a

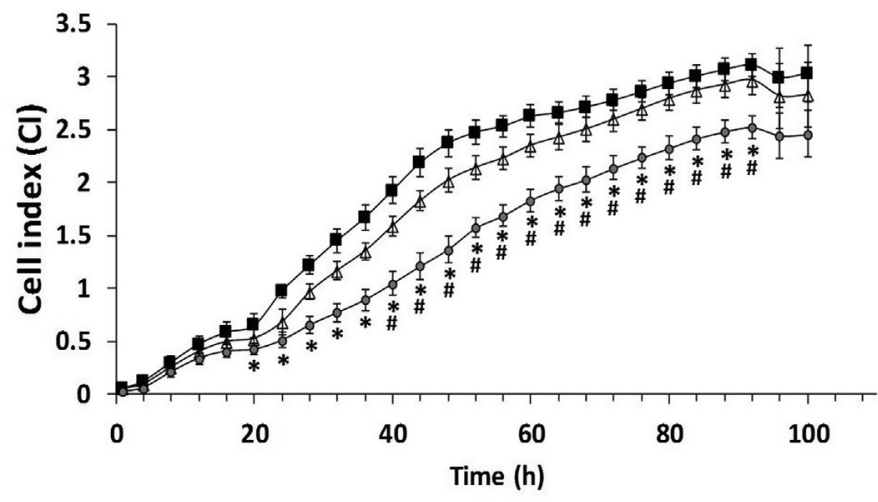

- uncoated $\triangle 1 \mu \mathrm{g} / \mathrm{ml}$ COMP coated $\rightarrow 10 \mu \mathrm{g} / \mathrm{ml}$ COMP coated b
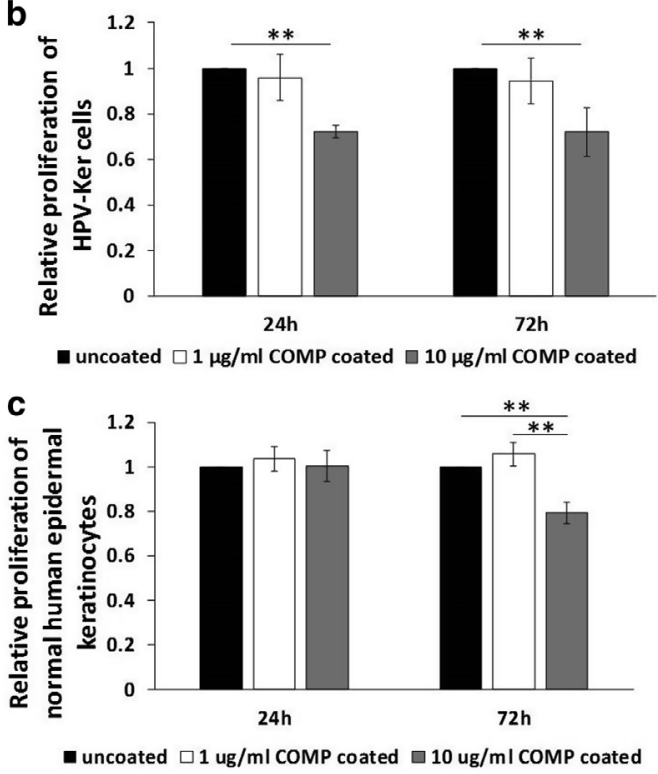

Figure 3. COMP negatively influences keratinocyte cell proliferation. (a) $\mathrm{Cl}$ measurement of HPV-KER cells cultured on surfaces that were uncoated or coated with rhCOMP (1 and $10 \mu \mathrm{g} / \mathrm{ml})$. Cl was determined using real-time impedance measurement-based cellular analysis. The graph is representative of four independent experiments, all showing similar results. The graph shows mean $\mathrm{Cl} \pm \mathrm{SEM}$ of four technical replicas for each group, $* P<0.05$ versus uncoated control, $\# P<0.05$ versus $1 \mu \mathrm{g} / \mathrm{ml}$ rhCOMP-coated group calculated by one-way ANOVA, followed by Tukey's post-hoc test. BrdU cell proliferation assay of (b) HPV-KER and (c) NHEK cells cultured on uncoated and rhCOMP protein ( 1 and $10 \mu \mathrm{g} / \mathrm{ml}$ )-coated surfaces at 24 and 72 hours following seeding. The graphs show mean proliferation \pm SEM $(n=3) .{ }^{* *} P<0.01$, calculated by one-way ANOVA followed by Tukey's post-hoc test. Cl, cell index; COMP, cartilage oligomeric matrix protein; NHEK, normal human epidermal keratinocyte; rhCOMP, recombinant human COMP.

et al., 2003). Therefore, we performed KRT17 immunofluorescence staining to further investigate the effect of COMP in the ex vivo wound healing model. In rhCOMPtreated wounds, KRT17 expression and re-epithelization were reduced and restricted to a smaller proportion of keratinocytes, compared with untreated control wounds (Figure 5e and Supplementary Figure S6b and c). This suggests that the presence of COMP compromised keratinocyte activation.

\section{DISCUSSION}

In psoriasis, the nonlesional skin contains ECM alterations compared with healthy skin. COMP is localized to the papillary dermis of healthy skin (Farina et al., 2006) and, through its interactions with type XII and XIV collagens, contributes to the stabilization of the DEJ (Agarwal et al., 2012). We found that, in psoriatic nonlesional skin, COMP is localized to the papillary dermis and, in contrast to healthy skin, it forms a continuous, more compact, linear layer beneath the basal keratinocytes. Apart from this altered localization, COMP expression was also elevated in dermal fibroblasts from psoriatic samples.

Psoriatic nonlesional skin is more sensitive to stress (Sonkoly et al., 2005; Széll et al., 2016), and abnormalities at the DEJ and the $\mathrm{BM}$ are believed to be important in the development of the disease (Bos et al., 1983; Ting et al., 2000). Interruption of the BM (Mondello et al., 1996; Vaccaro et al., 2002) may allow ECM components, normally located directly below the BM, to come in direct contact with basal keratinocytes. COMP reportedly binds directly to the extracellular domain of ITGB1 of both cardiomyocytes (Huang et al., 2013) and cardiac fibroblasts, resulting in the stabilization of ITGB1 by preventing its degradation and, subsequently, improving cellular survival (Huang et al., 2013; Posey et al., 2018). In cartilage, COMP mediates chondrocyte attachment and stabilization partially via $\alpha 5 \beta 1$-integrin (Tan et al., 2009). Our confocal microscopic analysis revealed a partial colocalization of papillary dermal COMP and ITGB1 in basal keratinocytes, which indicates the possibility of a direct interaction between these two proteins in vivo. In nonlesional skin, the $\alpha 5$-integrin (ITGA5) subunit is overexpressed in the basal layer of the epidermis, in contrast to healthy skin, where it is present at low levels or completely missing (Bata-Csorgo et al., 1998). Our findings are in line with this observation, as COMP and ITGB1 strongly colocalize in psoriatic nonlesional epidermis and expression of both are upregulated in nonlesional skin. Moreover, the BM is partially discontinuous in psoriatic nonlesional skin (Mondello et al., 1996; Vaccaro et al., 2002), allowing direct interaction. The possibility of this interaction is supported by our finding that, in areas where COMP and ITGB1 were found to have strong colocalization in psoriatic nonlesional skin, the expression of LAMA1, a member of the BM, is reduced or completely absent.

COMP also interacts with $\alpha 7 \beta 1$ - and $\alpha v \beta 3$-integrins (Chen et al., 2005; Rock et al., 2010). Of these proteins, only $\alpha 7 \beta 1$ contains a ITGB1 subunit. There is currently no information available about $\alpha 7 \beta 1$-integrin expression in basal keratinocytes. Thus, we assumed that, if COMP exhibits a strong interaction with ITGB1, its $\alpha$-subunit is likely to be ITGA5. In addition to binding to $\alpha 5 \beta 1$-integrin, an FN receptor, COMP might also bind to the $\mathrm{FN}$ protein itself (Di Cesare et al., 2002). Furthermore, $\alpha 5 \beta 1$-integrin-associated FN and $\mathrm{EDA}+\mathrm{FN}$ are known to play roles in psoriasis 
$R$ Bozó et al.

Cartilage Oligomeric Matrix Protein in Psoriasis

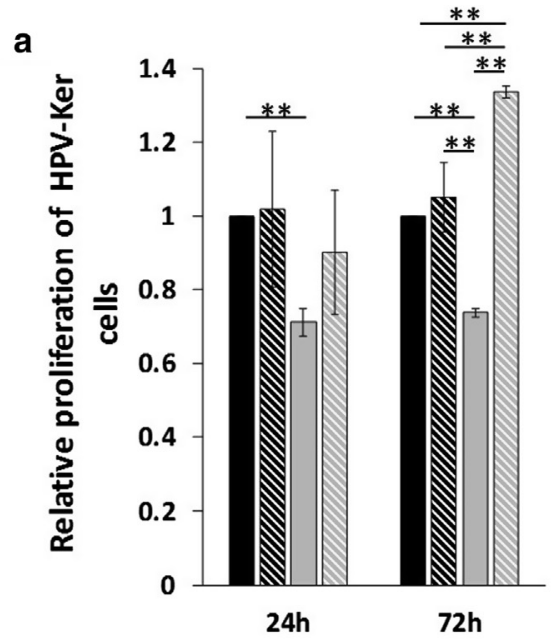

uncoated,
unblocked
uncoated,
ITGA5 blocked
$\square 10 \mu \mathrm{g} / \mathrm{ml}$ COMP
coated,
unblocked
$\square 10 \mu \mathrm{g} / \mathrm{ml}$ COMP
coated, ITGA5
blocked

b

C

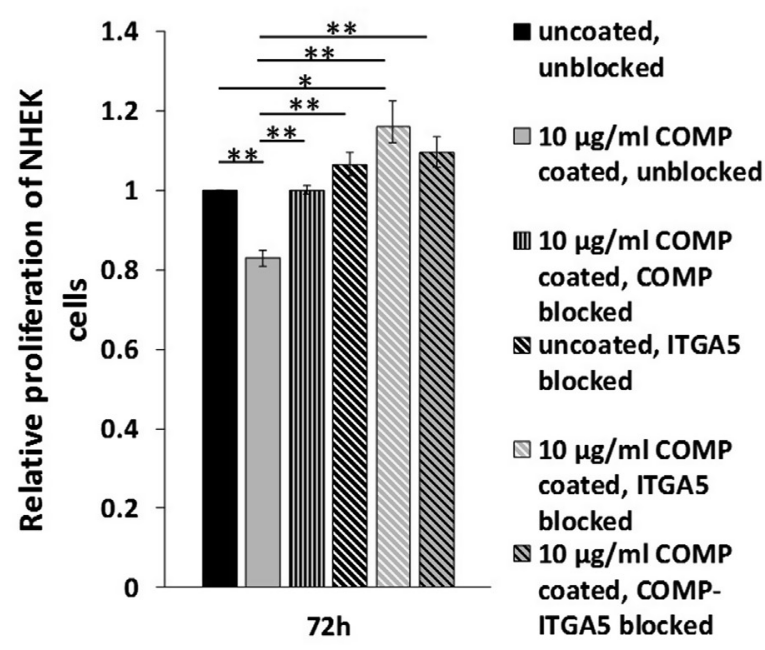

d
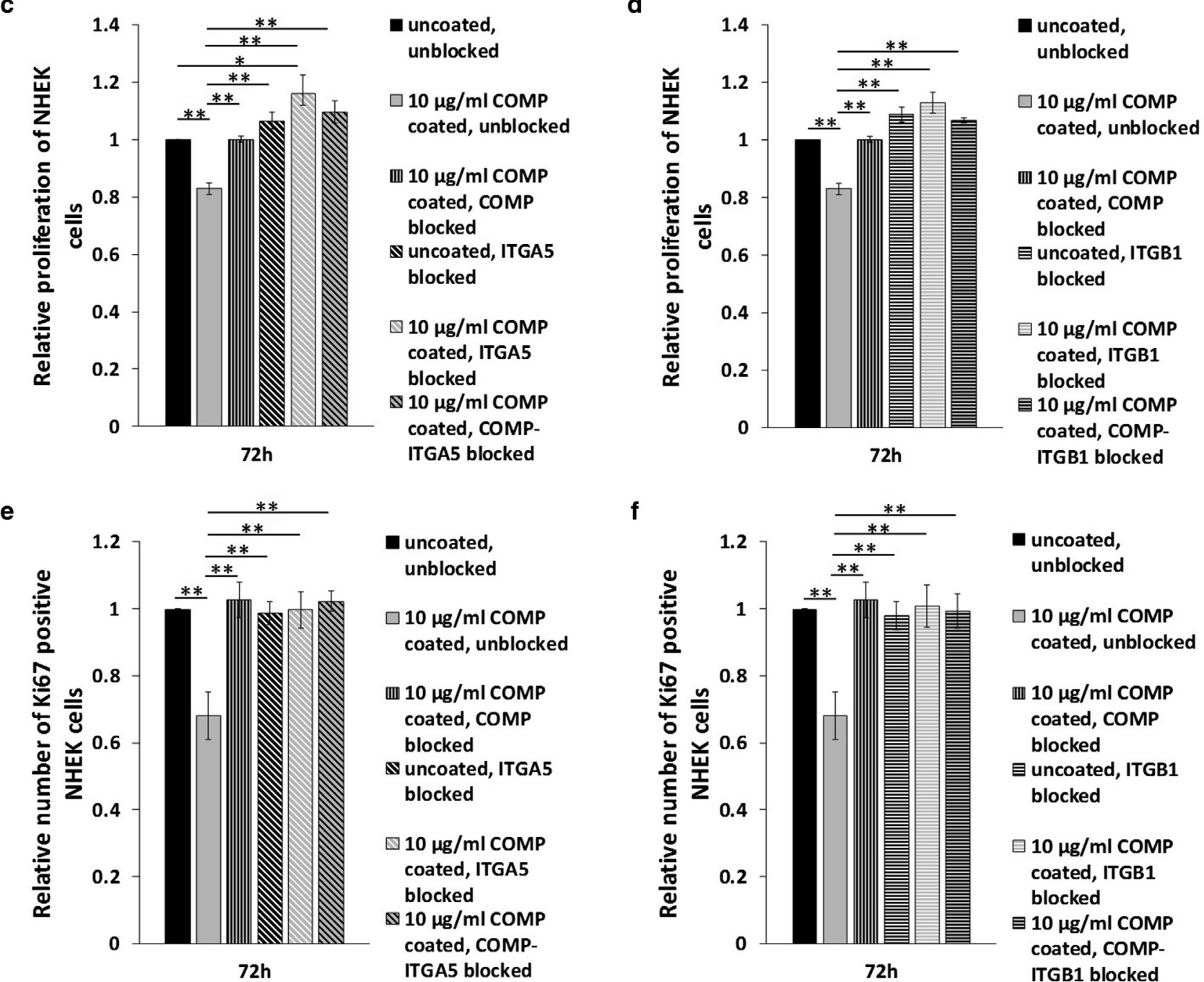

$\mathbf{f}$



Figure 4. COMP influences keratinocyte proliferation via $\alpha 5 \beta 1$ integrin. $(\mathbf{a}, \mathbf{b})$ BrdU cell proliferation assay of HPV-KER cells cultured on surfaces that were uncoated or coated with rhCOMP protein $(10 \mu \mathrm{g} / \mathrm{ml})$ for 24 and 72 hours following seeding and treated with (a) anti- $\alpha 5$-integrin or (b) anti- $\beta 1$-integrin subunit antibodies. (c, d) BrdU assay and (e, f) Ki67-positive proliferating cell number determination of NHEKs grown on surfaces that were uncoated or coated with rhCOMP protein $(10 \mu \mathrm{g} / \mathrm{ml})$ for 72 hours following seeding and treated with $(\mathrm{c}, \mathrm{e})$ anti- $\alpha 5$-integrin and $(\mathrm{d}$, $\mathrm{f})$ anti- $\beta 1$-integrin subunit antibody in a combination with COMP protein neutralization. The graphs show mean proliferation/mean number of Ki67-positive cells \pm SEM ( $\mathrm{n}=3$ ) versus uncoated control, ${ }^{*} P<0.05,{ }^{* * P}<0.01$ calculated by one-way ANOVA, followed by Tukey's post-hoc test. COMP, cartilage oligomeric matrix protein; NHEK, normal human epidermal keratinocyte; rhCOMP, recombinant human COMP. 

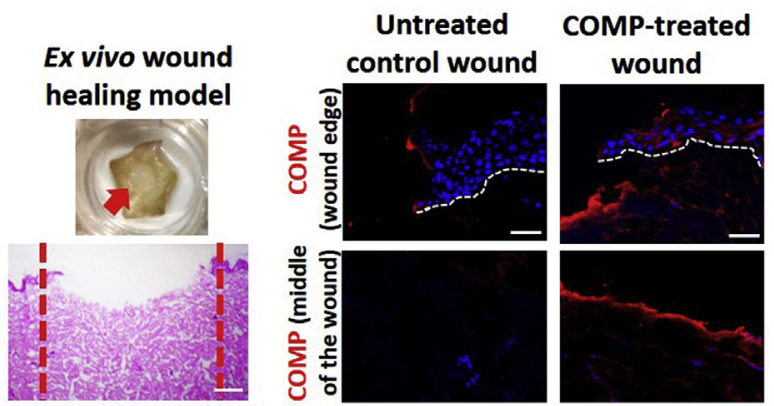

d
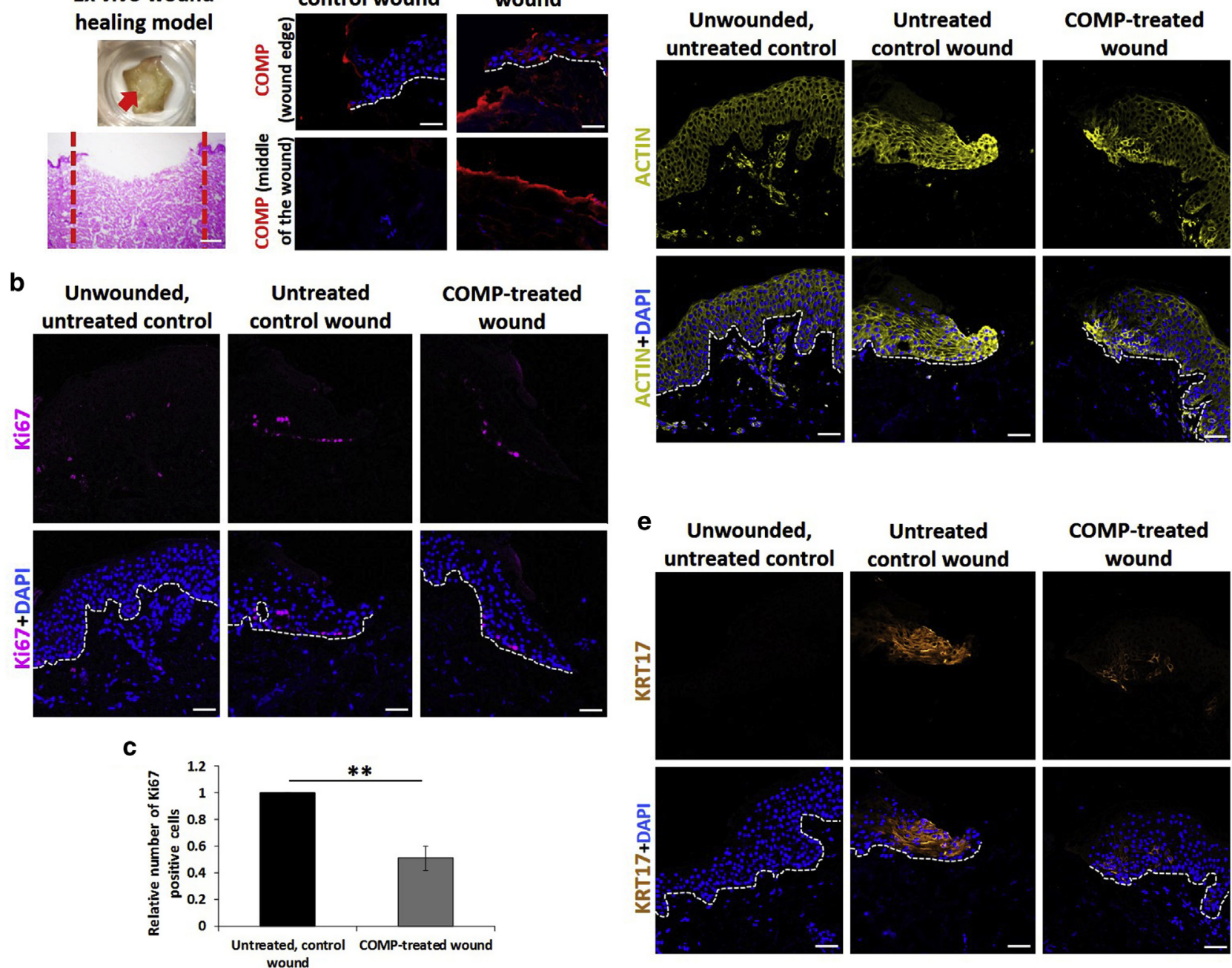

Figure 5. COMP has a negative effect on keratinocyte proliferation and is involved in keratinocyte migration and activation in ex vivo wound models. (a) Representative images of the ex vivo skin wound healing models $(n=3$; magnification $\times 4$; Bar $=250 \mu \mathrm{m})$. Immunofluorescent staining for COMPat wound edges and at the middle of the wounds of untreated controls and wounds treated with rhCOMP ( $\mathrm{n}=3$; magnification $\times 20$; Bar $=50 \mu \mathrm{m})$. Immunostaining for (b) Ki67, (d) actin, or (e) keratin-17 in the ex vivo unwounded skin (left column), and wound-healing skin models with (right column) and without (middle column) rhCOMP treatment. Representative images are shown. Dotted lines indicate the border of the dermal-epidermal junction $(\mathrm{n}=3$; magnification $\times 20$; bar $=50 \mu \mathrm{m})$. $(\mathbf{c})$ Ki67positive cells in wounds that were not treated and were treated with rhCOMP protein. The graph shows mean number of Ki67-positive cells \pm SEM ( $\mathrm{n}=3$ ) versus uncoated, untreated control ${ }^{* *} P<0.01$ determined by two-tailed Student $t$-test. COMP, cartilage oligomeric matrix protein; rhCOMP, recombinant human COMP.

pathogenesis (Bata-Csorgo et al., 1998; Ting et al., 2000). Enriched expression of $\alpha 5 \beta 1$-integrin and $\mathrm{EDA}+\mathrm{FN}$ in nonlesional skin is thought to be due to the incompleteness of the laminin layer (Mondello et al., 1996; Vaccaro et al., 2002). Our confocal microscopic analysis revealed partial colocalization of COMP and EDA + FN in nonlesional skin. These results suggest that, in addition to interacting with $\mathrm{EDA}+\mathrm{FN}$, COMP may also affect basal keratinocytes via interactions with both the EDA + FN and its receptor, $\alpha 5 \beta 1$ integrin.

Keratinocyte behavior is influenced by ECM proteins through interactions with different cell surface integrins (Hamill et al., 2012; Tjin et al., 2014), and connection of basal keratinocytes to the altered BM could enhance proliferation (Yang et al., 2016). We analyzed the biological relevance of the interaction of COMP and ITGB1 in basal keratinocytes using HPV-KER and normal human epidermal keratinocyte cells in vitro. We found that the presence of COMP resulted in reduced keratinocyte proliferation in both cell types and that this affect was reversible by blocking COMP with a specific antibody.

We also analyzed whether the observed negative effect of COMP on keratinocyte proliferation involves interaction with $\alpha 5 \beta 1$-integrin. By partially blocking the function of the ITGB1 or ITGA5 subunits with specific antibodies, the negative effect of COMP on cell proliferation was abolished, suggesting that the negative influence of COMP on keratinocyte proliferation involves $\alpha 5 \beta 1$-integrin.

Our in vitro findings were also validated in an ex vivo wound model; exogenous COMP treatment delayed healing of artificial wounds, and this affect was coupled with reduced keratinocyte proliferation and compromised actin expression, 
$\boldsymbol{R}$ Bozó et al.

Cartilage Oligomeric Matrix Protein in Psoriasis

both important aspects of wound healing (Gurtner et al., 2008). In addition, keratinocyte KRT17 expression, considered a hallmark of normal wound healing (Mazzalupo et al., 2003), was also decreased in the presence of COMP. These results suggest that COMP has a negative influence on ex vivo wound healing. In normally healing wounds of healthy donors, COMP was hardly detectable when re-epithelialization was complete (Agarwal et al., 2013). Similarly, in psoriatic lesions, in which keratinocyte proliferation is abnormally increased, COMP was found to be discontinuous or completely absent from the papillary dermis. Although there are no data regarding keratinocyte proliferation or migration in wounds of COMP-deficient mice (Schulz et al., 2016), in human nonhealing wounds, such as venous leg ulcers, the level of COMP is reported to be highly elevated (Agarwal et al., 2013). Our findings are in agreement with this observation.

In conclusion, our study shows that COMP is present at an elevated level in the papillary dermis of nonlesional psoriatic skin and that it possibly reduces keratinocyte proliferation via the $\alpha 5 \beta 1$-integrin. These aspects of COMP contribute to the maintenance of the nonlesional, nonhyperproliferative state of psoriatic nonlesional epidermis, despite the overexpression of EDA + FN and ITGA5. Similar interactions may also take place in other skin diseases in which nonhealing wounds are coupled with massive COMP accumulation.

\section{MATERIALS AND METHODS \\ Skin samples and ethics}

Skin punch biopsies (diameter $=6 \mathrm{~mm}$ ) were collected from healthy volunteers $(n=10$; age 18-70 years, Supplementary Table S1), and from patients with psoriasis with moderate-to-severe chronic plaquetype psoriasis from lesional $(\mathrm{n}=13)$ and nonlesional skin areas $(\mathrm{n}=$ 13; minimum of $6 \mathrm{~cm}$ from lesional region; age 18-70 years [Supplementary Table S1]). Patients with psoriasis did not receive local therapy for at least 4 weeks and had not been subjected to systemic therapy for at least 8 weeks. Skin biopsies were taken from areas of skin that were not exposed to sun. Tissue collection was obtained after written informed consent, in accordance with the rules of the Helsinki Declaration. The study was confirmed by the Human Investigation Review Board of the University of Szeged (PSO-EDAFN-002, 34/2015, 3517, 23 February 2015, Szeged, Hungary; PSO-ECMPR-002 IF-562-5/2016 and 157/2015-SZTE, 3638, 21 September 2015, Hungary).

\section{Fluorescence microscopic analysis}

Biopsies were frozen in a cryogenic matrix (Thermo Fisher Scientific, Waltham, MA) or were paraffin embedded and were subsequently cut into $5-\mu \mathrm{m}$ sections. For fixation and permeabilization, $4 \%$ paraformaldehyde followed by $0.25 \%$ TritonX-100 (Thermo Fisher Scientific) or commercially available staining buffer set (eBioscience, Santa Clara, CA) were used. For blocking, Trisbuffered saline containing $1 \%$ bovine serum albumin and $1 \%$ normal goat serum (Sigma-Aldrich, St. Louis, MO) was used, and for frozen samples, which were digested with chondroitinase $A B C$ (5U, 1:100; Sigma-Aldrich), 10\% fetal bovine serum (EuroClone, Pero, Italy) and 5\% normal goat serum (Sigma-Aldrich) were applied. Samples were incubated with the following primary antibodies: polyclonal rabbit anti-human COMP (1:250), a kind gift from Mats Paulsson and Frank Zaucke from the University of Cologne (Agarwal et al., 2012); mouse anti-human ITGB1 (clone: JB1B, 1:100, Abcam, Cambridge, United Kingdom); rabbit antihuman actin (1:100, Sigma-Aldrich); mouse anti-human Ki67 (1:100, Beckton Dickinson, Franklin Lakes, NJ); mouse anti-human KRT17 (ready to use, Dako, Santa Clara, CA); mouse anti-human LAMA1 (clone: LAM-89, 1:100, R\&D Systems, Minneapolis, MN); and mouse anti-human FN (EDA + FN, clone: IST-9, 1:500, Abcam). Isotype controls were the following: rabbit polyclonal $\lg G$ (Santa Cruz Biotechnology, Dallas, TX) and mouse IgG1 (Beckton Dickinson) antibodies. As secondary antibodies, Alexa Fluor 546-conjugated anti-rabbit IgG and Alexa Fluor 647-conjugated anti-mouse IgG (Life Technologies, Carlsbad, CA) were used. Nuclei were visualized with DAPI (Sigma-Aldrich) staining. Zeiss LSM 880 or Zeiss Axio Imager Z1 microscopes (Carl Zeiss AG, Oberkochen, Germany) were used for visualization.

Pearson's correlation coefficient, $R$, was calculated using ImageJ/ Fiji software.

\section{Cell cultures and examination of cellular properties}

Cell proliferation assay. To investigate the effect of COMP on keratinocyte proliferation, a BrdU cell proliferation colorimetric ELISA assay (Abcam) was performed. HPV-KER cells, a stable human keratinocyte cell line that has been characterized in our laboratory (Danis et al., 2018; Erdei et al., 2018; Tax et al., 2016), and normal human epidermal keratinocyte cells were plated at a density of 10,000 cells per well in 96 -well plates (Corning, NY) that were uncoated or coated with low- $(1 \mu \mathrm{g} / \mathrm{ml})$ or high-concentration $(10 \mu \mathrm{g} / \mathrm{ml})$ rhCOMP protein (R\&D Systems), in three technical replicates. For the blocking of ITGA5 and ITGB1, the following antibodies (1 $\mu \mathrm{g}$ antibody for $10^{6}$ cells) were used: mouse antihuman ITGA5 antibody (clone: IIA1, Beckton Dickinson) and mouse anti-human ITGB1 (clone: JB1B). Goat anti-human COMP antibody (1 $\mu \mathrm{g}$ antibody for $10 \mu \mathrm{g} / \mathrm{ml}$ rhCOMP protein, R\&D Systems) was applied to block the COMP protein. Integrin- and COMP-blocking was applied to cells grown on uncoated plates or plates coated with $10 \mu \mathrm{g} / \mathrm{ml}$ rhCOMP protein. BrdU assay was performed at 24 and 72 hours after blocking, according to the manufacturer's instructions.

\section{Ex vivo skin wound-healing assay}

Healthy skin samples were collected for the ex vivo organotypic wound healing assay. Approximately $1-\mathrm{cm}$ diameter skin pieces were cut and mildly wounded in the middle using a 4-mm punch biopsy blade (Steele Supply Company, St. Joseph, MI). Wounded skin samples and unwounded control samples were incubated for 72 hours at an air-liquid interface on the upper part of transwell cell culture inserts. The dermal part was in contact with DMEM F12 culture media (Lonza Group, Basel, Switzerland) supplemented with $10 \%$ fetal bovine serum (EuroClone) and 1\% antibiotic/antimycotic solution (Sigma-Aldrich). The middle of the wounds was treated for 72 hours with high-concentration (10 $\mu \mathrm{g} /$ $\mathrm{ml}$ ) rhCOMP (R\&D Systems) diluted in PBS or PBS only as a control. Samples were fixed in formalin and embedded in paraffin for immunofluorescent staining. To determine the rate of proliferation, 50 cells on each wound edge were counted and the proportion of Ki67-positive cells was determined. Re-epithelization of untreated, control (where only PBS was administered), and COMPtreated wounds were assessed by measuring the area using the ImageJ software. 


\section{Statistical analysis}

For comparing only two groups, two-tailed Student $t$-test was performed. One-way ANOVA with Tukey post-hoc test was used to compare more than two groups. Differences were considered statistically significant at ${ }^{* *} P<0.01, * P<0.05$. Data were analyzed using R-Studio software, version 3.2.2 (R-Studio, Boston, MA).

\section{Further methods}

More detailed information of the materials and methods regarding protein isolation and western blot analysis, cell culture experiments, $\mathrm{H} \& \mathrm{E}$ staining, RNA isolation, and real-time PCR are presented in the Supplementary Materials.

\section{Data availability statement}

No datasets were generated or analyzed during this study.

\section{ORCIDs}

Renáta Bozó: https://orcid.org/0000-0003-4242-2474

Edit Szél: https://orcid.org/0000-0001-9102-5542

Judit Danis: https://orcid.org/0000-0002-0270-5309

Barbara Gubán: https://orcid.org/0000-0002-9406-7489

Zsuzsanna Bata-Csörgő: https://orcid.org/0000-0002-3732-1743

Kornélia Szabó: https://orcid.org/0000-0002-6231-3251

Lajos Kemény: https://orcid.org/0000-0002-2119-9501

Gergely Groma: https://orcid.org/0000-0001-8487-0465

\section{CONFLICT OF INTEREST}

The authors state no conflict of interest.

\section{ACKNOWLEDGMENTS}

The authors wish to thank Mats Paulsson and. Frank Zaucke for the COMP antibody. The authors are grateful for Brigitta Gál, Krisztina V, and Róbert Kui for collecting tissue samples from patients. Furthermore, the authors wish to also thank Mónika Kohajda for her excellent technical assistance and Máté Manczinger and Balázs Koncz for their help in the statistical analysis. Our work was supported by grants from National Research, Development and Innovation Office, Hungary (former Hungarian Scientific Research Fund) PD116992, K111885 and GINOP-2.2.1-15-2016-00007 research grants and co-financed by the European Social Fund in the framework of TAMOP4.2.4.A/2-11-1/2012-0001 "National Excellence Program" A2-SZGYA-FOK13-0001, and European Union's H2020 Grant Agreement No. 739593. KS is a recipient of the János Bolyai Research Scholarship of the Hungarian Academy of Sciences. KS was supported by the UNKP-18-4 and RB by the UNKP-18-3 of New National Excellence Program of the Ministry of Human Capacities. KS was supported by the ÚNKP-19-4 and RB by the ÚNKP-19-3 of New National Excellence Program of the Ministry for Innovation and Technology. RB was also supported by the Gedeon Richter Talentum Foundation (H-1103 Budapest, Gyömrői str. 19-21.). The study took place in Szeged, Hungary.

\section{AUTHOR CONTRIBUTIONS}

Conceptualization: GG; Formal Analysis: RB, KS, GG; Investigation: RB, ES, JD, BG; Methodology: RB, GG; Supervision: LK, ZBC, GG; Writing - Original Draft Preparation: RB, GG; Writing - Review and Editing: KS, ZBC, GG.

\section{SUPPLEMENTARY MATERIAL}

Supplementary material is linked to the online version of the paper at www. jidonline.org and at https://doi.org/10.1016/j.jid.2019.12.037.

\section{REFERENCES}

Agarwal P, Schulz JN, Blumbach K, Andreasson K, Heinegård D, Paulsson M, et al. Enhanced deposition of cartilage oligomeric matrix protein is a common feature in fibrotic skin pathologies. Matrix Biol 2013;32:325-31.

Agarwal P, Zwolanek D, Keene DR, Schulz JN, Blumbach K, Heinegård D, et al. Collagen XII and XIV, new partners of cartilage oligomeric matrix protein in the skin extracellular matrix suprastructure. J Biol Chem 2012;287:22549-59.

Bata-Csorgo Z, Cooper KD, Ting KM, Voorhees JJ, Hammerberg C. Fibronectin and alpha 5 integrin regulate keratinocyte cell cycling. A mechanism for increased fibronectin potentiation of $\mathrm{T}$ cell lymphokine-driven keratinocyte hyperproliferation in psoriasis. J Clin Invest 1998;101: 1509-18.
Bata-Csorgo Z, Hammerberg C, Voorhees JJ, Cooper KD. Kinetics and regulation of human keratinocyte stem cell growth in short-term primary ex vivo culture. Cooperative growth factors from psoriatic lesional T lymphocytes stimulate proliferation among psoriatic uninvolved, but not normal, stem keratinocytes. J Clin Invest 1995;95:317-27.

Bos JD, Hulsebosch HJ, Krieg SR, Bakker PM, Cormane RH. Immunocompetent cells in psoriasis. In situ immunophenotyping by monoclonal antibodies. Arch Dermatol Res 1983;275:181-9.

Chen FH, Thomas AO, Hecht JT, Goldring MB, Lawler J. Cartilage oligomeric matrix protein/thrombospondin 5 supports chondrocyte attachment through interaction with integrins. J Biol Chem 2005;280:32655-61.

Chen G, McCormick TS, Hammerberg C, Ryder-Diggs S, Stevens SR, Cooper KD. Basal keratinocytes from uninvolved psoriatic skin exhibit accelerated spreading and focal adhesion kinase responsiveness to fibronectin. J Invest Dermatol 2001;117:1538-45.

Danis J, Janovák L, Gubán B, Göblös A, Szabó K, Kemény L, et al. Differential inflammatory-response kinetics of human keratinocytes upon cytosolic RNA- and DNA-fragment induction. Int J Mol Sci 2018;19:774.

Di Cesare PE, Chen FS, Moergelin M, Carlson CS, Leslie MP, Perris R, et al. Matrix-matrix interaction of cartilage oligomeric matrix protein and fibronectin. Matrix Biol 2002;21:461-70.

Dickhuth J, Koerdt S, Kriegebaum U, Linz C, Müller-Richter UD, Ristow O, et al. In vitro study on proliferation kinetics of oral mucosal keratinocytes. Oral Surg Oral Med Oral Pathol Oral Radiol 2015;120:429-35.

Dodge GR, Hawkins D, Boesler E, Sakai L, Jimenez SA. Production of cartilage oligomeric matrix protein (COMP) by cultured human dermal and synovial fibroblasts. Osteoarthr Cartil 1998;6:435-40.

Erdei L, Bolla BS, Bozó R, Tax G, Urbán E, Kemény L, et al. TNIP1 regulates Cutibacterium acnes-induced innate immune functions in epidermal keratinocytes. Front Immunol 2018;9:2155.

Farina G, Lemaire R, Korn JH, Widom RL. Cartilage oligomeric matrix protein is overexpressed by scleroderma dermal fibroblasts. Matrix Biol 2006;25: $213-22$.

Gliński W, Stepień-Sopniewska B, Majewski S, Glińska-Ferenz M, Górski A. Alterations of T-cell: extracellular matrix proteins interactions in psoriasis. Immunol Lett 1993;35:153-7.

Gubán B, Vas K, Balog Z, Manczinger M, Bebes A, Groma G, et al. Abnormal regulation of fibronectin production by fibroblasts in psoriasis. $\mathrm{Br} J$ Dermatol 2016;174:533-41.

Gurtner GC, Werner S, Barrandon Y, Longaker MT. Wound repair and regeneration. Nature 2008;453:314-21.

Hamill KJ, Hopkinson SB, Hoover P, Todorović V, Green KJ, Jones JCR. Fibronectin expression determines skin cell motile behavior. J Invest Dermatol 2012;132:448-57.

Huang Y, Xia J, Zheng J, Geng B, Liu P, Yu F, et al. Deficiency of cartilage oligomeric matrix protein causes dilated cardiomyopathy. Basic Res Cardiol 2013;108:374.

Inui S, Shono F, Nakajima T, Hosokawa K, Itami S. Identification and characterization of cartilage oligomeric matrix protein as a novel pathogenic factor in keloids. Am J Pathol 2011;179:1951-60.

Malashkevich VN, Kammerer RA, Efimov VP, Schulthess T, Engel J. The crystal structure of a five-stranded coiled coil in COMP: a prototype ion channel? Science 1996;274:761-5.

Mazzalupo S, Wong P, Martin P, Coulombe PA. Role for keratins 6 and 17 during wound closure in embryonic mouse skin. Dev Dyn 2003;226: 356-65.

McFadden JP, Kimber I. A review on the potential role of basement membrane laminin in the pathogenesis of psoriasis. Scand J Immunol 2016;83:3-9.

Mondello MR, Magaudda L, Pergolizzi S, Santoro A, Vaccaro M, Califano L, et al. Behaviour of laminin 1 and type IV collagen in uninvolved psoriatic skin. Immunohistochemical study using confocal laser scanning microscopy. Arch Dermatol Res 1996;288:527-31.

Mörgelin M, Heinegård D, Engel J, Paulsson M. Electron microscopy of native cartilage oligomeric matrix protein purified from the Swarm rat chondrosarcoma reveals a five-armed structure. J Biol Chem 1992;267: $6137-41$.

Müller G, Michel A, Altenburg E. COMP (cartilage oligomeric matrix protein) is synthesized in ligament, tendon, meniscus, and articular cartilage. Connect Tissue Res 1998;39:233-44. 


\section{$\boldsymbol{R}$ Bozó et al.}

Cartilage Oligomeric Matrix Protein in Psoriasis

Pellegrini G, De Luca M, Orecchia G, Balzac F, Cremona O, Savoia P, et al. Expression, topography, and function of integrin receptors are severely altered in keratinocytes from involved and uninvolved psoriatic skin. J Clin Invest 1992;89:1783-95.

Posey KL, Coustry F, Hecht JT. Cartilage oligomeric matrix protein: COMPopathies and beyond. Matrix Biol 2018;71-72:161-73.

Rock MJ, Holden P, Horton WA, Cohn DH. Cartilage oligomeric matrix protein promotes cell attachment via two independent mechanisms involving CD47 and alphaVbeta3 integrin. Mol Cell Biochem 2010;338: 215-24.

Schulz JN, Nüchel J, Niehoff A, Bloch W, Schönborn K, Hayashi S, et al. COMP-assisted collagen secretion-a novel intracellular function required for fibrosis. J Cell. Sci 2016;129:706-16.

Sonkoly E, Bata-Csorgo Z, Pivarcsi A, Polyanka H, Kenderessy-Szabo A, Molnar G, et al. Identification and characterization of a novel, psoriasis susceptibility-related noncoding RNA gene, PRINS. J Biol Chem 2005;280: 24159-67.

Szabó K, Bata-Csörgő Z, Dallos A, Bebes A, Francziszti L, Dobozy A, et al. Regulatory networks contributing to psoriasis susceptibility. Acta Derm Venereol 2014;94:380-5.

Széll M, Bata-Csörgo Z, Koreck A, Pivarcsi A, Polyánka H, Szeg C, et al. Proliferating keratinocytes are putative sources of the psoriasis susceptibility-related EDA+ (extra domain A of fibronectin) oncofetal fibronectin. J Invest Dermatol 2004;123:537-46.

Széll M, Danis J, Bata-Csörgő Z, Kemény L. PRINS, a primate-specific long non-coding RNA, plays a role in the keratinocyte stress response and psoriasis pathogenesis. Pflugers Arch 2016;468:935-43.

Tan K, Duquette M, Joachimiak A, Lawler J. The crystal structure of the signature domain of cartilage oligomeric matrix protein: implications for collagen, glycosaminoglycan and integrin binding. FASEB J 2009;23: 2490-501.

Tan K, Lawler J. The interaction of thrombospondins with extracellular matrix proteins. J Cell Commun Signal 2009;3:177-87.

Tax G, Urbán E, Palotás Z, Puskás R, Kónya Z, Bíró T, et al. Propionic acid produced by Propionibacterium acnes strains Contributes to their pathogenicity. Acta Derm Venereol 2016;96:43-9.

Ting KM, Rothaupt D, McCormick TS, Hammerberg C, Chen G, Gilliam AC, et al. Overexpression of the oncofetal Fn variant containing the EDA splicein segment in the dermal-epidermal junction of psoriatic uninvolved skin. J Invest Dermatol 2000;114:706-11.

Tjin MS, Chua AWC, Ma DR, Lee ST, Fong E. Human epidermal keratinocyte cell response on integrin-specific artificial extracellular matrix proteins. Macromol Biosci 2014;14:1125-34.

Vaccaro M, Magaudda L, Cutroneo G, Trimarchi F, Barbuzza O, Guarneri F, et al. Changes in the distribution of laminin alpha 1 chain in psoriatic skin: immunohistochemical study using confocal laser scanning microscopy. Br J Dermatol 2002;146:392-8.

Wang L, Zheng J, Du Y, Huang Y, Li J, Liu B, et al. Cartilage oligomeric matrix protein maintains the contractile phenotype of vascular smooth muscle cells by interacting with alpha(7)beta(1) integrin. Circ Res 2010;106:514-25.

Yang S, Sun Y, Geng Z, Ma K, Sun X, Fu X. Abnormalities in the basement membrane structure promote basal keratinocytes in the epidermis of hypertrophic scars to adopt a proliferative phenotype. Int J Mol Med 2016;37: $1263-73$. 


\section{SUPPLEMENTARY MATERIALS AND METHODS}

\section{Protein isolation and western blot analysis}

For preparation of tissue protein extracts, skin biopsies (healthy, psoriatic nonlesional, and psoriatic lesional) were cut into small pieces with a razor blade. Guanidine hydrochloride (6 M, Sigma-Aldrich, St. Louis, MO) solution was used as an extraction buffer for 24 hours at $4{ }^{\circ} \mathrm{C}$ under continuous agitation. For protein precipitation, an ethanolbased method was applied. Protein concentrations were measured using Bradford assay (Bio-Rad Laboratories, Hercules, CA). Protein extracts $(25 \mu \mathrm{g})$ were separated on a $4-20 \%$ gradient SDS polyacrylamide gel under reducing or nonreducing conditions. Proteins were transferred to a nitrocellulose membrane (Bio-Rad Laboratories) and blocked in 5\% nonfat milk powder containing Tris-buffered saline for 60 minutes at room temperature. Membranes were incubated for overnight at $4{ }^{\circ} \mathrm{C}$ with goat anti-human COMP primary antibody $(1: 2,000$, R\&D Systems, Minneapolis, MN), and rabbit anti-human actin primary antibody $(1: 2,000$, SigmaAldrich). Subsequently, membranes were incubated with horseradish peroxidase-conjugated anti-goat (Thermo Fisher Scientific, Waltham, MA), and anti-rabbit (Southern Biotech, Birmingham, AL) secondary antibodies, both diluted 1:2,000 for 60 minutes at room temperature. Signal was visualized with Clarity Max Western ECL Substrate (Bio-Rad Laboratories) on a C-digit blot scanner (LI-COR Biosciences, Lincoln, NE).

\section{H\&E staining and light microscopic analysis}

To visualize the tissue structure of ex vivo wound model samples, H\&E (Leica Biosystems, Wetzlar, Germany) staining was performed according to the manufacturer's instructions in a Leica ST5020 Multistainer device (Leica Biosystems). The stained samples were visualized with a Nikon eclipse TS100 microscope (Nikon, Minato, Tokyo, Japan).

\section{Cell cultures and examination of cellular properties}

Cell cultures. Primary dermal fibroblasts were isolated from healthy and psoriatic nonlesional skin biopsies, and normal human epidermal keratinocytes (NHEKs) were isolated from healthy skin samples. The epidermis was separated from the dermis with overnight incubation at $4{ }^{\circ} \mathrm{C}$ in Dispase II (neutral protease, grade II, $2 \mathrm{U} / \mathrm{ml}$, Roche Diagnostics, Basel, Switzerland) (Szabad et al., 2007) solution. Keratinocytes were obtained from the epidermal part after trypsin digestion for 10 minutes at $37{ }^{\circ} \mathrm{C}$ (Sigma-Aldrich). NHEK cells were then grown in keratinocyte serum-free medium (Life Technologies, Carlsbad, CA) supplemented with 1\% antibiotic/antimycotic solution (Sigma-Aldrich), brain pituitary extract $(50 \mu \mathrm{g} / \mathrm{ml}$, Life Technologies), and epidermal growth factor (5 ng/ml, Life Technologies).

Fibroblasts were obtained from the dermal part after digestion for 120 minutes at $37{ }^{\circ} \mathrm{C}$. The medium, DMEM supplemented with $1 \mathrm{~g}$ /liter glucose (Lonza Group, Basel, Switzerland), also contained collagenase (from Clostridium histolyticum, $2.7 \mathrm{mg} / \mathrm{ml}$, Sigma-Aldrich), deoxyribonuclease I (from bovine pancreas, $0.1 \mathrm{mg} / \mathrm{ml}$, Sigma-Aldrich), hyaluronidase (from bovine testes, $1.25 \mathrm{mg} / \mathrm{ml}$, Sigma-Aldrich), and fetal bovine serum $(2.5 \%$, EuroClone, Pero, Italy) (Gubán et al., 2016). Fibroblasts were cultured in DMEM with $1 \mathrm{~g} /$ liter glucose (Lonza Group), supplemented with 5\% fetal bovine serum (EuroClone), 1\% antibiotic/antimycotic solution (Sigma-Aldrich), and 1\% L-glutamine (PAA Laboratories $\mathrm{GmbH}$, Pasching, Austria).

The human immortalized keratinocyte cell line HPV-KER was also used for our experiments. HPV-KER is a stable cell line, generated from NHEKs transfected with the HPV16/E6 oncogene in a $\mathrm{pCMV}$ vector. It was established by continuous culturing (Tax et al., 2016). It shows similar responses to NHEK cells in various immune activation protocols (Danis et al., 2018; Erdei et al., 2018). Culture conditions of HPVKER cells are the same as NHEK cells. Each cell type was cultured at $37{ }^{\circ} \mathrm{C}$ in a humidified atmosphere with $5 \% \mathrm{v} / \mathrm{v}$ $\mathrm{CO}_{2}$.

Real-time, label-free cellular analysis of HPV-KER cells using the xCELLigence system. xCELLigence (ACEA Biosciences, San Diego, CA) is a real-time, impedance measurement-based cellular analysis system, where dimensionless cell index value is calculated (cell index = [impedance at time point $\mathrm{n}$ - impedance in the absence of cells]/nominal impedance value). Differences in cell index values could be due to altered cell proliferation rate, viability, morphology, and adhesion (Dickhuth et al., 2015). This system was used to investigate the effect of the COMP protein on keratinocytes. HPV-KER cells were plated at a density of 10,000 cells per well in uncoated 96-well E-plates (ACEA Biosciences) or wells that were coated with lowconcentration $(1 \mu \mathrm{g} / \mathrm{ml})$ or high-concentration $(10 \mu \mathrm{g} / \mathrm{ml})$ recombinant human COMP protein (R\&D Systems). Impedance measurement was performed every 15 minutes for 140 hours, and a dimension-free cell index value was calculated for every time point. Four technical replicates were performed.

Further investigation of keratinocyte cell proliferation. To further investigate the effect of COMP on the proliferation of NHEK cells, Ki67 immunofluorescent staining (mouse antihuman Ki67 antibody, 1:100, Beckton Dickinson, Franklin Lakes, NJ) was applied, using integrin and COMP-blocking as described in the main text. Cells were plated at a density of 20,000 cells per well in 8-well chamber slides (SPL Life Sciences, Naechon-Myeon, Pocheon-si, Korea) that were uncoated or coated with high-concentration $(10 \mu \mathrm{g} / \mathrm{ml})$ recombinant human COMP (R\&D Systems) in three biological replicates. Ki67-positive cells were counted on three randomly selected areas per group, and statistical analysis was performed.

RNA isolation and real-time PCR. Total RNA was isolated from primary fibroblasts from healthy and psoriatic nonlesional skin cultured in $75-\mathrm{cm}^{2}$ cell culture flasks (Corning, NY) and collected at the fifth passage using TRI-Reagent (Molecular Research Center, Cincinnati, OH) as described by the manufacturer. The iScript cDNA Synthesis kit (Bio-Rad Laboratories) was used for CDNA synthesis, and $0.5 \mu \mathrm{g}$ total RNA was reverse transcribed. RT-PCR was performed on a C1000 Touch Thermal Cycler (Bio-Rad Laboratories) with the Universal Probe Library system (Roche Diagnostics) using qPCRBIO Probe Mix Lo-ROX (PCR Biosystem Ltd., London, United Kingdom) and the following primers: 
R Bozó et al.

Cartilage Oligomeric Matrix Protein in Psoriasis

COMP FWD: CACCGACGTCAACGAGTG, COMP REV: TGGTGTTGATACAGCGGACT; $18 \mathrm{~S}$ rRNA FWD: CGCTCCAC CAACTAAGAACG, 18SrRNA REV: CTCAACACGGGAAACC TCAC. The expression of COMP was normalized to $18 \mathrm{~S}$ rRNA expression using the $\Delta \Delta \mathrm{Ct}$ method.

\section{SUPPLEMENTARY REFERENCES}

Danis J, Janovák L, Gubán B, Göblös A, Szabó K, Kemény L, et al. Differential inflammatory-response kinetics of human keratinocytes upon cytosolic RNA- and DNA- fragment induction. Int J Mol Sci 2018;19: 774.

Dickhuth J, Koerdt S, Kriegebaum U, Linz C, Müller-Richter UD, Ristow $\mathrm{O}$, et al. In vitro study on proliferation kinetics of oral mucosal

keratinocytes. Oral Surg Oral Med Oral Pathol Oral Radiol 2015;120: 429-35.

Erdei L, Bolla BS, Bozó R, Tax G, Urbán E, Kemény L, et al. TNIP1 regulates Cutibacterium acnes-induced innate immune functions in epidermal keratinocytes. Front Immunol 2018;9:2155.

Gubán B, Vas K, Balog Z, Manczinger M, Bebes A, Groma G, et al. Abnormal regulation of fibronectin production by fibroblasts in psoriasis. Br J Dermatol 2016;174:533-41.

Szabad G, Kormos B, Pivarcsi A, Széll M, Kis K, Kenderessy Szabó A, et al. Human adult epidermal melanocytes cultured without chemical mitogens express the EGF receptor and respond to EGF. Arch Dermatol Res 2007;299:191-200.

Tax G, Urbán E, Palotás Z, Puskás R, Kónya Z, Bíró T, et al. Propionic acid produced by Propionibacterium acnes strains contributes to their pathogenicity. Acta Derm Venereol 2016;96:43-9. 

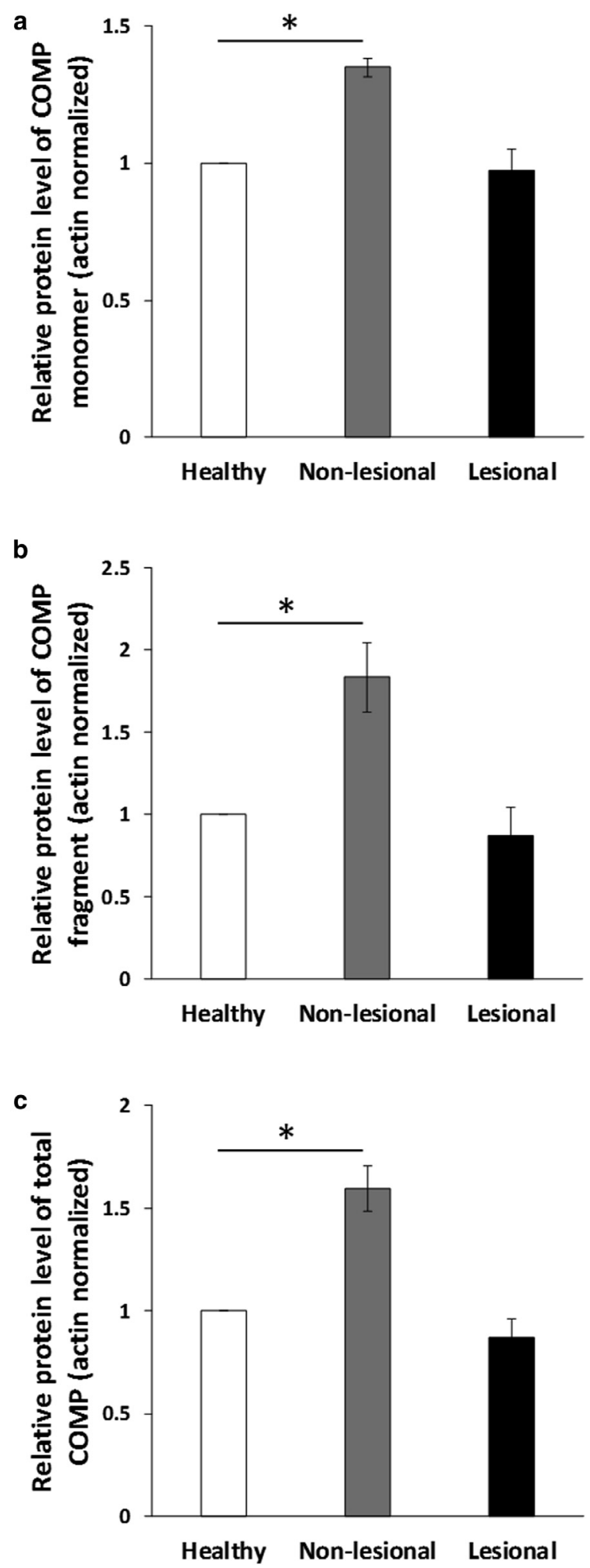

Supplementary Figure S1. COMP monomer and fragment level is elevated in psoriatic nonlesional skin under reducing conditions. COMP monomers and fragments were detected with western blot analysis from healthy, psoriatic nonlesional, and lesional skin under reducing conditions $(n=3)$. The band intensities of (a) COMP monomer and (b) COMP fragment separately, as well as (c) the level of monomer and fragment together were analyzed with Image Studio software (LI-COR Biosciences) and presented as fold changes normalized to actin. The graph shows mean $\pm \operatorname{SEM}(n=3)$, ${ }^{*} P<0.05$ versus healthy control, calculated by one-way ANOVA followed by Tukey's post-hoc test. COMP, cartilage oligomeric matrix protein.
COMP

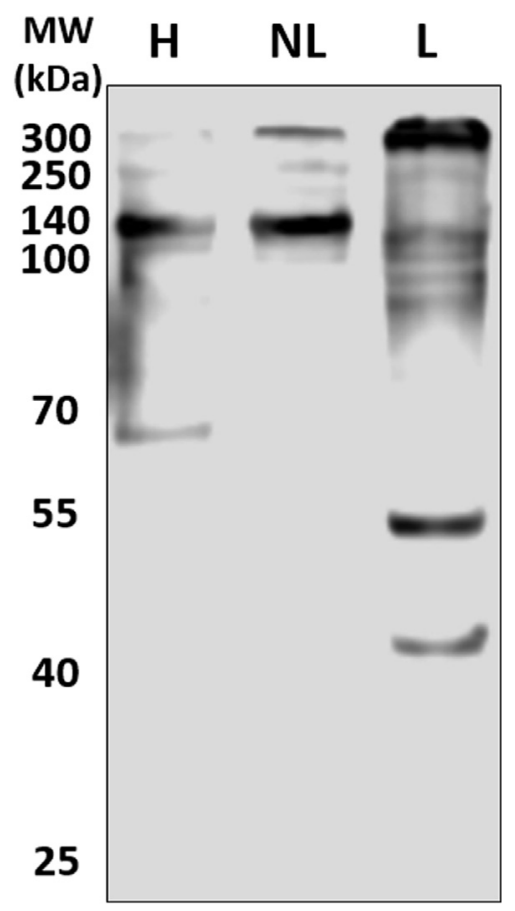

Supplementary Figure S2. COMP protein detection under nonreducing conditions. COMP protein was detected with western blot analysis from healthy, psoriatic nonlesional, and lesional skin under nonreducing conditions $(n=3)$. A representative blot is shown. COMP, cartilage oligomeric matrix protein; $\mathrm{H}$, healthy; $\mathrm{L}$, lesional; $\mathrm{NL}$, nonlesional. 
$R$ Bozó et al.

Cartilage Oligomeric Matrix Protein in Psoriasis

Supplementary Figure S3.

Characterization of COMP deposition in healthy, nonlesional, and lesional skin. Immunofluorescence staining for COMP in (a) healthy, (b) psoriatic nonlesional, and (c) psoriatic lesional skin $(n=10)$. Zeiss Axio Imager Z1

original magnification, $\times 20$. Bar $=50$ $\mu \mathrm{m}$. COMP, cartilage oligomeric matrix protein. a
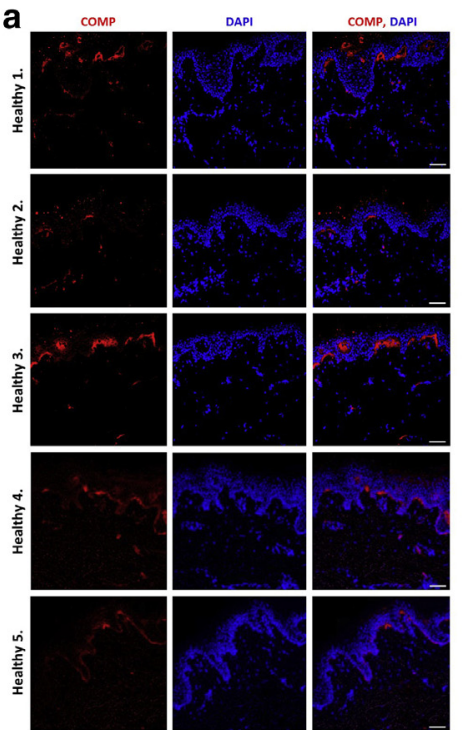

b

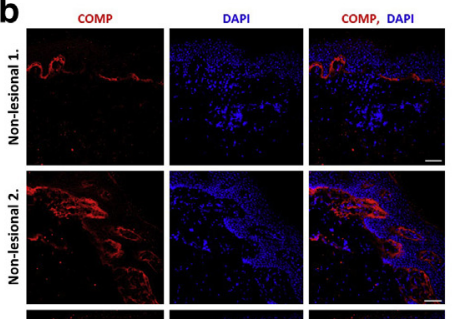

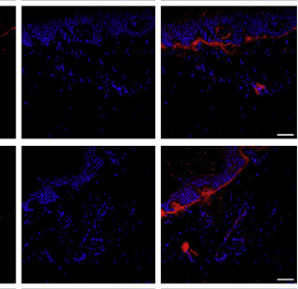

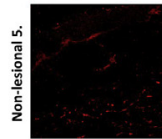



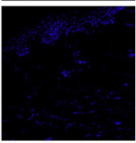

$\frac{\text { i }}{\mathrm{g}}$

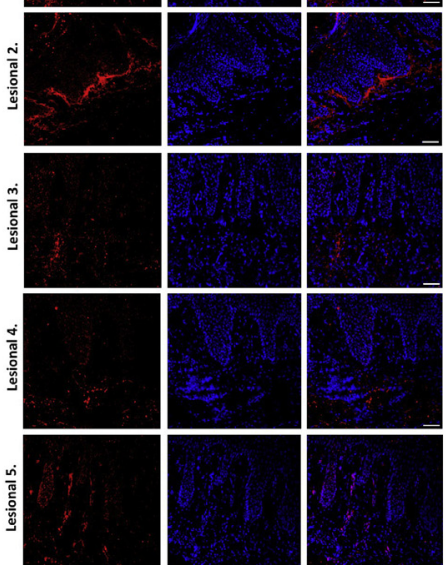

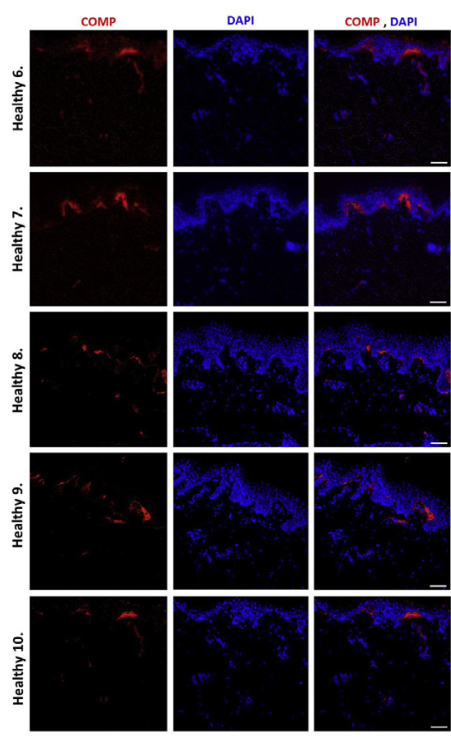

DAPI

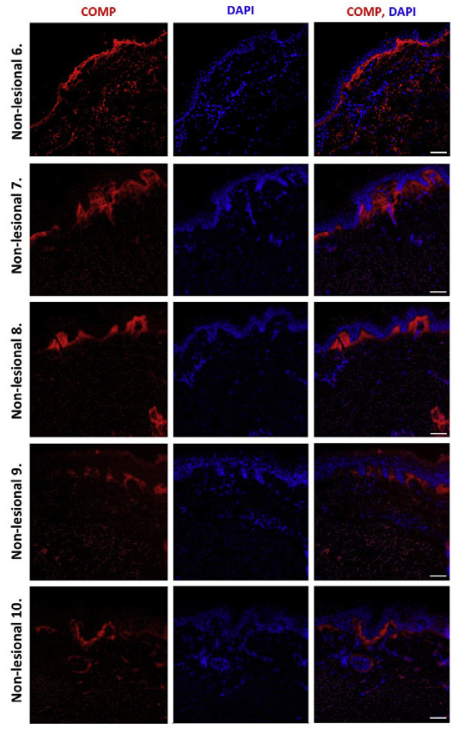

DAPI

COMP, DAPI




$\boldsymbol{R}$ Bozó et al.

Cartilage Oligomeric Matrix Protein in Psoriasis
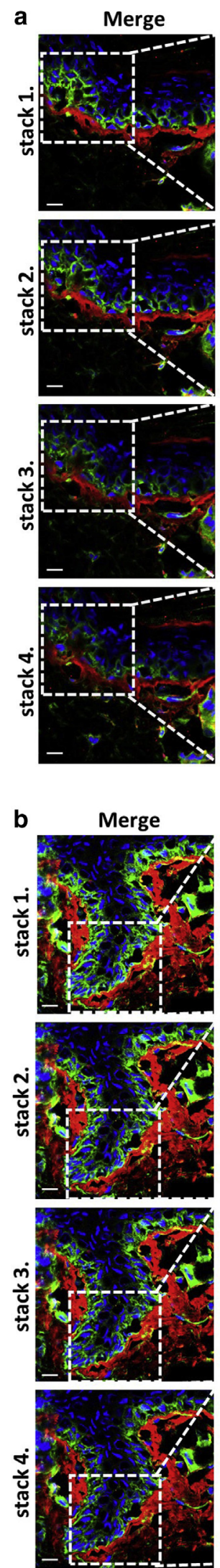

COMP


COMP


B1-intergin
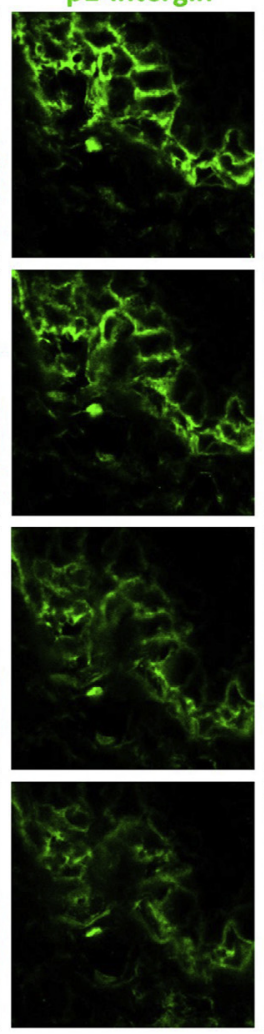

B1-intergin
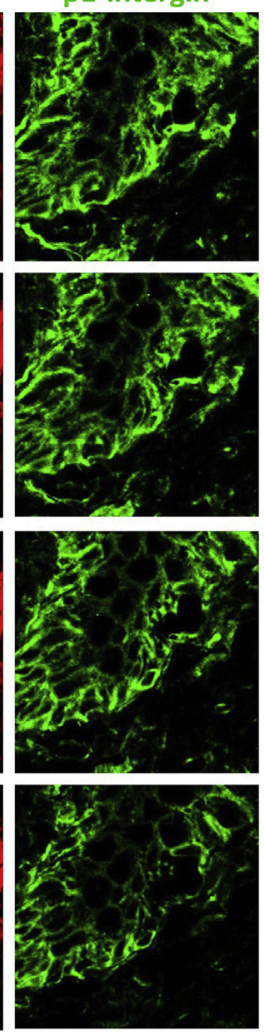
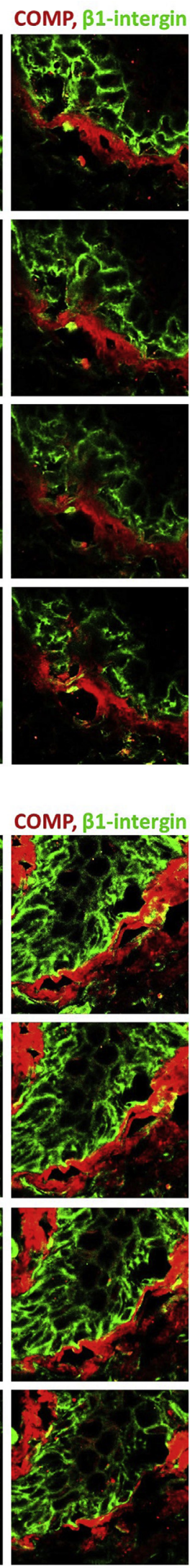

Supplementary Figure S4. Enhanced colocalization of COMP with $\beta 1$ -

integrin in nonlesional psoriatic skin. Confocal microscopic

immunofluorescence analysis of COMP and $\beta 1$-integrin in (a) healthy and (b) psoriatic nonlesional skin using z-stack pictures. Dotted lines indicate the borders of enlarged regions. Colocalized pixels of COMP and $\beta 1$-integrin were calculated by Image software $(\mathrm{n}=5)$. Original magnification, $\times 63$. Bar $=10 \mu \mathrm{m}$. COMP, cartilage oligomeric matrix protein. 
$\boldsymbol{R}$ Bozó et al.

Cartilage Oligomeric Matrix Protein in Psoriasis

Supplementary Figure S5. COMP negatively influences keratinocyte $\mathrm{CI}$ via $\alpha 5 \beta 1$-integrin. $\mathrm{Cl}$ measurement of HPV-KER cells cultured on uncoated and rhCOMP-coated $(10 \mu \mathrm{g} / \mathrm{ml})$ surfaces. $\mathrm{Cl}$ was determined using real-time impedance measurementbased cellular analysis. The graph is representative of three independent experiments, all showing similar results. Mean $\mathrm{Cl} \pm \mathrm{SEM}$ of four technical replicas for each group. $\mathrm{Cl}$, cell index; COMP, cartilage oligomeric matrix protein; rhCOMP, recombinant human COMP.

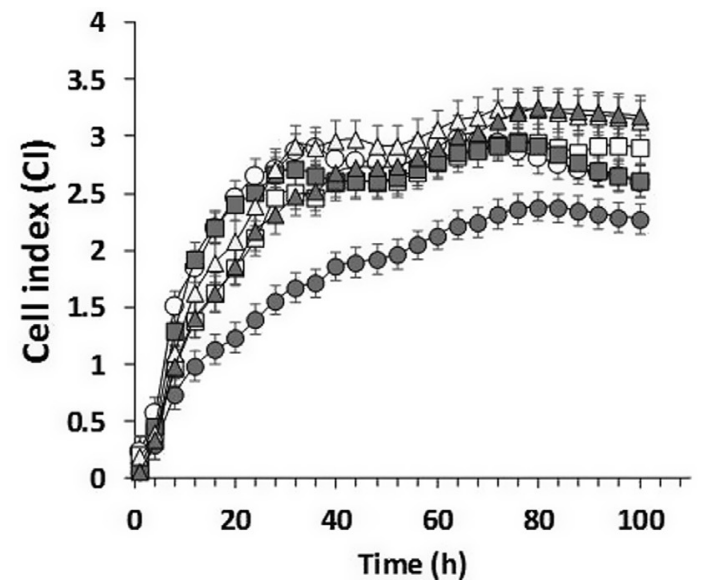

- uncoated, unblocked

$10 \mu \mathrm{g} / \mathrm{ml}$ COMP coated

uncoated, ITG A5 blocked

$10 \mu \mathrm{g} / \mathrm{ml}$ COMP coated, ITGA5 blocked

$\checkmark$ uncoated, ITG B1 blocked

$\triangle 10 \mu \mathrm{g} / \mathrm{ml}$ COMP coated, ITGB1 blocked
Supplementary Figure S6. Reduced proliferation and re-epithelization in the presence of COMP during ex vivo skin wound healing. (a) Reduced number of Ki67-positive cells was detected in wound samples treated with rhCOMP $(10 \mu \mathrm{g} / \mathrm{ml})$ compared with untreated control wounds. The graph shows mean \pm SEM $(n=3)$, $* P<0.05$ versus untreated control, calculated by two-tailed Student $t$-test. (b) Re-epithelization of artificial untreated and rhCOMP-treated (10 $\mu \mathrm{g} / \mathrm{ml}$ ) wounds on H\&E-stained sections $(n=3)$. Original magnification, $\times 20$. Bar $=50 \mu \mathrm{m}$. Representative pictures are shown. Arrowheads indicate the newly synthetized areas. (c) Reepithelization of untreated and control- and rhCOMP-treated wounds was measured using area measurement of ImageJ software. The graph shows mean $\pm \operatorname{SEM}(n=3)$, ${ }^{*} P<0.05$ versus untreated control, calculated by two-tailed Student $t$-test. COMP, cartilage oligomeric matrix protein; rhCOMP, recombinant human COMP. a


C

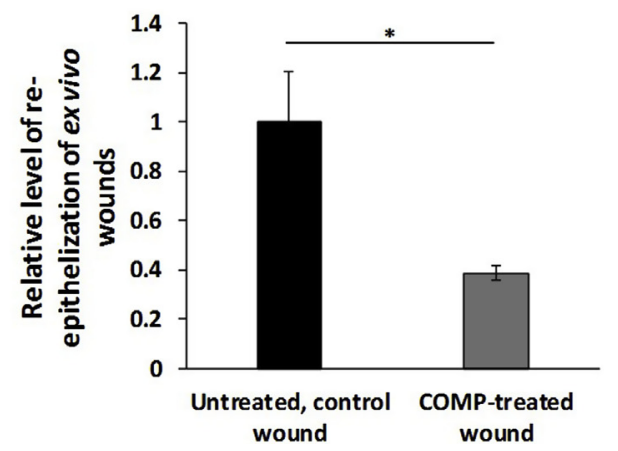




\begin{tabular}{|c|c|c|c|c|c|c|c|c|}
\hline \multicolumn{5}{|l|}{ Donor Information } & \multicolumn{4}{|c|}{ Experimental Application List of Donor Samples } \\
\hline Donor Groups & Donor ID & Sex & Age & PASI score & $\begin{array}{l}\text { Figure } 1 \mathrm{~b} \text { (Western } \\
\text { Blot Analysis) }\end{array}$ & Figure 1c (IF) & $\begin{array}{l}\text { Figure 1d } \\
\text { (RT-PCR) }\end{array}$ & $\begin{array}{l}\text { Used for } \\
\text { Figure } 2\end{array}$ \\
\hline \multirow[t]{13}{*}{ Plaque-type psoriasis } & PS1 & male & 66 & 17.1 & + & + & - & + \\
\hline & PS2 & male & 52 & 5.5 & + & + & - & - \\
\hline & PS3 & male & 61 & 12 & - & + & - & + \\
\hline & PS4 & male & 55 & 12.1 & + & + & - & + \\
\hline & PS5 & male & 70 & 5.9 & - & + & - & - \\
\hline & PS6 & male & 53 & 21.2 & + & + & + & + \\
\hline & PS7 & male & 67 & 17.8 & - & + & + & + \\
\hline & PS8 & male & 40 & 19.6 & + & + & + & - \\
\hline & PS9 & male & 69 & 12.4 & + & + & + & - \\
\hline & PS10 & male & 70 & 9.8 & - & + & + & - \\
\hline & PS11 & male & 69 & 11.5 & - & - & + & - \\
\hline & PS12 & male & 60 & 4.1 & - & - & + & - \\
\hline & PS13 & male & 63 & 26.4 & - & - & + & - \\
\hline \multirow[t]{10}{*}{ Healthy } & $\mathrm{H} 1$ & male & 39 & $\mathrm{n} / \mathrm{a}$ & + & + & + & - \\
\hline & $\mathrm{H} 2$ & male & 29 & $\mathrm{n} / \mathrm{a}$ & + & + & - & - \\
\hline & $\mathrm{H} 3$ & male & 37 & $\mathrm{n} / \mathrm{a}$ & - & + & + & - \\
\hline & $\mathrm{H} 4$ & male & 48 & $\mathrm{n} / \mathrm{a}$ & + & + & + & + \\
\hline & $\mathrm{H} 5$ & male & 53 & $\mathrm{n} / \mathrm{a}$ & + & + & + & + \\
\hline & $\mathrm{H} 6$ & male & 51 & $\mathrm{n} / \mathrm{a}$ & + & + & + & + \\
\hline & $\mathrm{H} 7$ & male & 46 & $\mathrm{n} / \mathrm{a}$ & - & + & + & + \\
\hline & $\mathrm{H} 8$ & male & 61 & $\mathrm{n} / \mathrm{a}$ & + & + & + & + \\
\hline & $\mathrm{H} 9$ & male & 37 & $\mathrm{n} / \mathrm{a}$ & - & + & + & - \\
\hline & $\mathrm{H} 10$ & male & 39 & $\mathrm{n} / \mathrm{a}$ & - & + & - & - \\
\hline
\end{tabular}

Abbreviations: IF, immunofluorescence; n/a, not applicable. 